\title{
Development of Analytical and Numerical Models for the Assessment and Interpretation of Hydrogeological Field Tests
}

\author{
V.A. Mironenko, V.G. Rumynin, and P.K. Konosavsky \\ St. Petersburg Mining Institute \\ St. Petersburg, Russia \\ S.P. Pozdniakov and V.M. Shestakov \\ Moscow State University \\ Moscow, Russia \\ A.A. Roshal \\ Geosoft-Eastlink \\ Moscow, Russia
}

July 1994
Lawrence Berkeley Laboratory
University of California
Berkeley, California 94720

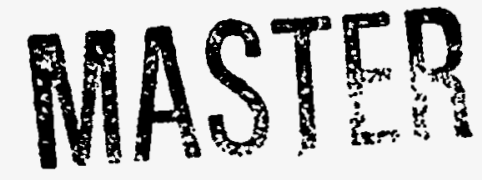

This work was supported by the U.S. Department of Energy, Office of Environmental Management, Office of Technology Development, and the Office of Energy Research, Office of Basic Energy Sciences, under Contract No. DE-AC03-76SF00098. 


\begin{abstract}
Mathematical models of the flow and tracer tests in fractured aquifers are being developed for the further study of radioactive wastes migration in ground water at the Lake Area, which is associated with one of the waste disposal site in Russia. The choice of testing methods, tracer types (chemical or thermal) and the appropriate models are determined by the nature of the ongoing groundwater pollution processes and the hydrogeological features of the site under consideration. Special importance is attached to the increased density of wastes as well as to the possible redistribution of solutes both in the liquid phase and in the absorbed state (largely, on fracture surfaces). This allows for studying physical-and-chemical (hydrogeochemical) interaction parameters which are hard to obtain (considering a fractured structure of the rock mass) in laboratory. Moreover, a theoretical substantiation is being given to the field methods of studying the properties of a fractured stratum aimed at the further construction of the drainage system or the subsurface flow barrier (cutoff wall), as well as the monitoring system thet will evaluate the reliability of these ground-water protection measures. The proposed mathematical models are based on a tight combination of analytical and numerical methods, the former being preferred in solving the principal (2D axisymmetrical) class of the problems. The choice of appropriate problems is based on the close feedback with subsequent field tests in the Lake Area.
\end{abstract}

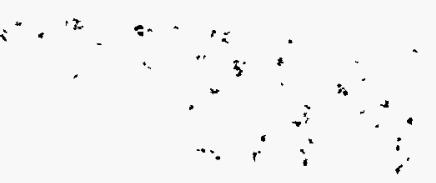




\section{DISCLAIMER}

This report was prepared as an account of work sponsored by an agency of the United States Government. Neither the United States Government nor any agency thereof, nor any of their employees, make any warranty, express or implied, or assumes any legal liability or responsibility for the accuracy, completeness, or usefuiness of any information, apparatus, product, or process disclosed, or represents that its use would not infringe privately owned rights. Reference herein to any specific commercial product, process, or service by trade name, trademark, manufacturer, or otherwise does not necessarily constitute or imply its endorsement, recommendation, or favoring by the United States Government or any agency thereof. The views and opinions of authors expressed herein do not necessarily state or reflect those of the United States Government or any agency thereof. 


\section{DISCLAIMER}

Portions of this document may be illegible in electronic image products. Images are produced from the best available original document. 
Contents

1 Introduction: background and objectives $\quad 5$

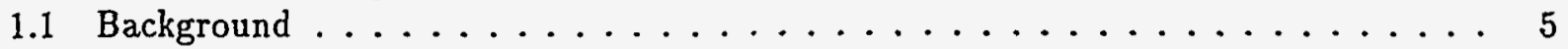

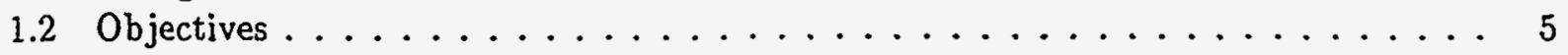

2 Site description 6

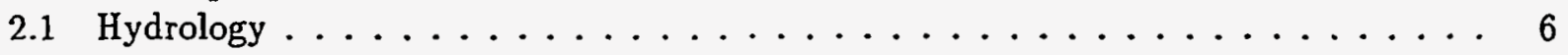

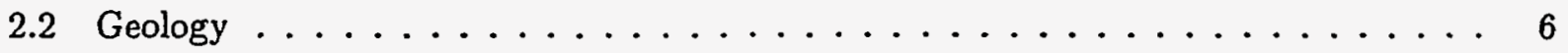

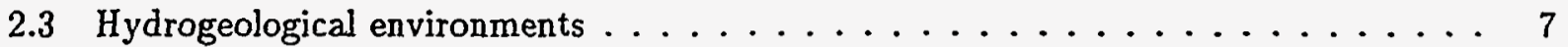

2.4 Statement of the field problems $\ldots \ldots \ldots \ldots \ldots \ldots \ldots$

3 A short overyiew of planning field tests at the key sites in the Lake area . 9

3.1 The objectives of the studies at the key sites $\ldots \ldots \ldots \ldots \ldots$

3.2 Flow and mass-transport parameters liable for identification by the field tests . . . 10

3.3 The general strategy of testing with regard to the major features of the migration

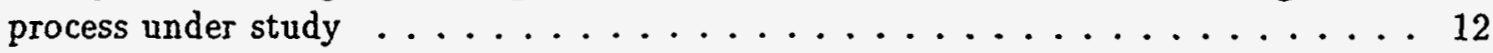

4 The main ideas of experimental schemes and the principles of a tests results analysis $\quad 14$

4.1 The brief description of the main experimental schemes ........... 14

4.1.1 Cluster-well injection and pumping . . . . . . . . . . . . . 14

4.1 .2 Doublet tests . . . . . . . . . . . . . . . . . . 14

4.1.3 Tests under natural-gradient flow conditions . . . . . . . . . . 14

4.1.4 Single-well tests, - pumping after injection . . . . . . . . . . . 14

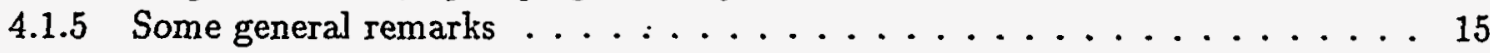

4.2 The typical program of field tests at the site "Transit" . . . . . . . . . 15

5 A study of efficiency of the well-flow experiments with the mathematical modelling approach 16

5.1 The main features of cluster-well pumping tests . . . . . . . . . . . 16

5.2 Numerical modelling of pumping tests at the key site "Transit" . . . . . . . 18

5.2.1 Analytical-and-numerical evaluation of flow tests peculiarities . . . . . 18

5.2.2 An example of the interpretation of cluster-well pumping tests . . . . . . 22

5.2.3 Use of numerical modeling for analyzing pumping tests in stratified layers . . 24

5.3 Analysis of pumping tests conducted near a narrow river (Site "River") . . . . . 29

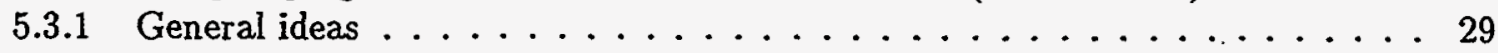

5.3.2 Numerical modeling of pumping test ............... 32

6 Mathematical models of mass-transport (tracer) tests 34

6.1 The parametric basis of the models ................... 34

6.2 Solutions for tracer tests in the divergent flow formed by a single injection well . . . 38

6.3 Solutions for impulse injection of tracer into observation well during pumping . . . . 38

6.3.1 A fully penetrating well in a cross-sectionally isotropic aquifer . . . . . . . 38

6.3.2 A partially penetrating well in a cross-sectionally anisotropic aquifer . . . . 38

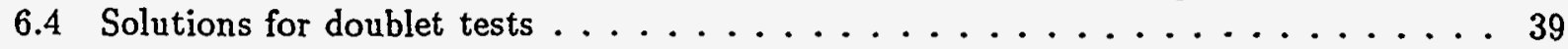

6.4 .1 An areal (subhorizontal) doublet . . . . . . . . . . . . 39

6.4 .2 A vertical doublet . . . . . . . . . . . . . . . . 42

6.5 Tests in the natural-gradient groundwater flow .............. . 42

6.6 On possible discrepancies between actual and modelled schemes of migration . . . 42

6.6.1 Distortion of the radial symmetry of areal flow for injection (pumping) tests . 42 
6.6.2 The approximate estimates of the influence of natural-gradient flow and anisotropy on doublet tests results . . . . . . . . . . . . . 43

6.6.3 Tests errors caused by the actual three-dimensionality of the flow . . . . . . 43

6.6.4 A draining effect of a large fracture tapped by the well . . . . . . . . . . . 43

6.7 The hydrochemical lag of observation wells $\ldots \ldots \ldots \ldots \ldots$

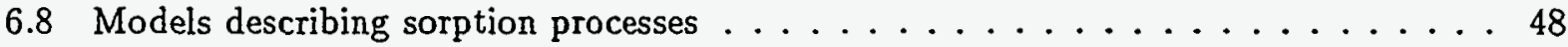

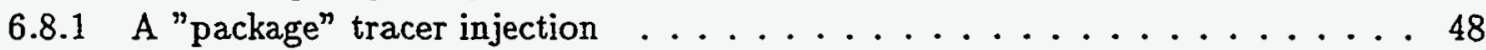

6.8.2 A model of the single-well tracer injection/pumping into the aquifer . . . . 50

6.8.3 Taking account of the kinetics of the sorption process . . . . . . . . 50

6.9 Description of a thermal impact on aquifer ................ 51

6.10 Models for tests interpretation by type-curve matching . . . . . . . . . 53

7 Numerical modelling for study of the tracer tests efficiency 54

7.1 Tracer transport modeling of the doublet well system . . . . . . . . . . . 54

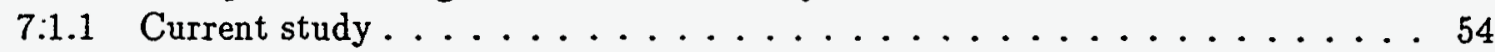

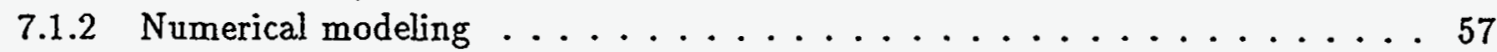

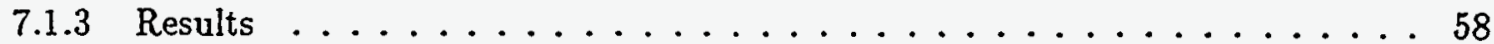

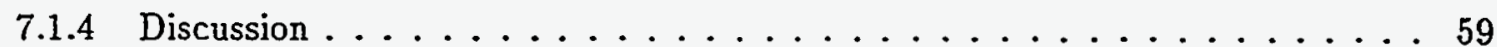

7.2 Analysis of the influence of rock macrofracturing on mass-transport field tests . . . 59

7.3 A study of tracer tests using $3 \mathrm{D}$ numerical models . . . . . . . . . . . . 62

8 Simulation of tests conducted at experimental grouting sites $\quad 70$

8.1 Models for individual fracture aperture estimation . . . . . . . . . . . . 70

8.2 Sensitivity analysis for tests evaluating the grouting quality . . . . . . . . . 71

$\begin{array}{lll}9 & \text { Conclusions } & \mathbf{7 2}\end{array}$

$\begin{array}{ll}\text { Appendixes } & 77\end{array}$

A The approximated solutions of the 1d radial microdispersion problem $\quad 78$

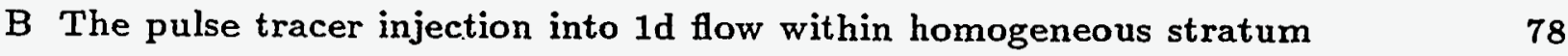

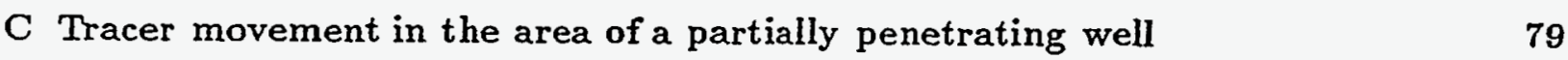

D Horizontal doublet test in an anisotropic homogeneous stratum (a piston-like flow)

E Vertical doublet test in a stratum of finite thickness $\quad 80$

F About the combined impact of natural-gradient flow and aquifer nonuniformity on tracer tests results

G Mass-transport within the fracture of finite length with an infinitely high permeability

$\mathrm{H}$ Flow and mass transport in a single fracture with a variable aperture

I The peculiarities of describing flow near "short" boundaries 85

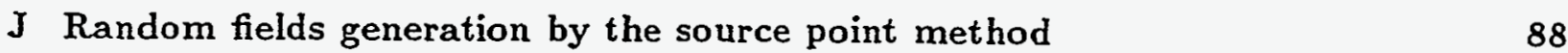

$\begin{array}{ll}\text { References } & 90\end{array}$ 


\section{Introduction: background and objectives}

The present work is devoted to the development of models affording the basis for designing and interpretation of further field investigations at one of the radioactive waste disposal site in Russia (further will be called as the Lake Area) within the plume of radionuclide and chemical ground-water pollution. Such field investigations will be aimed at obtaining a number of flow and mass-transport parameters governing the contamination process as well as the efficiency of possible water-protection measures.

\subsection{Background}

There are several surface waste reservoirs between two rivers that have been used over 30 years for the storage of medium-radioactivity liquids storage. The largest of these is the reservoir ("Lake") which contains the total of $120 \mathrm{mln} \mathrm{Ci}$. The leakage from the Lake $\left(5 \mathrm{mln} \mathrm{m}^{3}\right)$ has resulted in a contamination plume travelling through the aquifer represented by fractured metavolionic rock extensively weathered near the land surface. The high waste density of $1.05-1.06 \mathrm{~g} / \mathrm{cm}^{3}$ and aquifer heterogeneity with no well-developed aquitard has caused a complex $3 \mathrm{D}$ spreading of the plume. Increasing in volume, the plume moves towards the zones of ground-water discharge into streams and ponds which makes it hazardous for surface water and ground-water wellfields. Intensive natural precipitation creates a relatively pure ground water flow over the contaminated one. The interaction of these two flows in a highly heterogeneous media determines the dispersion of their interface and the size of the plume. The movement of salt (responsible for high flow density) and radioactive components is complicated by physical- chemical interactions within the fluid and with water-containing rock.

First steps (1953) of the hydrogeological investigations at the Lake Area were connected with field sampling and ground-water monitoring. Now there are about 100 prospecting and observation wells in the Lake Area that have been tested by pumping and geophysical logging. The flow regime . as well as changes in salinity and radionuclide content along the aquifer thickness are monitored by observation wells. As a rule, the studied zone's thickness does not exceed $100 \mathrm{~m}$ because of the assumption of the fractured rock impermeability below this depth. The tests results demonstrated the complex and strongly nonhomogeneous nature of the total transmissivity variability within the area. The strong variability of permeability in the cross section is caused primarily by weathering and fractures.

Time series of water levels demonstrate essential long-term and seasonal variability of natural ground-water resources in the area under consideration. A preliminary analysis of migration observations showed the pronounced density differentiation in the hydrogeological cross section and the irregular nature of the contamination front movement at different depths. The study showed the migration process to be extremely complex necessitating its further field and model study.

\subsection{Objectives}

Development and verification of models for predicting ground-water quality requires data on flow and mass transport parameters. Besides solving the inverse problem based on monitoring data processing, these parameters can be obtained through field tests at some key sites.

The water-bearing stratum under study already contains formidable waste concentrations. Because of that, many well developed test methods oriented to ground water pumping are of limited use. On the other hand, the situation opens up unique opportunities to study, alongside "mechanical" transport parameters (governing the subsurface advection and dispersion of conservative solutes), the important parameters of hydrogeochemical interactions which are hard to evaluate in the laboratory, considering the fractured nature of the medium. From this point of view, the field tests may well compete with the test-and-operation parameter estimation by interpretation of 
observational data, especially taking into account the low reliability of such interpretations in the case of $3 \mathrm{D}$ salt water intrusion into the aquifer.

At the same time, the existing interpretational models of the tests are heavily formalized and, very often, they fail to consider the major features of fractured rock structure, the role of large-scale effects arising during the tests as well as well-construction factors which could dramatically distort the tests results at a specific site.

The objectives of the present study are as follows.

1. Flow and mass-transport assessment for further designing of efficient field tests at key sites:

a) analyse of major mechanisms and parameters governing ground-water pollution;

b) analysis of the appropriate field data for the studied area. Here, a tentative territory typification is needed aiming to single out key sites where particular migration processes are dominating (convective transport under regional flow gradient conditions, densitydriven transport resulting in solution stratification, hydrogeochemical interactions, etc.)

c) selection of the optimal schemes for the field testing.

2. Assessment of reliable procedures for proper interpretation of field tests taking into account different factors which could distort the tests results.

3. Development of the appropriate mathematical models combining efficiently both analytical and numerical methods.

4. Outlining the major directions for further investigations concerning both field tests and ground-water modeling.

\section{Site description}

\subsection{Hydrology}

The site is located within the watershed of two rivers - the main one and its right-hand tributary the Southern river. Due to industrial operation, a number of servicing reservoirs have lately been constructed ranging in area from 1 to 20 square kilometres. The reservoirs' regime is conditioned by industrial waste dumping peculiarities. The Southern river accupies a narrow swampy valley and a meandering channel up to $3-5 \mathrm{~m}$ wide. The average of many-years' river discharge is 0.036 $\mathrm{m}^{3} / \mathrm{sec}$. During flooding discharge reaches $1.0-1.5 \mathrm{~m}^{3} / \mathrm{sec}$. There used to be a number of lakes and naturally communicating topographic hollows around the area which presently operate as servicing reservoirs. From 1951 one of the lakes has been operating as a liquid radioactive waste-storage site (Fig. 2.1).

\subsection{Geology}

The regional geological cross section is represented by fractured moderately metamorphosed effusive Lower-Silurian rocks including porphirites, their tuffs, sandy tuffs, and occasional metamorphased shales covered by a thin layer of weathering products. The body of effusive rocks has an areally and cross-sectionally complex fractured structure formed as a result of tectonic processes and weathering. Three tectonic fracturing systems are noted. The largest of them is associated with disjunctive faults striking submeridionally. Regional fracturing of the weathered rock attenuates at a depth of the order of $100 \mathrm{~m}$. Hawever, in linear fault zones, fracturing is found at a depth of $300 \mathrm{~m}$. As a rule, the fractures are filled with the products of weathering to depths of $20-40 \mathrm{~m}$. The interaction of regional and tectonic fracturing forms a body having areally the shape of relatively "strong" blocks broken by weakened narrow tectonic zones. 


\subsection{Hydrogeological environments}

An effusive-rock reservoir is unconfined, the ground-water potentiometric surface lies at the depth of $0.1-20 m$ (5-7 $m$ on average). Under natural conditions, ground-water was recharged primarily by precipitation. The ground-water discharge area is associated with the river-plain, and the lake. The ground water, recharge varies annually with the main bulk of the recharge during April-May. The recharge distribution is areally uneven depending on topography, the weathered area size, and the depth to ground water level. The average annual recharge rate makes up $10-25 \%$ of the annual precipitation.

The total aquifer transmissivity was estimated according to the data of cluster and individual well pumping tests; in all, about 40 tests were performed. The transmissivity was shown to vary from 1 to $800 \mathrm{~m}^{2} /$ day. The logarithmic transmissivity variance is 3.4 .

Cluster pumping tests revealed anisotropy in areal transmissivity north - south anisotropy values exceeding east-west anisotropy. The areal parameters distribution proved complex and almost unpredictable. It represents a combination of large blocks of low and narrow elongated zones of heightened transmissivity. Hydraulic conductivity distribution is cross-sectionally nonuniform , and one can discern 3 to 4 zones here. These are (from top to bottom): a low-permeability zone-1 $(k=0.1$ to0.5 $\mathrm{m} /$ day $)$, a relatively high-permeability zone-2 $(k=0.5$ to5.0 $\mathrm{m} /$ day $)$, and a low-permeability zone-3 $(k<0.1 \mathrm{~m} /$ day $)$. The existence of the upper low-permeability zone $(20-40$ $m$ thick) may be due to the filling of the fractures with weathering products, and a downward permeability decrease may be accounted for by the attenuation of fracturing, or lack of weathering of primary frac.-filling minerals.

Cross-sectional fracturing values within the depth of $0-60 \mathrm{~m}$ vary from 0.009 to 0.002 (0.004 on the average). The mean distance between the fractures ranges from $0.5 \mathrm{~m}$ (on the top of the cross section) to $25 m$ (near the bottom).

The position of the underlying bed rock is uncertain in the cross section due to the monotonous fading of permeability and fracturing. The conditional bedrock is assumed to lie at the depth of about $100 \mathrm{~m}$ below land surface(Fig 2.2).

At present, the Lake is filled up with wastes. Additional reservoirs have been created in the main river valley, and individual water-supply wells have been put in operation in the studied area. All this has resulted in changes of ground-water discharge/recharge conditions, but the principal flow structure stays the same.

Main pollution occurs due to the leakage of highly concentrated wastes from the Lake utilized for storage purposes. The solutions are radioactive and of heightened density. The latter is due to salt content (mainly, sodium nitrates up to $150 \mathrm{~g} / \mathrm{l}$ ) with density varying from 1.05 to $1.07 \mathrm{~g} / \mathrm{cm}^{3}$. The solutions contain all long-life decay products, their activity varying from 0.05 to $0.005 C_{i} / l$. The total volume of leakage to the ground water from the reservoir made up about $5 \mathrm{mln}$ cubic meters over the period 1951-1991. Over the past decade, the leakage rate made up about 0.001 $\mathrm{m} / \mathrm{day}$, the Lake bottom measuring $0.32 \mathrm{~km}^{2}$. Nitrates, acetates, rubidium, strontium, cesium serve as indicator pollutants.

Due to its heightened density, the plume first sinks to the aquifer bottom, then it migrates laterally. The plume boundaries mapped using nitrate (a conservative component) are moving largely southwards and northwards from the reservoir at the velocity of 70 to $80 \mathrm{~m} / \mathrm{yr}$. In the south, the plume has reached southern river at the depth of over $60 \mathrm{~m}$.

\subsection{Statement of the field problems}

The major factors preconditioning the unique complexity of the migration process at the Mayak Site are: 

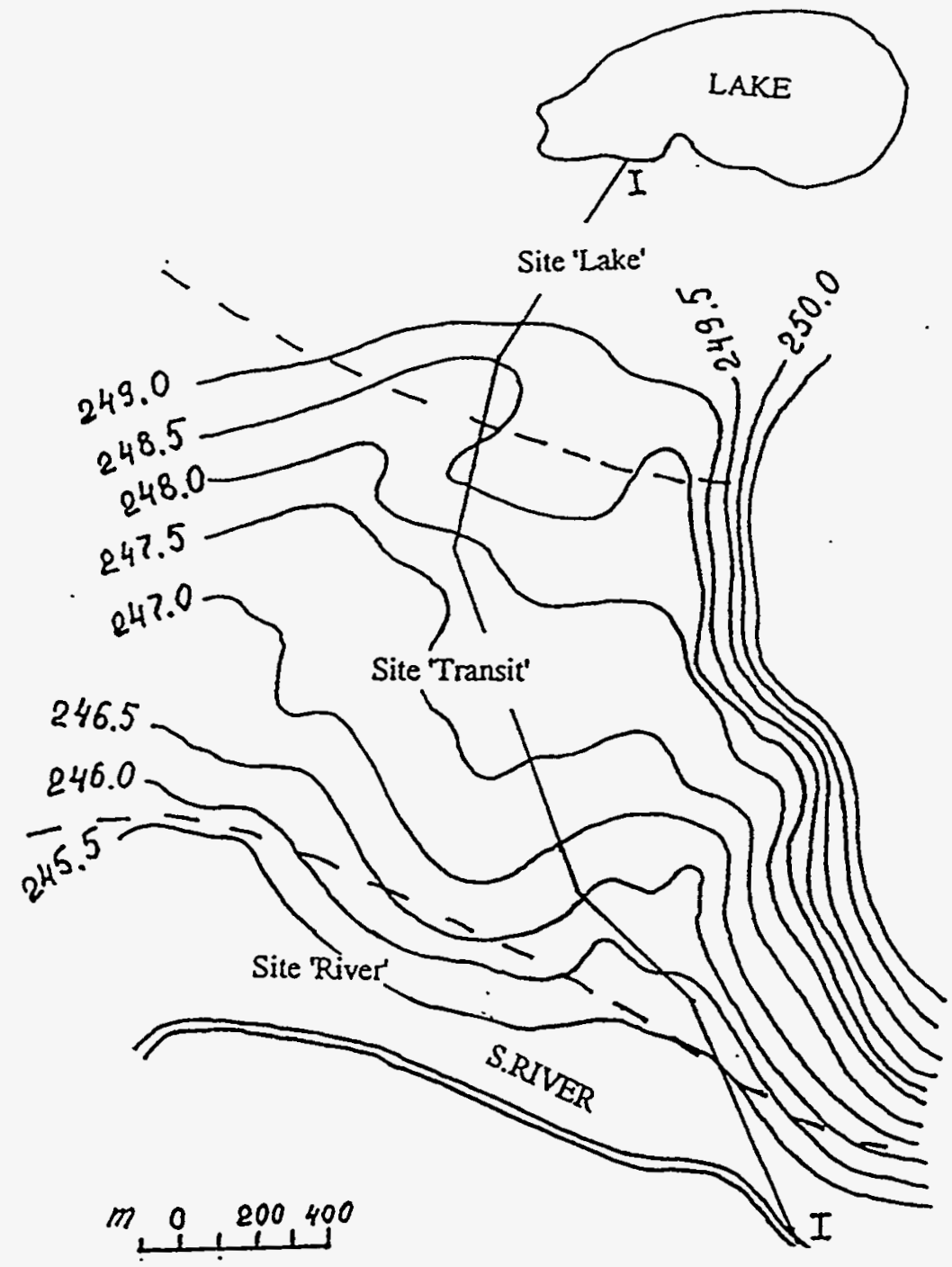

Fig.2.1 A schematic of potentiometric ground-water surface I-I is the line of the cross section on Fig.2.1.

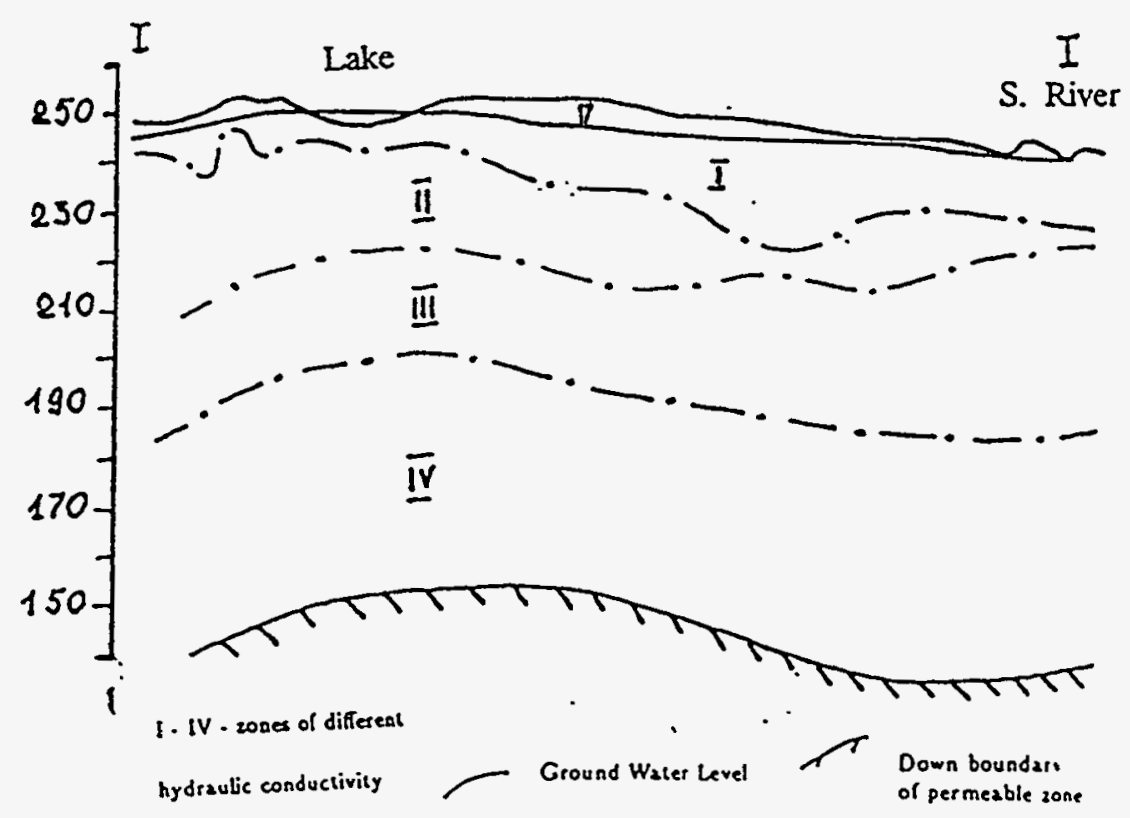

Fig.2.2 Schematical hydrogeological cross section for line I - I 
a) the most complicated structure of the crystalline fractured rock due to the presence of joints, erosion cuts, zone of weathering, etc., which predetermines strong nonhomogeneity and anisotropy of flow properties at several levels of 3-D heterogeneity;

b) the extensive development of 3-D density convection complicated by large undulation of the aquifer semipermeable bed which results in highly irregular movement of the brines "toe" as well as brine accumulation within numerous hollows ("dead zones");

c) the supplementary 3-D spreading of contaminants because of transverse dispersion and convective velocity field fluctuations due to periodical changes in ground-water regime;

d) the possible strong impact of sorption and of some other retarding physical-chemical interactions at fracture wall surfaces and by thin "films" coating rocks, modifed by secondary geochemical processes;

e) the possible influence on radionuclide migration of colloidal particles, in particular, originated within the upper zone of weathering. Those particles could considerably decrease the retarding effect of water-rock interactions because of contamination redistribution between colloids and fracture surfaces;

f) the manifestation of several heterogeneity levels during the migration process which could be quite different for some subprocesses mentioned above.

All these complex features of the migration process make its field study most difficult. On the one hand it means that analysis and generalization of previous investigations data are to be considered (filtered) critically, as at some part of them could be unreliable. On the other hand it demands a thorough assessment of the special system of field tests and observations as well as its trial - and - operational realization. We propose to run some "key" flow and tracer tests in the fractured aquifer and to evaluate their representativeness for different levels of heterogeneity as well as feasibility of transferring their results from one level to another. For the same purpose we plan to organize some "key" observation points (stations) which would permit, in particular, to evaluate the representative procedure (and the representative volume) for ground water quality sampling in the crystalline fractured formation. Special injection tests using grouting mixtures are also feasible to determine the possible efficiency of grouting barriers.

\section{A short overview of planning field tests at the key sites in the Lake area}

Using mathematical models, the present project analyzes the conditions of the perfomance and the principles of interpretation of planned field tests. Hence, first of all, it is necessary to formulate rather distinctly the objectives, strategy, and the structure of such tests.

\subsection{The objectives of the studies at the key sites}

The field tests to be conducted at the key sites have the following major objectives:

a) checking the quality of earlier field tests for estimating reliability of the flow and mass-transport parameters values obtained through them;

b) correcting these parameters at the actual and potentially polluted sites directly;

c) estimating the parameters disregarded by the previous field tests and observations; 
d) testing of methods for hydrochemical sampling in observation wells. ${ }^{1}$.

It should be stressed that the previous parameters estimation based on groundwater regime observation data and inverse problems solving could not be considered compltete. Concerning mass-transport parameters, in particular, their evaluation in the conditions of $3 \mathrm{D}$ density advection entails peculiar difficulties.

On the whole, field tests are to widen considerably and to specify the data base for designing subsequent water-protection and control measures, the principal of them being protective drainage and the ground-water monitoring system (creating of a protective barrier is to be considered also, but this variant is rather questionable).

At the same time, in formulating the objectives of field tests, one should keep it in mind that part of the necessary parameters could be estimated more or less reliably only by a trial-and-operational approach, that is, during construction of the water-protection facilities.

\subsection{Flow and mass-transport parameters liable for identification by the field tests}

It is well-known (Mironenko and Rumynin, 1986) that by no means all necessary parameters for solving forecasting and optimization problems could be actually found by field tests. Table 3.1 illustrates this for the situation under consideration.

\footnotetext{
${ }^{1}$ This problem is not considered in the present project
} 
Table 3.1: The major flow and mass-transport processes and parameters for the Lake Area

1. Flow (advection) through nonhomogeneous fractured and jointed media:

2. Density convection in the aquifer with indefinite lower boundary:

3. Infiltration of fresh water (including the Lake after its reclamation):

4. Discharge into the River:

5. Recharge of waste out of the Lake:

6. Natural ground water flow-velocity $\left(v_{e}\right)$ and direction

7. Dispersion:

8. Diffusion into fissured-porous matrix:

9. Sorption / desorption at the fractures walls and within matrix:

10. Colloids transport:

$$
\begin{aligned}
& k_{x}, T_{x}, k_{y}, T_{y}, \underline{n} \\
& \rho_{f}, \rho_{s}, \underline{k}_{x}(z), k_{z}(z), m_{\text {cond }} \\
& w, k_{z}^{o}, w^{l} \\
& \frac{k_{z}^{r}(z)}{k^{r}} \\
& k_{z}^{l}(z), \frac{n^{r}}{n^{l}}
\end{aligned}
$$

\section{Colloids transport:}

Nomenelature.

$k_{x}, k_{y}, k_{z}$ are permeability values ${ }^{2}$.

$k_{z}^{l}$ - the same for the reclaimed Lake,

$k_{z}^{\tau}$ - the same near the River,

$k_{z}^{\circ}$ - the same for surface layer,

$T_{x}, T_{y}$ - transmissivity values;

$\rho_{f}, \rho_{s}$ - density of saline and fresh water,

$m_{\text {cond }}$ - the effective thickness of the aquifer,

$n$ - effective (active) fracture porosity,

$n^{r}$ - the same near the River,

$w$ - infiltration rate,

$w^{l}$ - the same for the reclaimed Lake,

$D_{x}\left(\delta_{x}\right), D_{y}\left(\delta_{y}\right), D_{z}\left(\delta_{z}\right)$ - coefficient of dispersion (dispersivity) values,

$D_{m}$ - coefficient of molecular diffusion,

$\lambda_{m}=S_{b}^{2} * n_{o}^{2} * D_{m}$ - coefficient of exchange between fractures and porous blocks,

$n_{0}$ - interconnected porosity of matrix,

$\lambda_{T}$ - thermal analog for $\lambda_{m}$ - Sect. 61 ,

$K_{a s}$ - coefficient of surface sorption,

$K_{\text {ad }}$ - the same for desorption,

$K_{d m}$ - distribution coefficient for matrix,

$n_{c e}, K_{c m}$ - effective fracture capacity for colloidal particles and coefficient of exchange between colloids and solid matrix,

- the major parameters for identification by field tests,

- - the additional parameters for approximate identification by field tests.

\footnotetext{
${ }^{2} k_{x}(z), k_{y}(z), k_{x}(z)$ are permeability values for different layers
} 


\subsection{The general strategy of testing with regard to the major features of the migration process under study}

To estimate flow and migration parameters, one has to carry out two major types of in-situ tests: flow tests and mass-transport (migration) tests.

In most cases, it is feasible to observe simultaneously both the hydrodynamic response and the water composition changes in the boreholes. Therefore, each test can be interpreted as a combined flow and tracer test. Nevertheless, the representativeness of data obtained for evaluating various parameters at various observation points could considerably differ. So, the optimal clusterwell spacing (i.e. the distance between observation wells and an injection well for divergent flow schemes, or between a pumping well and an injection well in doublet test schemes) must be guided by fairly different criteria when studying flow and migration parameters.

Tests objectives on the whole and cluster-well test system's peculiarities should be tailored to the type of the dominating solute transport mechanisms which could change within the time-andspace range of the migration process under study. From this point of view, it would be sensible to single out three typical key sites within the area under investigation (Table 3.2.).

Two of them (the "Lake" and the "River") are associated respective by with ground- water recharge and discharge areas. Here, along with traditional parameters describing the subhorizontal water movement of major importance could be also the parameters of subvertical flow and solute transport including parameters of hydrodynamic surface-ground water interactions. Tests to be conducted at the key site "Transit" (located between the two key sites mentioned above) are to characterize the cross-sectional flow heterogeneity in particular, to single out the predominant brines transfer zones, and to determine the regularities of permeability decrease with depth. Vertical transport parameters might be of some interest too, especially to assess the role of density advection.

Tests aimed to assess the efficiency of cut-off walls at the key site "Transit" (after experimental grouting) need a special validation. Their results would be used for choosing the spacing between the injection boreholes and for evaluating of the grouting quality.

Of major importance is the "Transit" site which should coincide with the location of the future water-protection facility (drainage or protective barrier). Here, the maximum amount of field experiments would be done. In contrast, the site "Lake" is of minor importance since the main parameters could be determined here fairly reliably by inverse problems solving on the basis of the regime observation data. Moreover, large-scale and long-term tests are hindered at the lace due to the radiation conditions.

The field tests procedures are essentially determined by the high content of radionuclides and nitrate salts in the aquifer near the Lake. This imposes serious restrictions on the tests or even altogether exclude those in which the hydrodynamic regime is caused by water-withdrawal. In this situation the main possibilities are as follows.

a) Fresh water injection tests with futher putting tracer into the divergent flow. Here, in parallel with tracking the tracer and water component concentration changes, observations of the temperature front spreading observations could prove very informative; nonconservative components of ambient water could be used for evaluating of the sorption-desorption parameters.

b) Closed-cycle well tests (the "doublet" scheme). Here, the water pumped out of the aquifer through one well is injected back into the aquifer by the other well (or the other group of wells). Such tests are often called "circulation well" or "doublet" tests. ${ }^{3}$. Adding an organic dye or some other tracer to the injected water solves the problem of labelling. Moreover, at sites having a pronounced profile zonation in water composition, observations of a shift in hydrochemical zones' boundaries in the course of the tests can also be used for determination of flow and migration parameters.

\footnotetext{
${ }^{3}$ Circulation of labelled water could be subhorizontal or subvertical
} 
c) Tracking of tracers in natural flow by means of a row of observation wells oriented normally to the main flow direction.

d) Injection of nonconservative indicators into the aquifer and pumping of the labelled water out of the same well after its "quiet" period ("single well" test).

Table 3.2: Types of the key sites

\begin{tabular}{|c|c|c|c|}
\hline Name & "Lake" & "Transit" & "River" \\
\hline $\begin{array}{l}\text { The initial } \\
\text { hydrogeologic } \\
\text { situation }\end{array}$ & 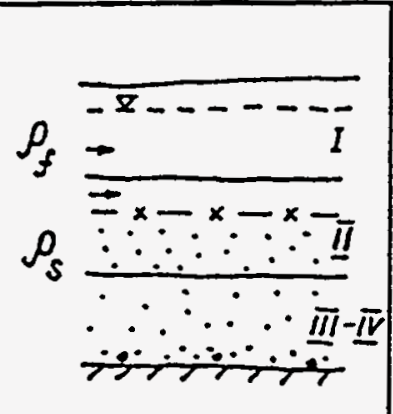 & 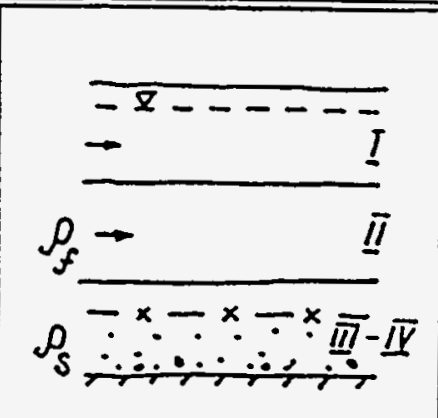 & 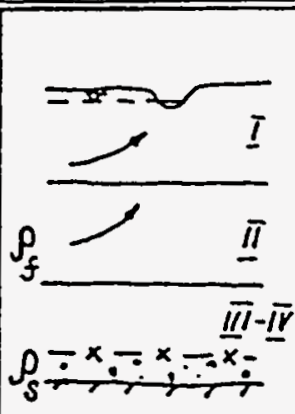 \\
\hline $\begin{array}{l}\text { Parameters } \\
\text { for field } \\
\text { identification (flow) }\end{array}$ & $k_{x}, k_{y}, k_{z}^{0}$ & $\begin{array}{l}k_{x}, T_{x}, k_{y}, T_{y}, \\
k_{x} \\
(z), k_{z}^{0}, m_{\text {cond }}\end{array}$ & $\begin{array}{l}k_{z}, T_{x}, k_{y}, T_{y}, \\
k_{z}^{o}, \frac{k_{z}^{n}}{k_{z}}(z)\end{array}$ \\
\hline $\begin{array}{l}\text { Parameters } \\
\text { for field } \\
\text { identification } \\
\text { (mass-transport) }\end{array}$ & $\underline{n}, \underline{D_{x}}, \underline{\lambda}_{\underline{m}}\left(\lambda_{\underline{T}}\right)$ & $\begin{array}{l}\frac{n, D_{x}, D_{y}, D_{z, n}}{S_{b}\left(\lambda_{m}\right)}, S_{b}\left(\lambda_{T}\right), \\
k_{a s}, k_{a d}\end{array}$ & $\begin{array}{l}n^{r}, D_{x}, S_{b}\left(\lambda_{m}\right) \\
S_{b}\left(\lambda_{T}\right)\end{array}$ \\
\hline Experimental schemes & $\begin{array}{l}\text { Cluster-well injection } \\
\text { into zones of fresh } \\
\text { and saline water }\end{array}$ & $\begin{array}{l}\text { Cluster-well pumping } \\
\text { test; horizontal doublet } \\
\text { scheme; vertical doublet } \\
\text { scheme; } \\
\text { cluster-well injection } \\
\text { test (within intervals } \\
\text { separated by packers } \\
\text { as well as in fully } \\
\text { screened wells); } \\
\text { pumping after injection } \\
\text { single-well test; } \\
\text { injection of tracer into } \\
\text { a natural gradient flow }\end{array}$ & $\begin{array}{l}\text { Cluster-well } \\
\text { pumping test; } \\
\text { vertical doublet } \\
\text { scheme; } \\
\text { pumping after } \\
\text { injection } \\
\text { single-well test; }\end{array}$ \\
\hline
\end{tabular}




\section{The main ideas of experimental schemes and the principles of a tests results analysis}

\subsection{The brief description of the main experimental schemes}

\subsubsection{Cluster-well injection and pumping}

Thanks to the presence of a pumping or injection well, converging or diverging axi-symmetric nonsteady flows are formed, For a partially penetrating well the flow is cross-sectionally 2D. From the viewpoint of the interpretation efficiency, this comes as a positive moment since, the possibility arises of evaluating the aquifer's vertical permeability. Major interpretation problems are associated with the influence of the layered nature of the cross section and the hydrodynamic boundaries displayed on the indicator plots (for instance, the river boundary causes development of steady flow). When the injected water differs in density and viscosity from that in the aquifer, some additional hydrodynamic effects emerge. Such a combination of factors necessitates a study of the test flow process on a numerical model.

Tracer tests interpretation within the framework of transient 1D models for radial masstransport can also lead to various errors due to both the partial penetration of the central well and additional natural or technical factors (e.g. the influence of the natural flow and the riverboundary or the observation well's hydrochemical lag). Of major importance could be the influence of individual fractures and channels (Tsang, 1989; Tsang et al., 1991).

\subsubsection{Doublet tests}

Tests conducted under the two-well (doublet) scheme have two major steady-flow modifications, the vertical doublet (a) and the horizontal doublet (b). An important advantage of doublet schemes, especially in large - block fractured rock, is a large-scale averaging of the studied medium's flow and mass-transport properties. Here, a more uniform tracer saturation is reached (thanks to pronounced transverse advection and dispersion) in various zones of the cross section noticeably differing in flow velocities. At the same time, a concurrent flow properties evaluation is ensured notably at the test site as the undesirable scale effects due to the discrepancy between the migration and flow zones of influence are eliminated. The anisotropy of permeability and the influence of hydrodynamic profile boundaries on the flow structure (in case of induced subvertical flow) should be reflected in interpretation models.

Doublet tests could be of special importance in assessing the quality of grouting for construction of cut-off walls.

\subsubsection{Tests under natural-gradient flow conditions}

In this case, limited volumes of labelled fresh water are injected with a subsequent tracking the water body migrating through the aquifer due to the induced (given the hydrodynamic flow gradient) and natural (density) advection complicated by dispersion. All in all, the process is going to take on a $3 \mathrm{D}$ form, and its interpretation will involve a 3D numerical model. Nevertheless, some rough estimates could be obtained on the basis of fairly simple analytical solutions.

\subsubsection{Single-well tests, - pumping after injection}

Tests of this type include injection of tracer, its temporal conservation within the aquifer and subsequent rapid pumping out of the same well. Thereby one can manage to evaluate the mass-exchange properties (diffusion and sorption) of the aquifer using quasi-steady asymptotic solutions. Similarly, one can estimate the specific surface of blocks in fractured rock by thermal tracer injection. 


\subsubsection{Some general remarks}

On the whole, different types of fresh water injection tests seem informative enough for further predictions. Here, a combined detection of conservative (e.g., nitrate) and reactive (implying, first of all, radionuclides involved in ion exchange and sorption processes) solutes will allow estimates not only of traditional advection and dispersion parameters, but also of those hydrogeochemical interactions occurring in the "water-rock" system. So, within the framework of simple analytical models, the effective coefficients of sorption distribution on fracture surfaces can be found for various radionuclides. For the further deciphering of those results, in particular, aiming to compare them to laboratory sorption (batch) experiments on intact samples, data are needed on the specific surfaces of the rock blocks. Such data could be obtained by tests with a thermal tracer.

Finally, let us dwell on some general considerations pertaining to the development of theoretical models used to interpret tests results. Considering the regional scale of the forecasts, the scale of tests has to satisfy the well-known demands of continuous medium models. Unfortunately, this aspect is hard to control in fractured rocks, and the so called assumption of Representative Elementary Volume (REV) often proves inappropriate here. Roughly speaking, there may occur a limited number of fractures between an injection/pumping well and the observation point which is insufficient for volume-averaged estimates. Therefore, to properly diagnose test regimes, one has to look also at alternative solutions for discrete medium models describing flow and mass - transport in individual fractures or in a fracture system having a small number of intersections.

\subsection{The typical program of field tests at the site "Transit"}

The principal propositions considered above are illustrated here for the case of the key site "Transit" which is to be regarded as a pilot site within the studied area. Its geographical location is determined, above all, by the degree of hydrochemical stratification of ground water. Since great differences in water density at the top and bottom parts of the aquifer hinder an unequivocal interpretation of the tests, it would be sensible to refer this key site to an area where saline water layer thickness is minimal and the respective differences in the total dissolved solids do not excede some grams per liter. These conditions are met by the site located $300-500 \mathrm{~m}$ away from the river where protective drainage (or protective barrier) is most likely to be constructed.

In the process of testing, the rock permeability and fractured storage capacity profiles, dispersivity and diffusion capacity of the porous matrix as well as absorption properties of fractures (taking account for their hysteresis) are to be studied.

The test schemes and the cluster well design depend on the character of the cross - section in which three major zones could be singled out:

1. the upper zone (with the thickness of $m_{1}=10 t o 20 \mathrm{~m}$, the hydraulic conductivity being $k_{1}=0.1$ to $0.5 \mathrm{~m} /$ day $)$,

2. the middle zone $\left(m_{2}=30 t 050 m, k_{2}=0.5\right.$ to5.0 $\mathrm{m} /$ day $)$, and

3. the lower zone $\left(m_{3}=50 t o 70 \mathrm{~m}\right.$ with the permeability diminishing with depth to a negligible value).

A noticeable rise in the total dissolved solids content is presumed at the depth of $60-80 \mathrm{~m}$ below surface, that is, within the lower poor-permeable zone.

So, a pilot cluster well should have, at least, two- or three-level structure with its upper wells located within the active zone (10-15 $\mathrm{m}$ below surface) and the lower wells, within the relatively poor-permeable zone containing most heavily polluted water (80-100 m below surface). A tentative scheme of the pilot cluster well is shown in Fig. 4.1. It includes two groups of wells:

- production wells (pumping/injection), $N N 1^{e}-4^{e}$; 
- observation wells (utilized, at the final stages of pumping; also for tracer injection), NN $1^{p}-10^{p}$

Horizontal well spacing (Fig.4.1) was chosen according to the expected discharge/recharge of the central well, that is, about $200 \mathrm{~m}^{3} /$ day.

The field procedures include:

1. A long-term cluster-well pumping out of the well $1^{e}$ aimed at estimating the flow parameters;

2. Observations of changes in the chemical composition of the pumped out water for studying subvertical mass-transport parameters (given the initial vertical hydrochemical zonation); pumping terminates if the safety level for radionuclides concentration in the pumped out water is exceeded;

3. Pulse tracer injection into observation wells at the final stage of pumping;

4. A successive fresh-water and tracer cluster-well injection into the wells $1^{e}$ and $2^{e}$ for studying mass-transport parameters (including sorption-desorption interactions) in the upper and lower layers. Simultaneously, injection-induced temperature changes in the natural thermal field of the stratum are being studied;

5. Horizontal two-well tracer tests (the well pairs $1^{e}-3^{e}$ and $2^{e}-4^{e}$ are used) with the well spacing being accordingly increased;

6. Vertical doublets (the pairs $1^{e}-2^{e}$ and $3^{e}-4^{e}$ are successively used);

7. Single-well tracer tests under the "injection-pumping" scheme (the wells $1^{e}$ and $2^{e}$ are successively used);

8. Tracer injection tests in a natural-gradient flow using the well pair $1^{p}-2^{p}$ located upstream the row of wells oriented perpendicular to the flow (the wells $1^{e}-9^{p}$ ); for more reliable tracer detection one or two additional wells (the wells $11^{p}-12^{p}$ ) are to be drilled along this row.

If the pumping (see 1) proves to involve excessive amounts of saline and radioactive water from the bottom of the cross section, the field test strategy must be changed. Here, the emphasis must be placed on radial injection and doublet (see 4-6) testing schemes.

Using the so called "double" pumping can also be advisable. Here, low-rate pumping is to be performed from the deep well ( 2 or 3 ) to contain the vertical rise of the fresh/salt water interface. Thereby the volume of polluted water will sharply decrease, and relatively small-power demineralizers could be used here to clean it up. Preliminary model estimations have shown that the discharge of such an auxiliary water withdrawal would not exceed 10-15\% of the major pumping.

All the operations (excluding the time of well drilling and equipping) will take 3-4 months.

The hydrogeological field tests must be preceeded by a study of cores from boreholes, geophysical well logging (including flowmeter measurements), and the estimations of ther hydraulic and hydrochemical lags.

\section{A study of efficiency of the well-flow experiments with the mathematical modelling approach}

\subsection{The main features of cluster-well pumping tests}

Development of cluster-well pumping test models must be carried out with regard to the actual structure of the fractured-rock aquifer within the Lake Area. As it has been said above the srosssectional structure of the ground water reservoir is nonhomogeneous and could be illustrated by the fig. 5.1. The main features of the latter, within the study domain,are as follows: 


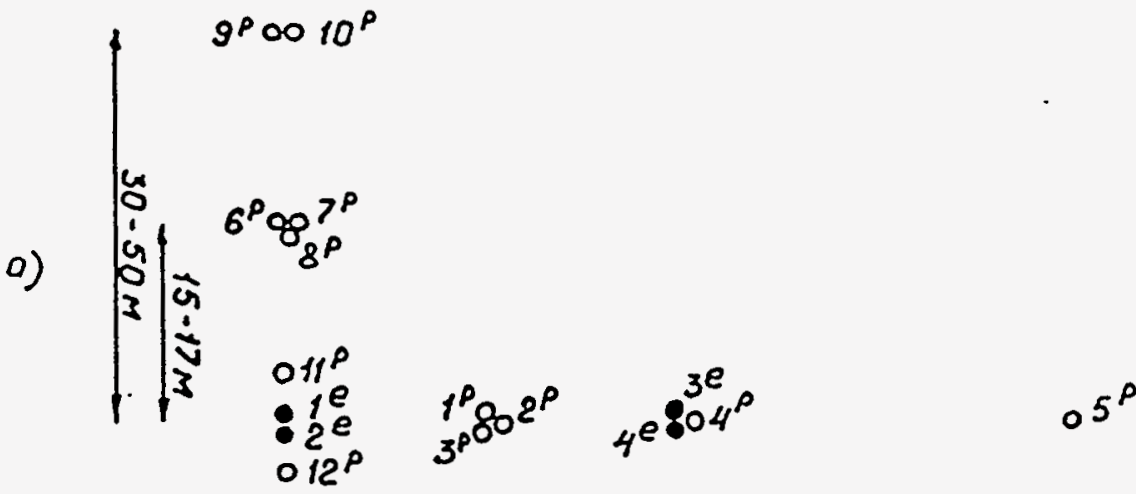

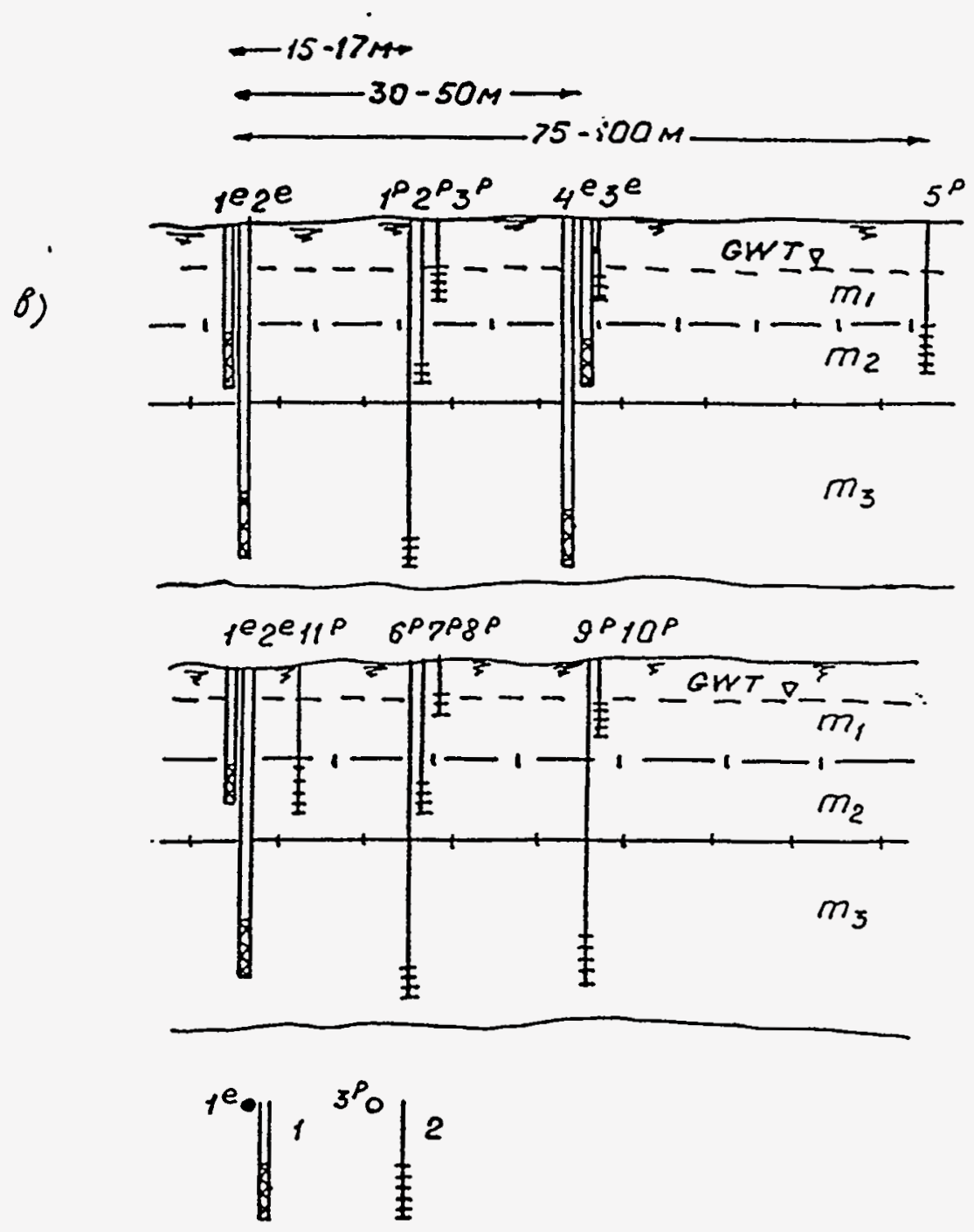

Fig.4.1. Wells location (1-pumping wells; 2-pezometers used as injection wells) at the testing site. 
- the unconfined aquifer's water-table lies most in the zone where wide-aperture fractures are filled with weathering products;

- the aquifer's top zone has a lowered permeability compared to its central, most permeable, part;

- the bottom of the water-bearing stratum is characterized by a gradual permeability attenuation with depth, the lower boundary being blurred;

- areal anisotropy and flow heterogeneity are likely to manifest themselves within the zones of test influence.

The diagnosis of earlier cluster-well pumping tests shows the drawdown curves $S-\lg \left(t / r^{2}\right)$ to be $S$-shaped with a fairly pronounced false stabilization segment before achieving a straight-line asymptote. Some observation wells, which are mostly located close to a withdrawal well, fall out of the overall asymptotics.

Given such conditions, it would be reasonable to orient cluster-well pumping tests to estimating the total aquifer transmissivity, the leakage coefficient for the upper layer, the specific yield coefficient, and the areal anisotropy coefficient.

Pumping tests interpretation is to be preceded by modelling studies to validate the applicability of the standard scheme for a 2-layered aquifer according to the following provisions:

- the influence of partial penetration of wells on the applicability of a fully penetrating well scheme;

- the influence of fracturing attenuating with depth on the total transmissivity estimation;

- the influence of specific water-yield retardation (so-called Boulton phenomenon) on drawdown curves;

- the influence of deviation from the REV assumption on the data obtained from the wells nearest to observation wells.

The analysis of the influence of partial penetration could be conducted on the basis of numericaland-analytical estimations for a layered, areally radial, flow (Lomakin et al.,1989) taking into account the well construction factor ("skin-effect" and well's storage)..

The water-yield dynamics could be evaluated using the "capillary fringe scheme" (Mironenko and Shestakov, 1978) and the volume-and- budget method of tests interpretation (Pozdnyakov and Stepanishev, 1992). To assess the scale of this phenomenon, saturated-unsaturated flow simulation could be carried out.

The diagnosis of the anomalous behaviour of the nearest observation wells during the test will help to identify the minimal representative testing volume (within which the REV assumption is valid).

\subsection{Numerical modelling of pumping tests at the key site "Transit"}

\subsubsection{Analytical-and-numerical evaluation of flow tests peculiarities 4}

Model studies were conducted to validate the applicability of the scheme of fully penetrating well pumping in a 2-layered aquifer according to a typical permeability profile.

Analytical-and-numerical calculations (ANC) of the stratified axisymmetrical flow (Lomakin, Mironenko and Shestakov, 1988) were realized by transition from a system of differential equations in partial derivatives to common differential equations according to the Laplace-Carson transformation

\footnotetext{
${ }^{4}$ Dr. Stepanischev, Sergey L. participated in preparing this Section
} 


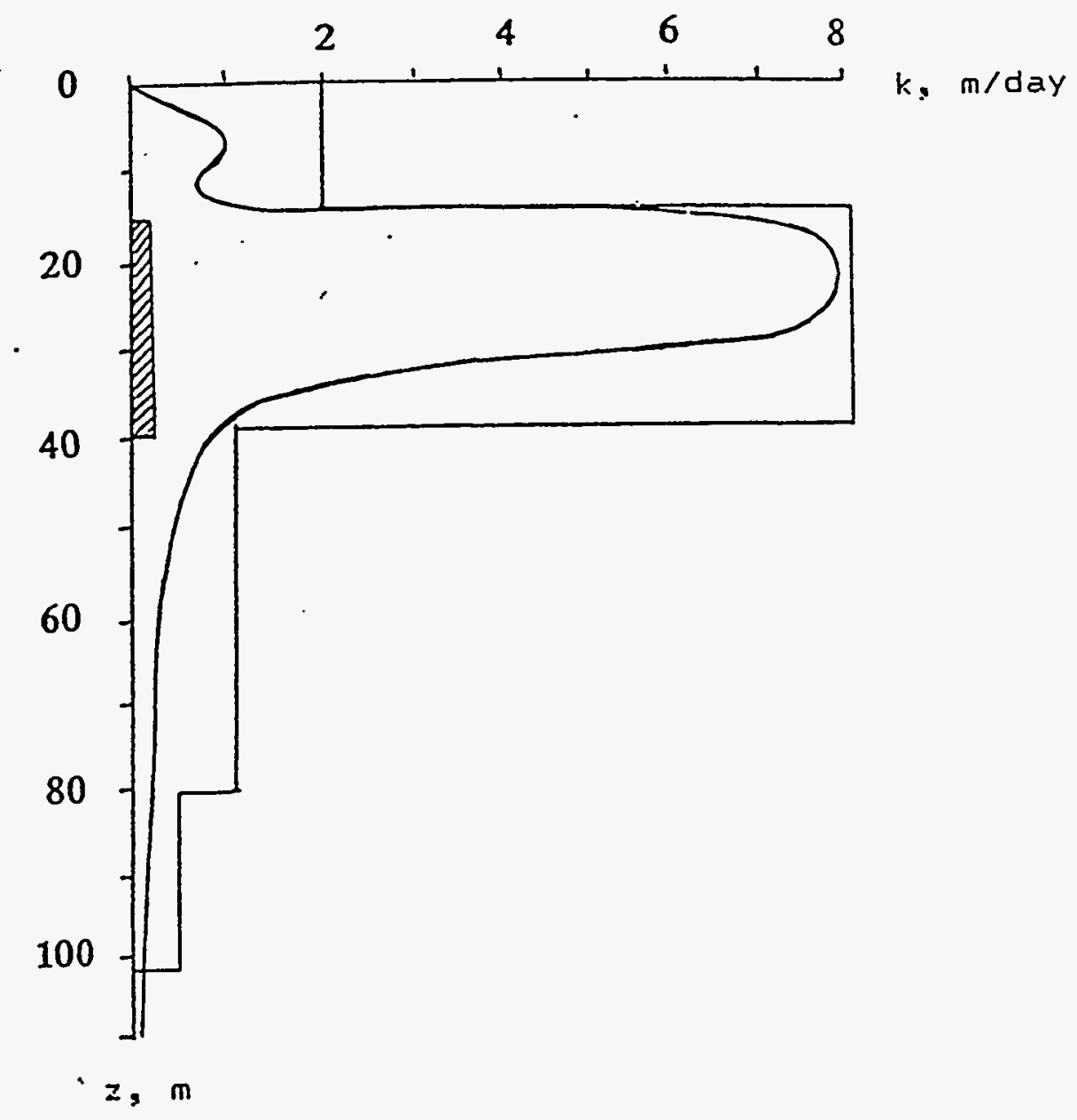

Fig.5.1 Hydraulic conductivity vertical distribution in Silurian porphyrites 
(Lomakin, Mironenko and Shestakov, 1988). Analytical solution for the latter system of equations is found by methods of linear algebra. An inverse transition from drawdowns images to the originals is performed according to the algorithm suggested by Gokhberg (Mironenko and Shestakov, 1978). In such formulation, it is possible to solve not only a direct problem, but also an inverse one for parameter estimation using the well-known Levenberg-Markwardt minimization method. For specific modelled situation, the modelling time on IBM PC AT 286/287 takes some minutes which testifies to the efficiency of the ANC approach.

Initial data (Fig.5.1) were provided by the hydraulic conductivity distribution in cross-section obtained through injection tests into the wells along the geological profile between the Lake 9 and River (Fig.2.2). Hydrogeological data analysis (borehole cores and field tests results) leads to consider the given distribution to be representative for the site under study. Parameters of the surface layer for the direct problem solving were taken according to the results of cluster well test (see below, item 5.2.2).

The modelled experiment considers conditions of pumping based on the schematization of the available data for hydraulic conductivity profile distribution and actual range of flow parameters variability (direct problem solving). Then these results interpretation was conducted by inverse problem solving for the simplified scheme of 2-layered aquifer.

Pumping was performed from the most permeable zone, within depths interval $15-40 \mathrm{~m}$. The drawdowns were noted in wells positioned in the main aquifer $(S)$ and at the free surface $S_{o}$ at the distances of $10,25,50$, and $100 \mathrm{~m}$ from the central well.

The inverse problem solving is oriented to determining the total transmissivity of the aquifer $T$, the gravitational storativity $\mu_{o}(\eta)$ and the paramter of leakage between the upper and middle parts of the aquifer - $\chi_{o}$ (the latter parameter represents the ratio of the upper layer's hydraulic conductivity $k_{o}$ and its thickness $m_{o}$ ).

The model experiments were preceeded by a special assessment of the influence of grid discretization for the model and the possiblity of employing the adopted algorithm for the inverse transformation from images to drawdowns originals.

A conditional dividing of the model domain into four layers (Table 5.1) sharply differing in permeability and the total transmissivity $T=137 \mathrm{~m}^{2} /$ day, $\chi_{0}=0.011 /$ day, $\mu_{o}=0.003$ was acceped as the principal option. Table 5.1 shows the results of the analytical-and-numerical modeling of the pumping test for this option. Analysis of the direct and inverse problems solving (the parameters were estimated as $T=137 \mathrm{~m}^{2} /$ day, $\chi_{0}=0.008$, and $\mu_{0}=0.003$ ) shows that for all the wells, excluding the nearest one at the distance of $10 \mathrm{~m}$, the accepted 2-layered scheme proves valid.

Similar experiments were also conducted for other options within the actual parameter variability range $\left(T=95-137, \chi_{0}=0.001-0.01\right.$, and $\mu=0.001-0.003$, the number of layers in grid representation was varied between 4 and 20 ). They have shown that the uncertainty of the thickness and hydraulic conductivity estimates in the lower, nonpumped part of the cross section as well as possible changes in the upper layer parameters for various options of its nonuniformity and the possible errors due to schematizing the initial permeability distribution do not essentially influence the direct and inverse problems solving results.

So, on the basis of analytical-and-numerical experiments, the possiblity was validated to interpret pumping tests (with wells screened within the most permeable zone and with the observation wells being distanced enough from the central well) in the same way as for a fully penetrating pumping well in a 2-layered flow. In this scheme, the water yield dynamics is taken into account automatically in flow resistance values for the upper layer, proceeding from the "capillary fringe" model (Mironenko, Shestakov, 1978) formally identical to the Boulton model.

It is noteworthy that a more comprehensive evaluation of the water yield dynamics must be done using simulation of saturated-unsaturated flow for which purpose one has to find out a moisturesuction characteristics for the upper layer.

At the same time, the carried out numerical experiments corroborate the possibility of employing 
Table 5.1: Results of simulating the main option for the pumping test

a) grid representation of the model

\begin{tabular}{|c|c|c|}
\hline layer $\mathrm{N}$ & $\mathrm{k}, \mathrm{m} /$ day & $\mathrm{m}, \mathrm{m}$ \\
\hline 1 & 1 & 15 \\
2 & 4 & 25 \\
3 & 0.5 & 40 \\
4 & 0.1 & 20 \\
\hline
\end{tabular}

b) input parameters values: $T=137 \mathrm{~m}^{2} /$ day; $\quad \chi_{0}=0.01$ day $^{-1} ; \quad \mu_{0}=0.003$, c) direct $\left(S_{n}\right)$ and inverse $\left(S_{m}\right)$ problems solutions:

\begin{tabular}{|c|c|c|c|c|c|c|c|c|}
\hline \hline Time, day & \multicolumn{7}{|c|}{ drawdowns in the main aquifer } \\
\cline { 2 - 9 } & $\mathrm{r}=10$ & $\mathrm{r}=10$ & $\mathrm{r}=25$ & $\mathrm{r}=25$ & $\mathrm{r}=50$ & $\mathrm{r}=50$ & $\mathrm{r}=100$ & $\mathrm{r}=100$ \\
\cline { 2 - 9 } & $S_{n}$ & $S_{m}$ & $S_{n}$ & $S_{m}$ & $S_{n}$ & $S_{m}$ & $S_{n}$ & $S_{m}$ \\
\hline 0.01 & 0.49 & 0.52 & 0.33 & 0.32 & 0.22 & 0.2 & 0.12 & 0.1 \\
\hline 0.1 & 0.51 & 0.54 & 0.35 & 0.35 & 0.23 & 0.22 & 0.13 & 0.11 \\
\hline 1 & 0.61 & 0.66 & 0.45 & 0.45 & 0.33 & 0.33 & 0.22 & 0.21 \\
\hline 3 & 0.71 & 0.76 & 0.55 & 0.55 & 0.42 & 0.43 & 0.3 & 0.3 \\
\hline 5 & 0.75 & 0.8 & 0.59 & 0.59 & 0.47 & 0.47 & 0.35 & 0.35 \\
\hline 7 & 0.78 & 0.83 & 0.62 & 0.62 & 0.5 & 0.5 & 0.38 & 0.37 \\
\hline 10 & 0.81 & 0.86 & 0.65 & 0.65 & 0.53 & 0.53 & 0.41 & 0.41 \\
\hline 50 & 0.95 & 1 & 0.79 & 0.79 & 0.67 & 0.67 & 0.55 & 0.54 \\
\hline \hline
\end{tabular}

\begin{tabular}{|l|l|l|l|l|l|l|l|l|}
\hline \hline Time, day & \multicolumn{70}{|c|}{ drawdowns at free surface } \\
\cline { 2 - 10 } & $\mathrm{r}=10$ & $\mathrm{r}=10$ & $\mathrm{r}=25$ & $\mathrm{r}=25$ & $\mathrm{r}=50$ & $\mathrm{r}=50$ & $\mathrm{r}=100$ & $\mathrm{r}=100$ \\
\cline { 2 - 9 } & $S_{n}^{o}$ & $S_{m}^{o}$ & $S_{n}^{o}$ & $S_{m}^{o}$ & $S_{n}^{o}$ & $S_{m}^{o}$ & $S_{n}^{o}$ & $S_{m}^{o}$ \\
\hline 0.01 & 0.01 & 0.01 & 0.01 & 0.01 & 0 & 0.01 & 0 & 0 \\
\hline 0.1 & 0.1 & 0.11 & 0.07 & 0.08 & 0.05 & 0.05 & 0.03 & 0.03 \\
\hline 1 & 0.52 & 0.49 & 0.37 & 0.39 & 0.27 & 0.29 & 0.17 & 0.18 \\
\hline 3 & 0.7 & 0.63 & 0.53 & 0.53 & 0.41 & 0.42 & 0.29 & 0.29 \\
\hline 5 & 0.75 & 0.68 & 0.59 & 0.58 & 0.46 & 0.46 & 0.34 & 0.34 \\
\hline 7 & 0.78 & 0.71 & 0.62 & 0.61 & 0.49 & 0.5 & 0.37 & 0.37 \\
\hline 10 & 0.81 & 0.74 & 0.65 & 0.64 & 0.53 & 0.53 & 0.41 & 0.4 \\
\hline 50 & 0.95 & 0.88 & 0.79 & 0.78 & 0.67 & 0.67 & 0.55 & 0.54 \\
\hline \hline
\end{tabular}

d) Estimated parameters values: $T=137 \mathrm{~m}^{2} /$ day; $\quad \chi_{0}=0.008 ; \quad \mu_{0}=0.003$ o 
Table 5.2: Position of observation wells for the cluster well test $N 164$

\begin{tabular}{|l|l|l|l|}
\hline \hline ray $N$ & well $N$ & Distance from the central well, $r(m)$ & Screen installation interval, $(m)$ \\
\hline \hline 1 & 171 & 67.7 & $15-80$ \\
& 172 & 5 & $40-80$ \\
& 165 & 15 & $10-105$ \\
& 166 & 34 & $5-120$ \\
& 167 & 59.1 & $10-110$ \\
\hline \hline 2 & 160 & 126.8 & $10-80$ \\
& 161 & 94.4 & $20-120$ \\
& 162 & 68.3 & $30-120$ \\
& 168 & 22.6 & $15-105$ \\
\hline \hline 3 & 169 & 20.6 & $10-120$ \\
& 170 & 50.3 & $5-115$ \\
\hline \hline
\end{tabular}

the "capillary fringe" model (Pozdnyakov and Stepanishchev, 1992).

Of special interest is a study of pumping tests near a river where a steady-state regime is reached. Such tests interpretation can be carried out on the basis of a numerical-analytical solution using Fourier's integral transformation (for the coordinate axis directed along the river) and the Laplace time transformation.

\subsubsection{An example of the interpretation of cluster-well pumping tests}

To test the possibility of using the accepted simplified scheme for a 2-layered aquifer, a specific cluster-well pumping test performed in the area was considered. The well spacing within the cluster is shown in Table 5.2 .

According to available data, one can single out in the vertical cross section three conditional water-bearing intervals characterized by attenuation in fracturing and permeability with depth. Pumping was carried out from the upper, most permeable zone within the $10-50 \mathrm{~m}$ interval. The pumping discharge ranged within $130-190 \mathrm{~m}^{3} /$ day averaging $160 \mathrm{~m}^{3} /$ day. Observation wells are screened through the entire aquifer and are positioned along three rays at the angle of about $120^{\circ}$ to each other.

The diagnostics of the experimental data shows the tracer curves $\bar{S}-\lg \left(t / r^{2}\right)$ to be $S$-shaped with well enough pronounced segment of false stabilization approaching a straight-line asymptote. Here, the plot shows a considerable dispersion of points due to the areal flow nonuniformity, the observation wells lag (N 170), as well as to their vicinity to the central well $(N N 168,169)$ which also can be seen from the areal plot $\bar{S}-\lg r$ (Fig.5.3).

Interpretation of areal and combined tracking data (graphs $\bar{S}-\lg r, \bar{S}-\lg \left(t / r^{2}\right)$ ) are of interest for assessing the extent of aquifer nonuniformity. The variance of data observed for wells 172 and 169 which are nearest to the central well might be accounted for by the influence of areal rock micro-nonuniformity (10-20 m-long).

Table 5.3 presents the results of parameter estimation for different observation wells rays. Dispersion of the parameters obtained by different methods (Mironenko and Shestakov, 1978; Pozdnyakov and Stepanishchev, 1992) is quite noticeable: $T=74-220 \mathrm{~m}^{2} /$ day; $\chi_{o}=0.0012-0.013 ; \mu_{o}=$ $0.0019-0.005$. The values $T=95 \mathrm{~m}^{2} /$ day, $\chi_{o}=0.011 /$ day, $\mu=0.003$ were taken as average parameters.

The experience of interpreting pumping tests of such kind at the studjed site shows that the implementation of the 2-layered scheme is hindered by the influence of areal flow nonuniformity 


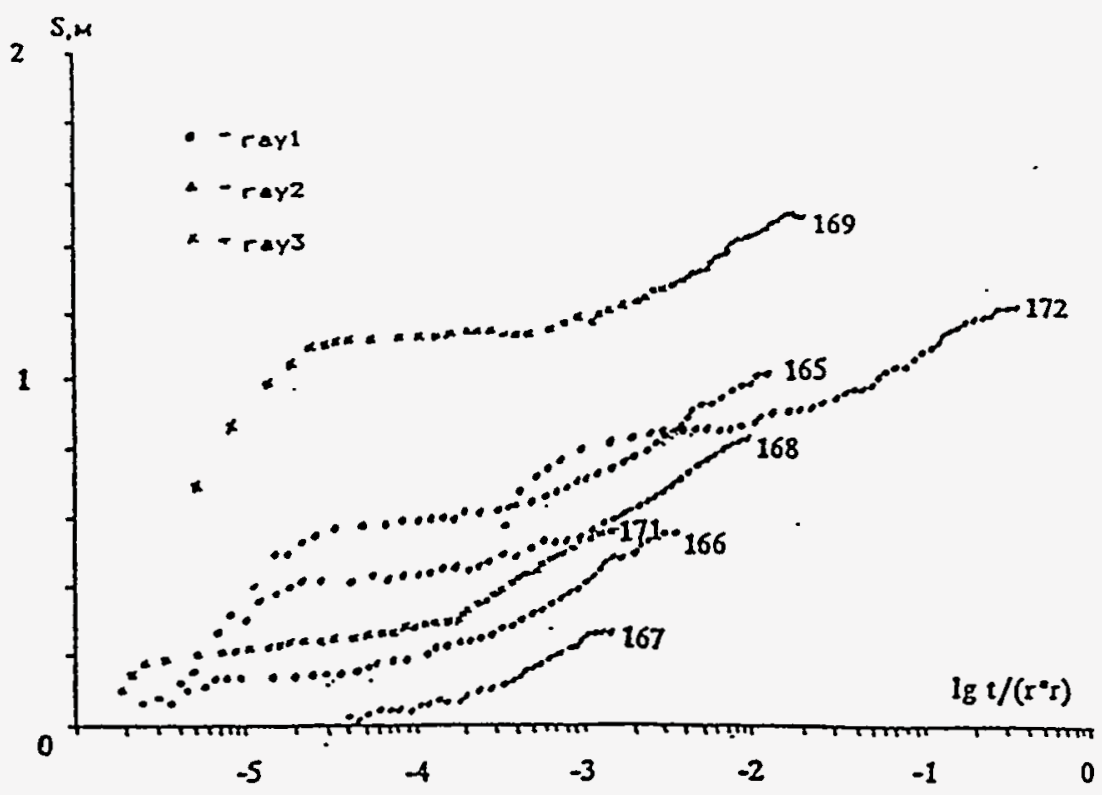

Fig.5.2 Combined plot $S-\lg t /(r \cdot r)$

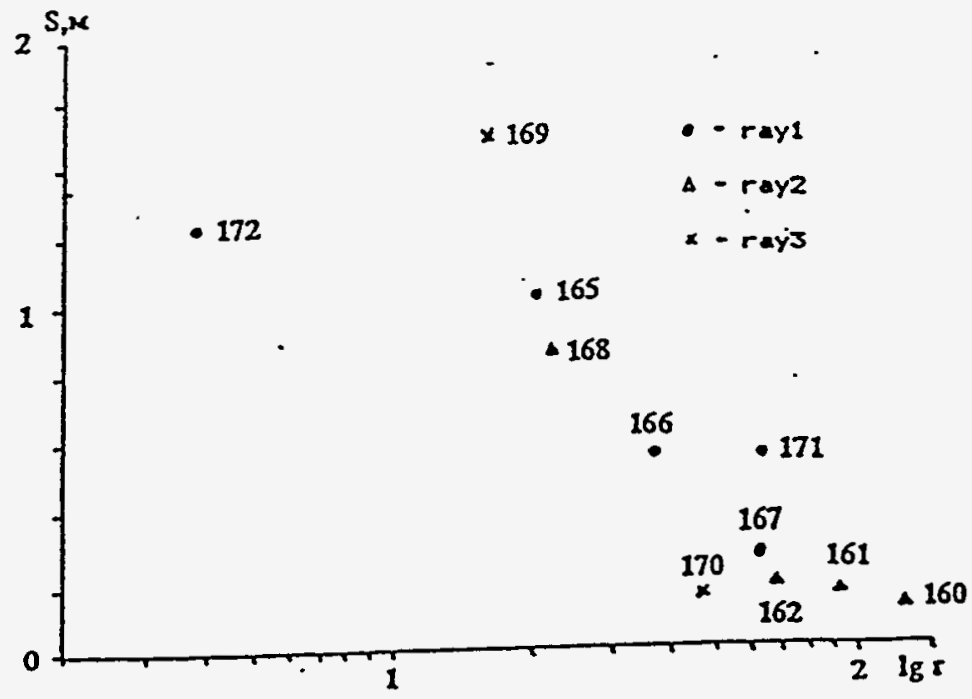

Fig.5.3 Areal plot $S-\lg r$ 
Table 5.3: Results of flow parameters estimation according to cluster-well tests data

\begin{tabular}{|l|l|l|l|l|}
\hline \hline Method of estimation & \multicolumn{1}{|c|}{ Observation wells } & \multicolumn{3}{|c|}{ Estimated parameters values } \\
\cline { 3 - 5 } & & $T, m^{2} /$ day & $\chi$, day & $\mu_{o}$ \\
\hline \hline$S \div \lg t / r^{2}$ & $165,166,167,172$ & 93 & - & - \\
& $160,161,162$ & 153 & - & - \\
& $165,166,167,171,172,168,169$ & 97 & - & - \\
\hline$S \div \lg r$ & $165,166,167,172$ & 74 & $2.3 \cdot 10^{-3}$ & - \\
& $160,161,162$ & 220 & $2.1 \cdot 10^{-3}$ & - \\
& $165,166,167,171,172,168$ & 80 & $1.2 \cdot 10^{-3}$ & - \\
\hline ANC & $172,168,171,166$ & 95 & $1.3 \cdot 10^{-2}$ & $4.1 \cdot 10^{-3}$ \\
& $172,168,171$ & 110 & $6.7 \cdot 10^{-3}$ & $1.9 \cdot 10^{-3}$ \\
\hline Water balance & $160,161,162,165,166$ & - & - & $5 \cdot 10^{-3}$ \\
& $167,168,172$ & - & - & $5 \cdot 10^{-3}$ \\
\hline Accepted values & & 95 & $1 \cdot 10^{-2}$ & $3 \cdot 10^{-3}$ \\
\hline \hline
\end{tabular}

which is impossible to take into account on the basis of the simplified analytical models for areally anisotropic stratum or aquifer with stripe-type nonuniformity. Deciphering and taking account for the nonuniformity in flow parameter estimation is possible on the basis of analyzing a great number of representative pumping tests. The substantiation of such tests requires an attentive preliminary validation by numerical models.

In conclusion, it is necessary to note that, in equipping cluster test wells, one should preclude the technical errors connected with well discharge variability and the piezometer lag. As model calculations have shown (variable-yield pumping was simulated, the processing being done according to the 2-layered aquifer scheme with the constant averaged discharge), yield changes during pumping out of the well $\mathrm{N} 164$, from 130 to $190 \mathrm{~m}^{3} /$ day, could lead to drawdowns differences of up to $10 \%$ in direct problem solving and the error reaching up to $15 \%$ while estimating main parameters.

\subsubsection{Use of numerical modeling for analyzing pumping tests in stratified layers}

\subsubsection{A brief characterization of the basic program (numerical code) for simulation of radial $2 \mathrm{D}$ flow in a layered aquifer}

The numerical model is based on a conservative, finite-difference (purely implicit) scheme. To preserve the scheme's uniformity, the boundary conditions were materialized using the method of imaginary blocks where the model domain takes on the shape of a rectangle (Saul'jev, 1964).

Envisaging a likely flow nonlinearity (partial drying of aquifer, etc.), the iteration Hauss-Seidel algorithm was taken as a basis together with the successive over-relaxation (SOR). To optimize convergence, a semi-empiric relaxation parameter estimation was performed (Saul'jev, 1964) with acceleration according to Chebyshev (Hockney and Eastwood, 1981) and the "two-colored" arrangement of the model grid points (the chess algorithm).

The appropriate numerical code RELIS is targeted for the implementation of the following options:

1. an arbitrary change in time of the discharge rate in a production well;

2. simulation of test regime with a preconditioned drawdown in the pumping well;

3. packering of the pumping well well for independent water withdrawal from each interval (which permits, in particular, to simulate flow tests under a vertical doublet scheme): 
Table 5.4:

\begin{tabular}{|l|l|l|l|l|}
\hline \hline layer $N$ & $\mathrm{k}, \mathrm{m} /$ day & $\mathrm{m}, \mathrm{m}$ & $\eta, 1 / \mathrm{m}$ & $\mathrm{Q}, \mathrm{m}^{3} /$ day \\
\hline 5 & 0.00102 & 1 & 0.02 & 0 \\
\hline 4 & 0.7 & 15 & 0 & 0 \\
\hline 3 & 2.74 & 25 & 0 & 100.0 \\
\hline 2 & 0.36 & 40 & 0 & 0 \\
\hline 1 & 0.1 & 20 & 0 & 0 \\
\hline \hline
\end{tabular}

4. a regard of the withdrawal well's capacity;

5. input of an arbitrary initial heads both in layers and each discretization blocks;

6. each block has its own values of storativity and hydraulic conductivity (horizontal and vertical);

7. the latter option allows to materialize an arbitrary function of the well's skin-effect;

8. a regard of infiltration;

9. use of service subroutines allowing to compare calculated and actual field tests data on screen in the graphics mode.

Preliminary verification of the program RELIS on leakage problems (as the hardest from the viewpoint of test data processing) showed a good agreement of the calculated data with the numerical results obtained through the more common computer code WELL (Mucha, 1991).

For 3D flow problems we will use the numerical finite-difference code developed by $A$.Roshal, GEOLINK, 1991 (see Section 5.3.2.).

\subsubsection{Code validation procedure}

The results of the above field tests processing on the basis of numerical-and-analytical models were compared to the direct problem solving on the numerical code RELIS. Initial data are given in Table 5.4. The cross section was represented by five layers, the zero specific yield being taken for the four lower layers while only in the upper, recharging, layer, its value was 0.02 .

The plots 5.4 show the comparison of numerical-and-analytical calculations and RELIS-modelled results. Tracer plots in the recharging layer virtually coincide. At the same time,for the first period of pumping one can note a general trend to some lag in drawdown values according to RELIS, compared to numerical-and-analytical calculations. Although the absolute error of those discrepancies is pretty small $(\sim 4 \div 6 \mathrm{~cm})$, this trend persists throughout all the lower layers. After this first period the flow process reaches a quasi-steady regime (according to the observation wells), and the plots $S \div \lg t$ coincide completely.

\subsubsection{Sensitivity analysis on numerical models}

The present example consideres the conditions of pumping from a partially penetrating well screened through the heterogeneous aquifer at the key site "Transit". The objective of the test would be evaluating the flow parameters of fractured rock at the site. The conditions of conducting such tests could be restricted by a possible upconing of radioactive brines to the well from the lower (unscreened) zones of the aquifer. The main parameters accepted for the basic modelling scenario are reflected in Table 5.5. 

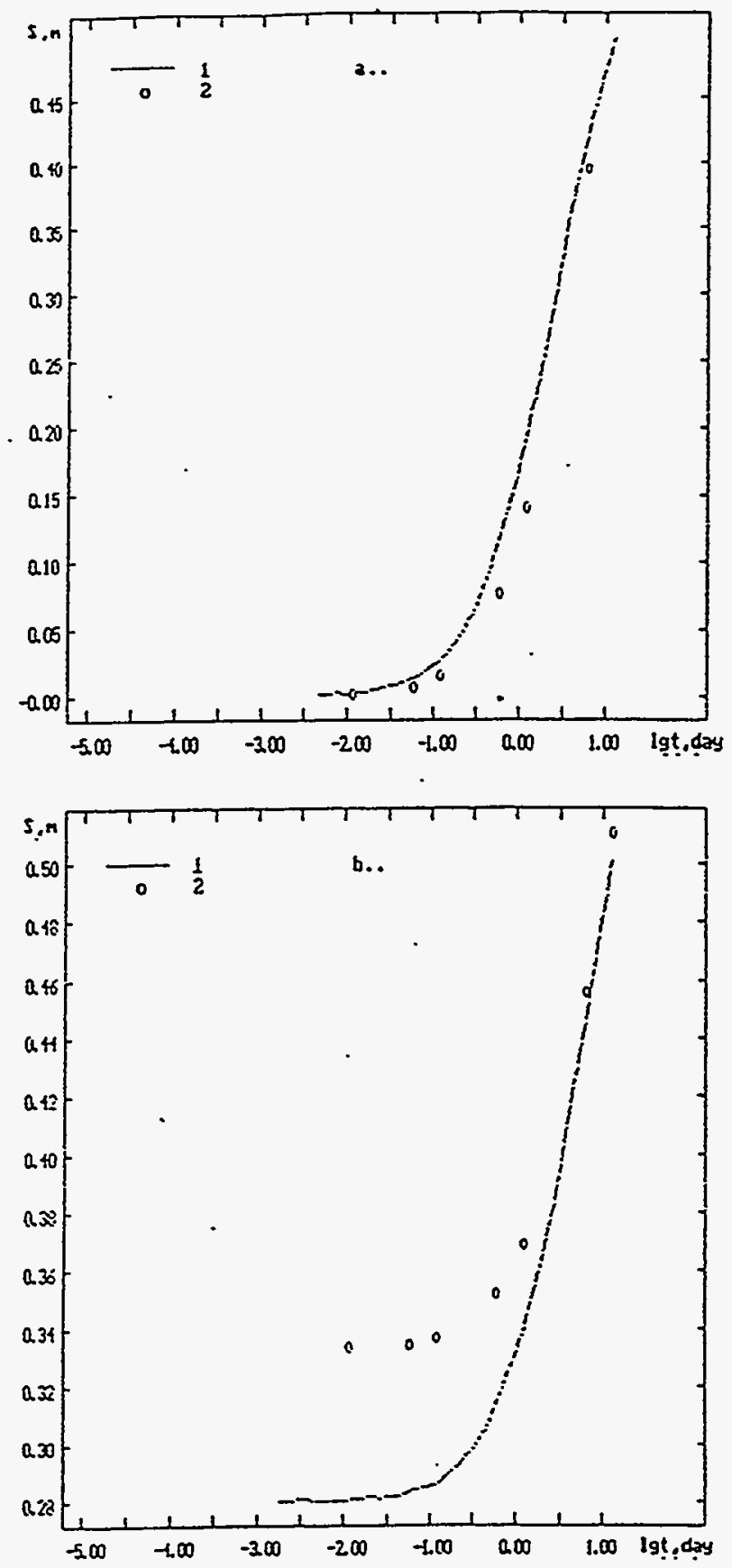

Fig. 5.4. Comparison of numerical (1) and numerical-andanalytical modelling results 
Table 5.5:

\begin{tabular}{|c|c|c|c|c|c|c|c|}
\hline $\begin{array}{c}\text { Layer number } \\
\text { (from the) } \\
\text { land surface }\end{array}$ & $\begin{array}{c}k_{x} \\
(m / \text { day })\end{array}$ & $\begin{array}{c}k_{z} \\
(m / d a y)\end{array}$ & $\mu$ & $\begin{array}{c}\eta^{*} \\
(1 / m)\end{array}$ & $\begin{array}{c}\mathrm{m} \\
(m)\end{array}$ & $\begin{array}{c}r_{w} \\
(m)\end{array}$ & $\begin{array}{c}\mathrm{Q} \\
\left(m^{3} / \text { day }\right)\end{array}$ \\
\hline 1 & 1 & 0.1 & 0.003 & $5 \cdot 10^{-6}$ & 15 & 0.1 & \\
\hline 2 & 4 & 0.5 & & $5 \cdot 10^{-6}$ & 25 & 0.1 & 500 \\
\hline 3 & 0.5 & 0.1 & & $5 \cdot 10^{-6}$ & 40 & & \\
\hline 4 & 0.1 & 0.05 & & $5 \cdot 10^{-6}$ & 20 & & \\
\hline
\end{tabular}

Here, $k_{x}$ and $k_{z}$ are hydraulic conductivities in the horizontal and vertical directions; $\mu$, gravitational yield; $\eta^{*}$, the specific elastic storage; $r_{w}$, the well radius; $Q$, pumping rate from the second layer (the pumping interval being $25 \mathrm{~m}$ ).

Under consideration were also some additional scenarios with an increased gravitational yield ( the maximal value of $\mu=0.02$ ) and depth to the relative aquiclude (the fourth layer's thickness being increased to $60 \mathrm{~m}$ ).

The numerical program RELIS was used. The numerical grid was presented by 30 radial cross sections and 8 horizontal slices.

As a result, the drawdown curves $s=f(\lg t)$ were constructed for various layers (see, for example, Fig. 5.5 and 5.6), and also those $s=f(\lg r)$ for the quasi-steady zone. The analysis of the curves as well as that of the entire drawdown data makes it possible to get the following conclusions:

1). the drawdown curves $s=f(\lg t)$ (Fig.5.5.) are mainly of a typical $s$-shape with a pseudosteady segment and a slow approach to the final rectilinear asymptote; to reach the latter, one would need 3 days of pumping given $\mu=0.003$, and up to 30 days for $\mu=0.02$;

2). the drawdown curves $s=f(\lg r)$ for the main layer during the quasi-steady regime are practically rectilinear and have a slope matching the layer's transmissivity $(T)$;

$3)$. the depression curve is practically horizontal near the central well, and its drawdown plot $s=f(\lg t)$ reaches the rectilinear asymptote matching the main layer's transmissivity as early as in several tens of hours (Fig. 5.6.);

4). all this testifies to the possibility of a fairly sound estimation of the first and second layer's parameters according to the standard scheme of a two-layered unconfined aquifer;

5). pumping test data are very low-sensitive to both the changes in the depth of the relatively nonpermeable bottom of the aquifer and the flow parameters of the lower layers;

6). equipotential lines within the third and the fourth layers are practically horizontal near the central well.

The latter circumstance permits to evaluate the risk of a radioactive brines upconing to the well during pumping. One could assume the maximal upward flow gradient in the above-mentioned near-well zone $I=0.025$ being obtained at the model. for the asymptotic regime. For the active 
fractured porosity value equal to 0.001 , one could conclude that the first portions of contaminated water from the fourth layer would come into the well not earlier than in 15-20 days ${ }^{5}$.

The estimated time includes some safety factor since the hightened density of the brines is disregarded here. At the same time, the pumping test lasting up to 2-3 weeks under these conditions is fairly enough for a proper testing of the upper zone of the aquifer.

On the other hand, the modelling has shown that the flow parameters estimations for the lower zone (including the depth of the low permeable bedrock) is possible only by means of its direct testing. A long- term pumping from the second layer aimed at estimating the vertical permeability of the underlying zone could be the only significant exception here. For that purpose, observations of the initial stage of radioactivity and salinity growth in the pumped-out water could be used. Tentative estimations of the respective analytical solution (Mironenko and Rumynin, 1986), as well as this model results show that the duration of such a pumping should be measured in several tens of days. It is sensible to conduct such tests at the site "River" where vertical permeability estimates will be needed for forecasting the rate of radioactive brines upconing to the river.

As for the lower zone testing by injection wells, the modelling shows that the transmissivity of the $3 \mathrm{~d}$ and the 4 th layers could be properly found only by the s-lgr-matching using a row of observation wells in the quasi-steady area. On the contrary, the time-drawdown matching gives very poor results here due to the influence of the upper zone. The period of injection some hours long is enough for quasi-steady regime which could be used also for evaluating the vertical permeability of the overlapping (the third) layer. For excluding the influence of density convection during injection into the lower layer filled by radioactive brines it is advisable to use for injection the salt water with the same density (the volume of $5 \mathrm{~m}^{3}$ is quite enough for this purpose).

This conclusion is supported by modelling of fresh water injection into the lower (No. 4) layer. For this model the numerical code HST-3D (K. Kipp, 1987) was used. The density of salt water in the lower layer was $\rho_{s}=1.05 \mathrm{~g} / \mathrm{l}$, the fractured porosity $n=0.003$, the dispersivities were: $\delta_{x}=0.2 \mathrm{~m}, \delta_{z}=0.02 \mathrm{~m}$, the period of injection $t_{\text {in }}=5$ days. All other parameters were similar to the previous case. The main conclusions are as follows: 1) during the injection test the convective cell develops near the central well (within the zone $r<10 \mathrm{~m}$ ); 2) because of this anomaly both the s-t matching and s-r matching don't permits to obtain the proper values of transmissivity or other flow paramters.

\footnotetext{
${ }^{5}$ According to the transmissivity ratio, the maximal radioactive component concentration in the pumped-out water matches the dilution cocficient of the order of 50-70 (if the lower layer is contaminated to its entire thickness).
} 


\subsection{Analysis of pumping tests conducted near a narrow river (Site "River")}

\subsubsection{General ideas}

To estimate flow parameters characterizing surface-ground water interactions, it is recommended to conduct observations and tests by the system of wells positioned as seen from Fig. 5.7. Each of those wells taps an aquifer (the well $C_{p w}$ is fully penetrating the active zone of the stratum) and is suplemented with a piezometer installed directly under the free surface of the flow.

At such a site, flow regime observations are conducted with a precise registration of levels during steady-state and, especially, unsteady-state periods. These observations' data interpretation is conducted according to the appropriate finite-difference equations (Shestakov, 1982). It should be noted that the influence of heavy nonuniformity can considerably distort the acquired data so that the flow parameters for the river bottom could not be properly estimated.

In this connection, long-term pumping test is to be conducted from the well $C_{p w}$ until a steadystate condition is reached. Such a pumping tests interpretation is could be performed on the basis of numerical-and-analytical solutions (Veselova, Shestakov and Yazvin, 1991; Nevecherya and Shestakov, 1990).

In case of a narrow river, the relationship between the head difference $\Delta H^{\circ}$ in the river and the aquifer, and the specific discharge $q^{\circ}$ from the river into the aquifer can be expressed by the following:

$$
\Delta H^{\circ}=\frac{q^{\circ}}{T} L^{*}
$$

where $T$ is aquifer transmissivity; $L^{*}$, the parameter (equivalent length) of the hydraulic underriver flow resitance. For a pumping test with fully penetrating well positioned at the distance $L$ from the river the cross section of which meets the condition (5.1), a steady drawdown $s$ for the cross-section perpendicular to the river can be expressed as:

$$
S=\frac{Q}{2 \pi T}\left[\ln \frac{x+L}{|x-L|}+e^{\bar{x}} W(\bar{x})\right], \quad \bar{x}=\frac{x+L}{2 L^{*}}, \quad W(\bar{x})=\int_{\bar{x}}^{\infty} \frac{e^{-x}}{x} d x
$$

where $Q$ is the pumping rate; $x$ is the distance from the river to the particular observation point; $W^{T}$ is the well function for an isolated confined layer (Theis function).

Using the expression ( 5.2 ), one can numerically evaluate the influence of the river during pumping. Such an evaluation's results show that the real estimation of the value $L^{*}$ by pumping tests is possible provided that $L^{*}<10 \mathrm{~L}$. It means that for $L$ values equal some tens of meters, such a pumping test makes sense for $L^{*}$ values being more that first hundreds of meters.

To evaluate the duration of pumping test necessary for reaching a steady-state regime, one should first of all proceed from the condition that the time of stabilizing the flow regime must, at least, exceed the time of the gravitational regime onset which could be found from the pseudo-steady period $t_{p s}$.

For a two-layered aquifer with the upper layer being an aquitard of thickness $m_{0}$ and the hydraulic conductivity $k_{o}, t_{p s}$ is estimated by the following:

$$
t_{p s}=\frac{5 \mu_{o} m_{o}}{k_{o}}
$$

where $\mu_{o}$ is the gravitational yield (storativity) of the rock.

Defining site-specific values of hydraulic conductivity and upper sediments thickness $\left(k_{0}=\right.$ $0.1 \div 1 \mathrm{~m} /$ day. $m_{o}=10 \mathrm{~m}$ and the storativity $\mu_{o}=0.1$, according to (5.3), we can obtain the valucs $t_{p s}=50 \div 500$ days which exceeds the real time of the traditional pumping tests. 


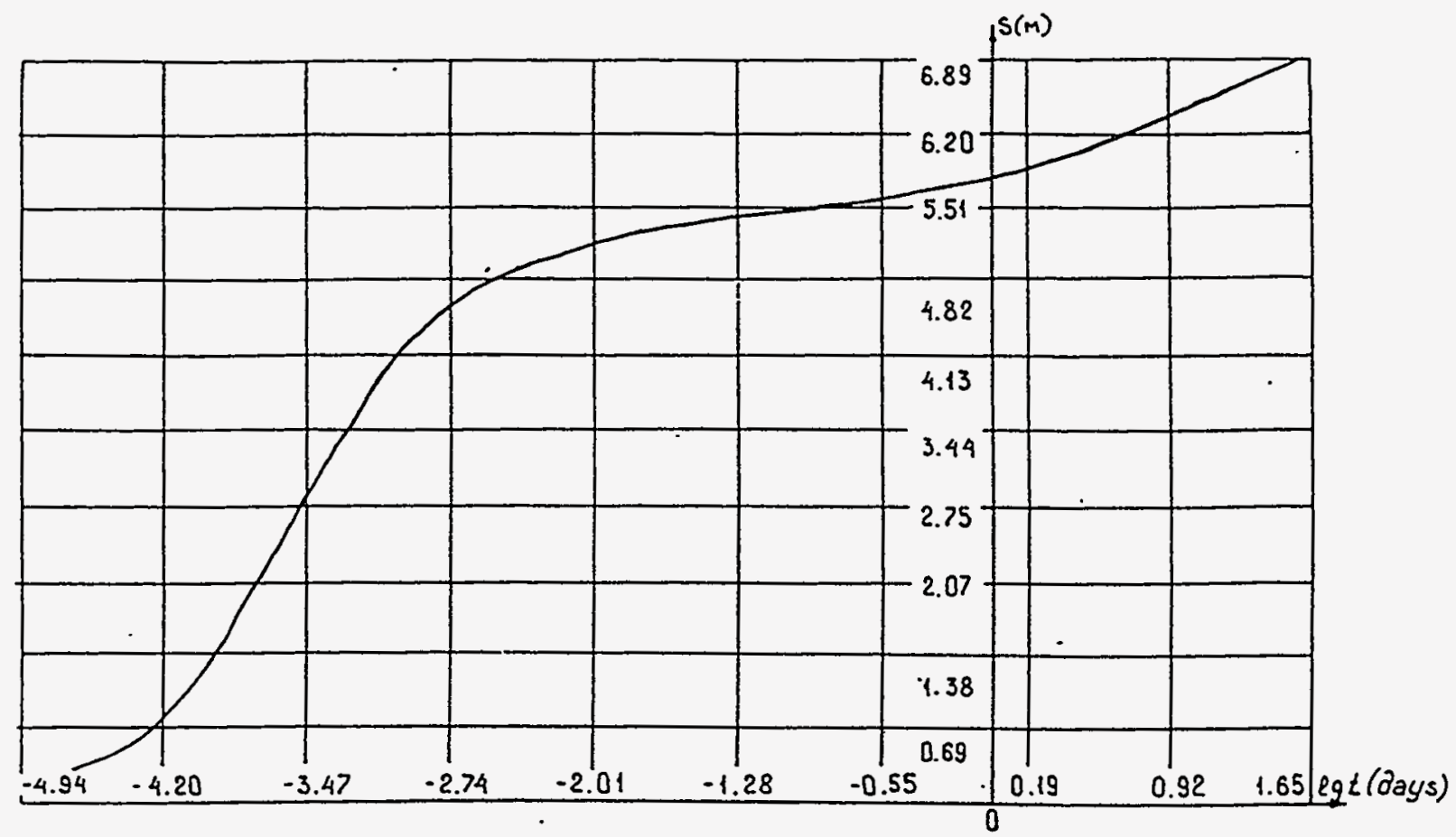

Fig.5.5. Drawdown curve $s=f(\lg t)$ for the main layer

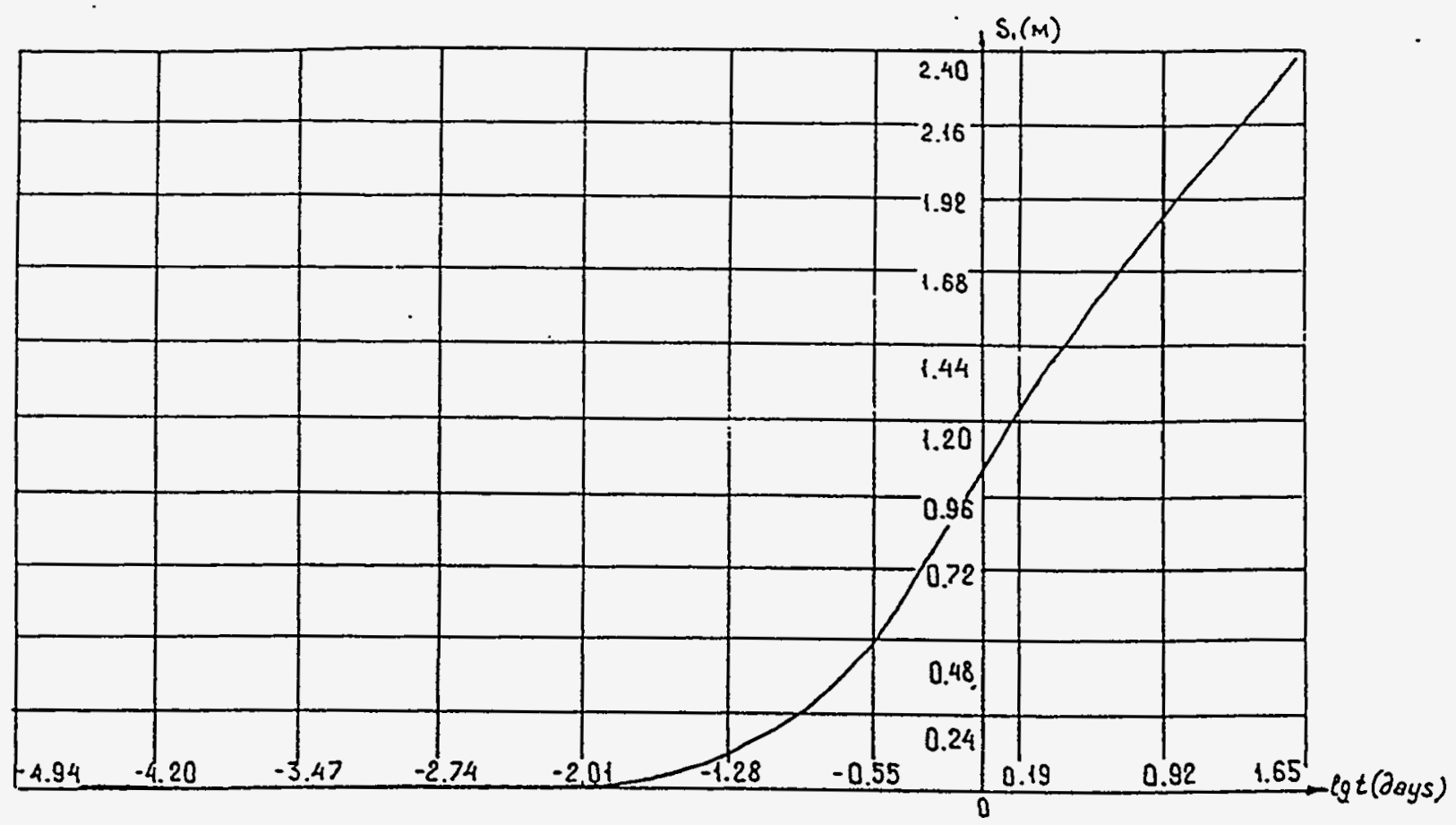

Fig.5.6 Drawdown of the depression surface $s_{1}=f_{1}(\lg t)$ 

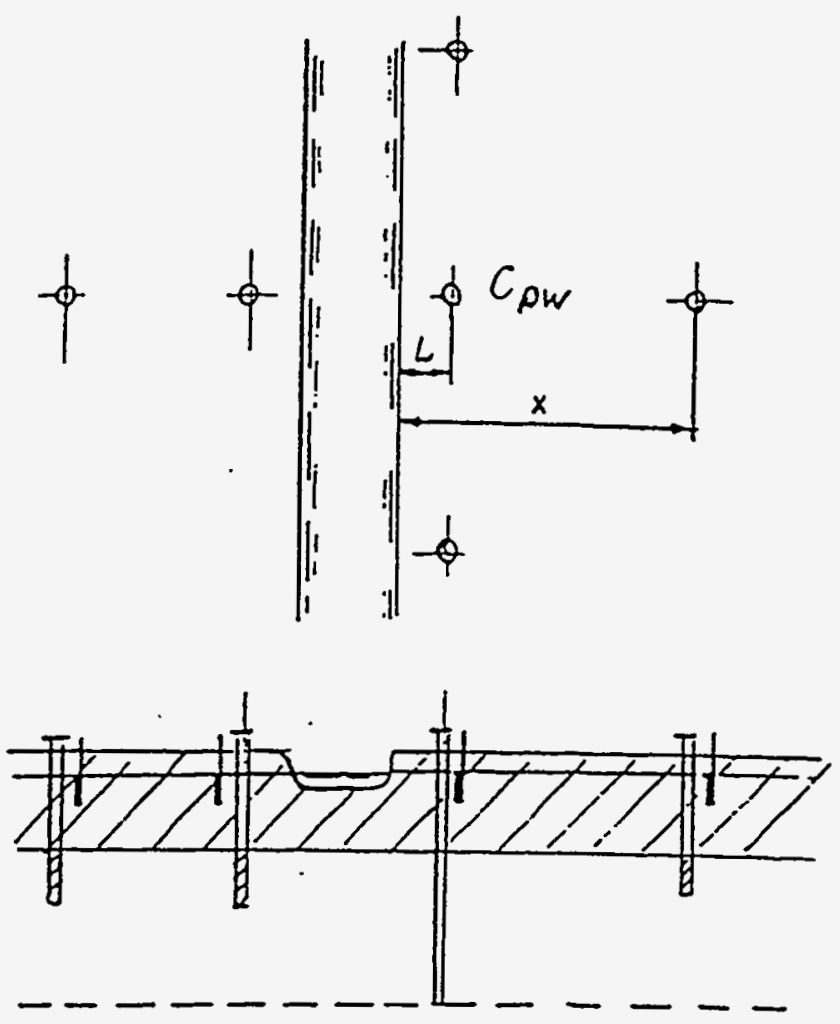

Fig.5.7 The optimal scheme of cluster-well location near the river 
Such estimates could be supported by numerical analysis of the nonsteady regime under the conditions of pumping tests using numerical-analytic solutions of such a problem. In this case the practical solution of the problem of estimating the hydraulic resistance parameter $L^{*}$ could be found, if one can presume that the upper sediments are spreading under the river and, respectively, the hydraulic conductivity of the river bottom is the same as of the upper layer. Then the upper layer permeability could be found by processing data for the initial period of pumping, disregarding the river influence, while the stream bottom's hydraulic resistance could be evaluated by the known analytical solution for a two-layered stream bottom.

\subsubsection{Numerical modeling of pumping test}

To study the regularities of groundwater movement stirred up by pumping tests near a river, numerical modeling was conducted on a 3D (4-layer) model of a cross-sectionally nonuniform aquifer parameters of which are presented in Table 5.5. The upper layer was assumed unconfined; the rest of the layers, confined.

Software developed in the company Geosoft-Easlink was used. The numerical model was built using the finite-difference method on a rectangular irregular grid. The Chebyshev chess algorithm was employed to solve the problem.

Pumping from the most permeable (second from top to bottom) layer was simulated. Here, the pumping well was positioned 45 meters off the river. The river width was defined as equal to 16 meters, and the parameter of surface-ground water relationships $\left(k_{o} / m_{o}\right)$ was defined as 0.001 (a); 0.01 (b) and 0.1 (c) 1/day. The duration of the pumping was assumed to be 90 days.

Since the problem was symmetric, a semi-limited layer was simulated. The symmetry axis represented a perdendicular drawn from the river through the pumping well, and an impermeable boundary was defined along the axis. The grid step by $X$ and $Y$ was ranging from 2 to 8192 meters. The overall dimensions of the model made up $50 \times 37$.

The modeling results are presented in Fig. 5.8. Here one can see the regularities of the groundwater drawdown changes in time in all four layers of the aquifer in a point positioned on the symmetry axis 2 meters off the pumping well. As seen from the figure, it is only in case (c) that the pumping practically enters the steady-state regime. Indeed, it can be inferred from the model budget that by the end of the pumping (90th day) the water-withdrawal rate is nearly $90 \%$ compensated by the inflow from the river. In cases (a) and (b), however, the inflows from the river makes up by the end of the pumping 10 and $54 \%$ of the water-withdrawal rate, correspondingly.

Additionally, a steady-state problem was solved. The solution's results (along the symmetry axis) are presented in Fig. 5.9. For comparison, a theoretical curve is also given here based on the equation (5.2) given the total average layer transmissivity being equal to (a) 132 ; (b) and (c) $134 \mathrm{~m} /$ day. As seen from the figures, model data for the second layer are in good match with the theoretical function. From this circumstance, one can draw a methodological conclusion that, to determine the total layer transmissivity, one can employ theoretical solutions obtained from a cross-sectionally unifrom layer. However, one has to use data on the most permeable layer for the processing. 


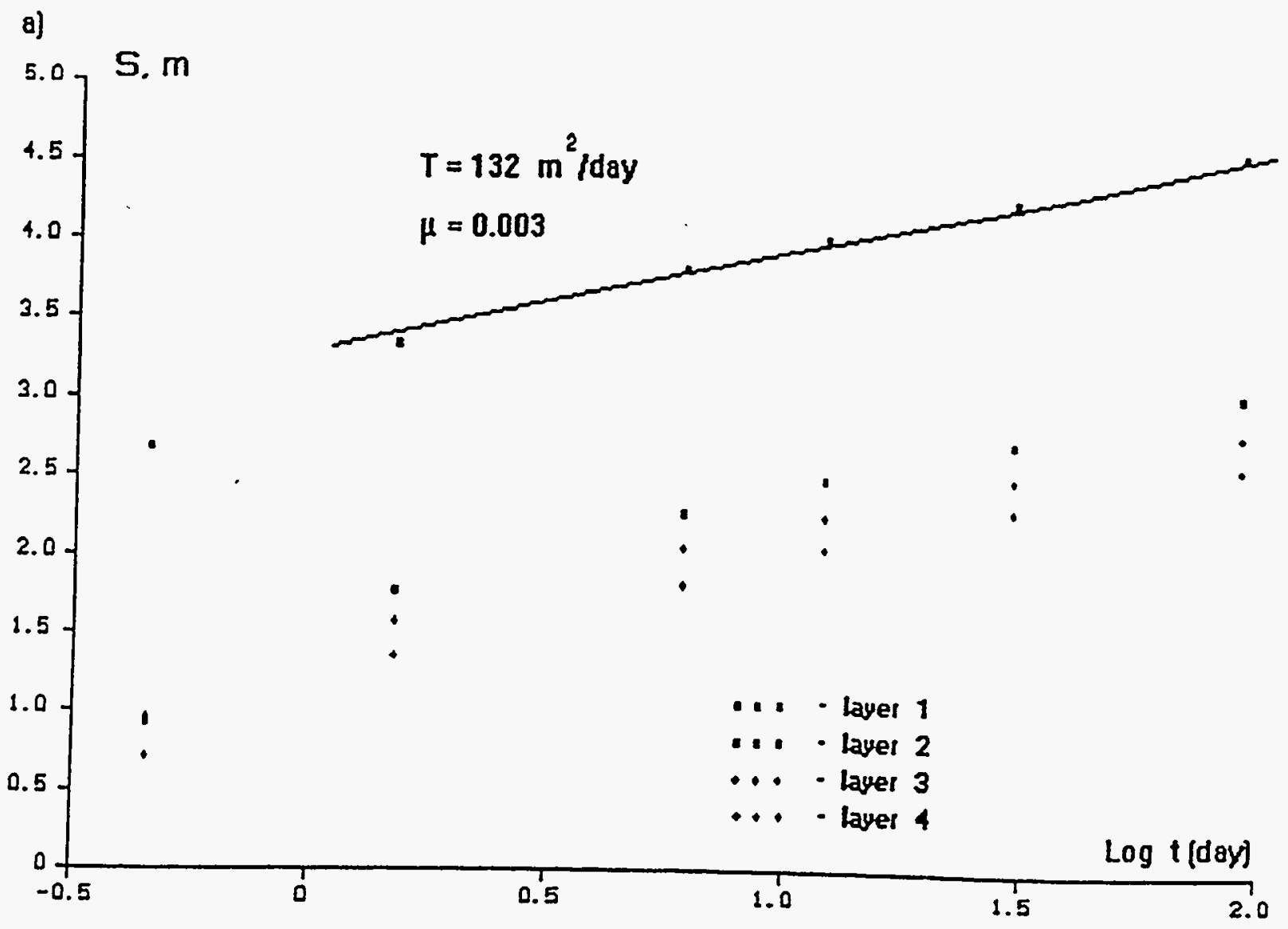

Fig.5.8 Graphs of the dependence of drawdowns on time in observation points. The coefficient of surface-ground water relationships $\left(k_{o} / m_{o}\right)$ is a) 0.001 b) 0.01 and c) $0.11 /$ day 


\section{Mathematical models of mass-transport (tracer) tests}

\subsection{The parametric basis of the models}

The fractured crystalline rock body under study is regarded at first approximation as quasihomogeneous in the respect of its capacity which is conditioned by fairly low porosity and diffusive permeability values of the rock matrix. Correspondingly, the interpretation of chemical tracer tests results can be based (if the REV assumption is valid) on a model of advective - dispersive transport. Active fracturing (relative fracture volume $-n$ ) and dispersivity (longitudinal and transverse constituents are designated as $\delta_{L}$ and $\delta_{T}$, respectively) are the parameters governing the nonreactive components transport.

The accuracy of estimating the parameter $n$ in the areal (subhorizontal) flow often depends on the reliability of data concerning the aquifer's effective thickness (m) supporting flow discharge into a well (or recharge of the injected fluid). Since the cross section always contains relatively low permeable zones, this value proves always less than the total aquifer thickness $\left(m_{T}\right)$. In tests with partially penetrating wells, $m_{S}<m<m_{T}$, where $m_{S}$ is the screen length. Therefore, when interpreting the tests, it is often sensible to confine oneself to estimating the combined parameter: $\bar{m}=m n$. Its decyphering for the $n$-value being singled out, should be done using additional data (the latter could be obtained, say, by geophysical methods).

The longitudinal dispersivity, $\delta_{L}$ value may be of interest as a control parameter. By its absolute value or, better, by its spatial variability (depending on the observation wells spacing), one can judge on the manifestation of large-scale effects. Using it directly for forecasting purposes would practically always underestimate the role of dispersion.

By injecting into the fractured collector some reactive components, it is possible to obtain a generalized value of their sorption retardation $\Delta n=K_{a} S_{b}$ where $K_{a}$ is the surface sorption coefficient, $S_{b}$, specific block surface exposed to sorption. Experimental values of the parameter $K_{a}$ reflect also the "instantaneous" matrix diffusion into pores within thin films of modified rock along fractures walls. For an equilibrium sorption, the effective fracturing value could be used:

$$
n_{e}=n+\triangle n
$$

Hence, given a known value of $n$, the generalized parameter $\Delta n$ can be found and directly incorporated into the forecasting model. At the same time, it is always useful to evaluate the coefficient $K_{a}$, which is commonly studied on samples in laboratory (Vandergraaf and Abry, 1982; Kamineni et al., 1983). For this purpose, data of the parameter $S_{b}$ are needed which could be found by thermal regime interpretation (the injected fluid is represented by fresh water with the temperature differing from the ambient one).

In this case, the tests are to estimate the parameter (Mironenko and Rumynin, 1986)

$$
\lambda_{T}=S_{b}^{2} a_{b}\left(C_{b} / C_{w}\right)^{2},
$$

which characterizes the intensity of heat exchange between fractures and blocks. Since the values $C_{b}, C_{w}$, and $a_{b}$ (the specific thermal storativity per unit of blocks volume, the same for water and blocks' thermal conductivity coefficients) can be easily estimated in laboratory, a formal transition from the coefficient $\lambda$ to the coefficient $S_{b}$ is always feasible.

Moreover, the crystalline rocks under study may well exhibit heterogeneous storage capacity in relation to chemical components due to the delayed diffusion into matrix through pores and minor fractures. Here, an appropriate macrodispersion model should be used with and the mass-exchange parameter (Mironenko and Rumynin, 1986) $\lambda_{m}=S_{b}^{2} D_{m} n_{o}^{2}$ being analogous to the parameter $\lambda_{T}$

Yet, due to the lack of field data confirming the manifestation of heterogeneous storage capacity in the crystalline rocks under consideration, homogeneous medium solutions only are used here. If 


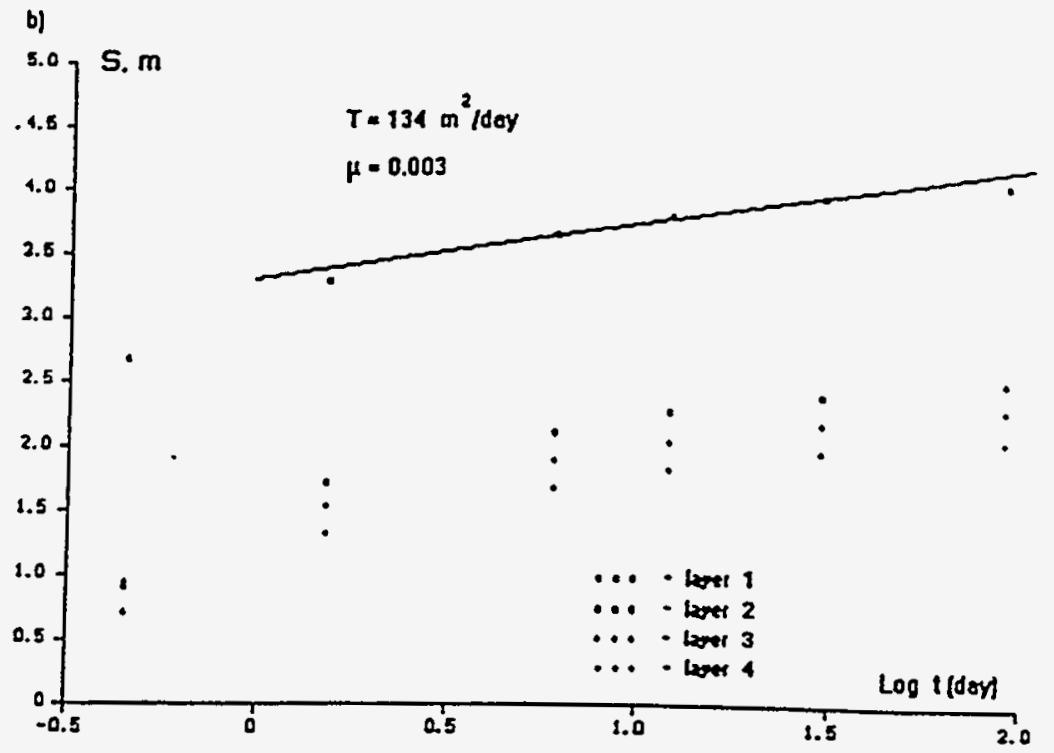

Fig.5.8 continued

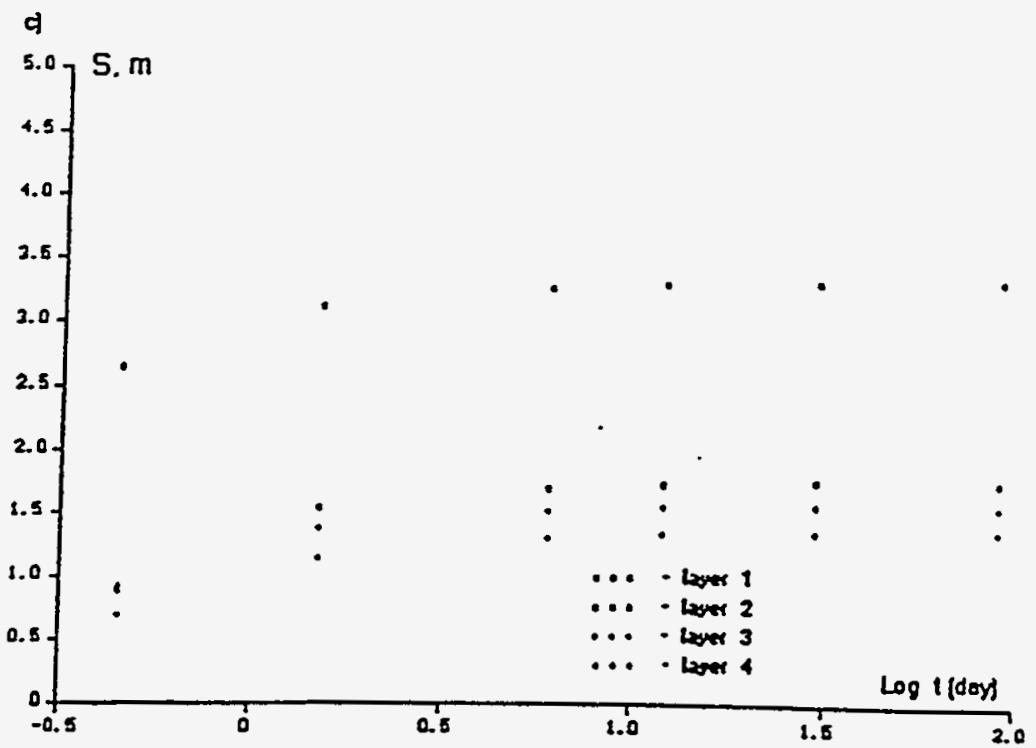

Fig.5.8 continued 
a)

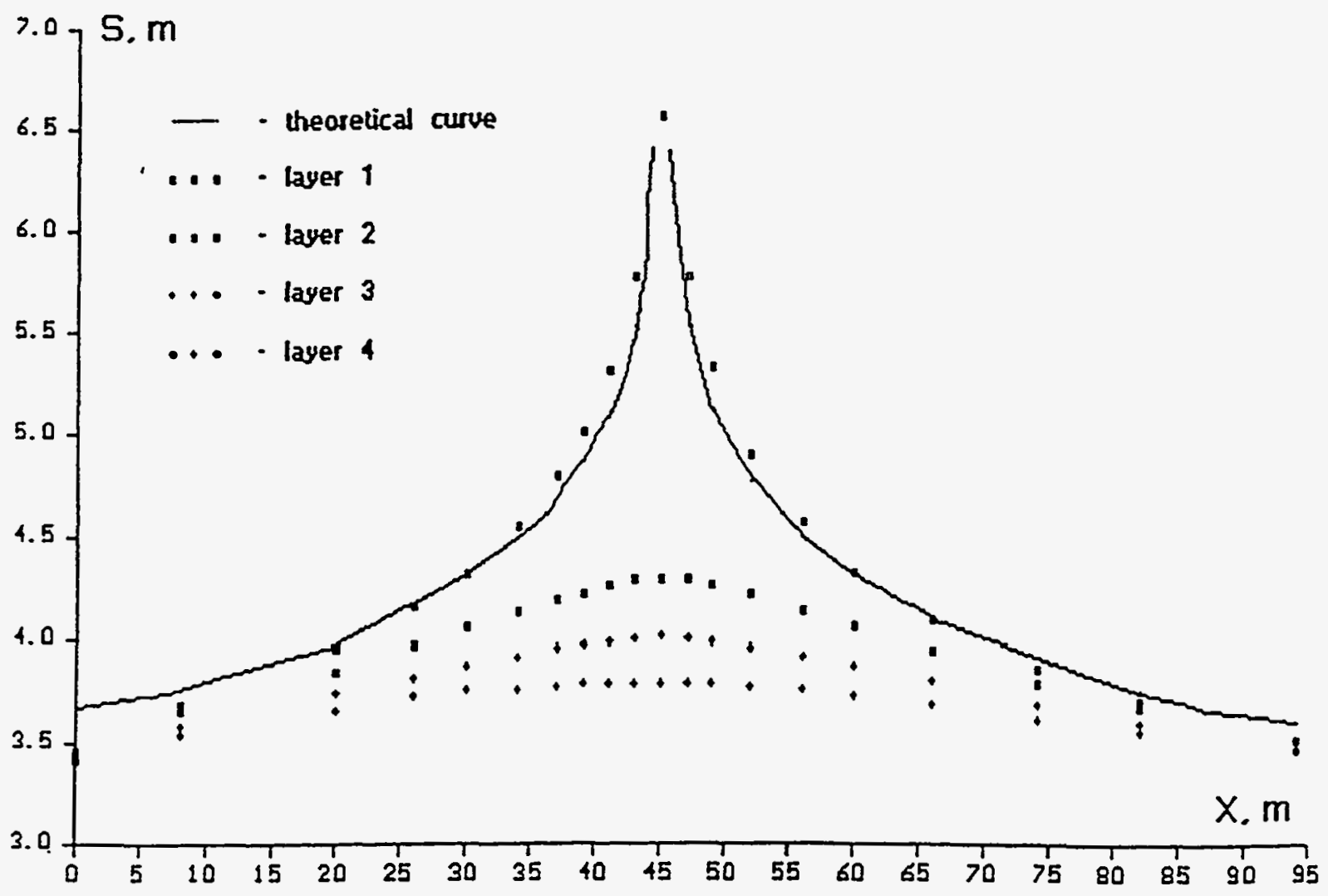

Fig.5.9 Graphs of the dependence of drawdowns on the distance from the river. The coefficient of surface-ground water relationships $\left(k_{o} / m_{0}\right)$ is: a) 0.001 b) 0.01 and c) $0.11 /$ day 

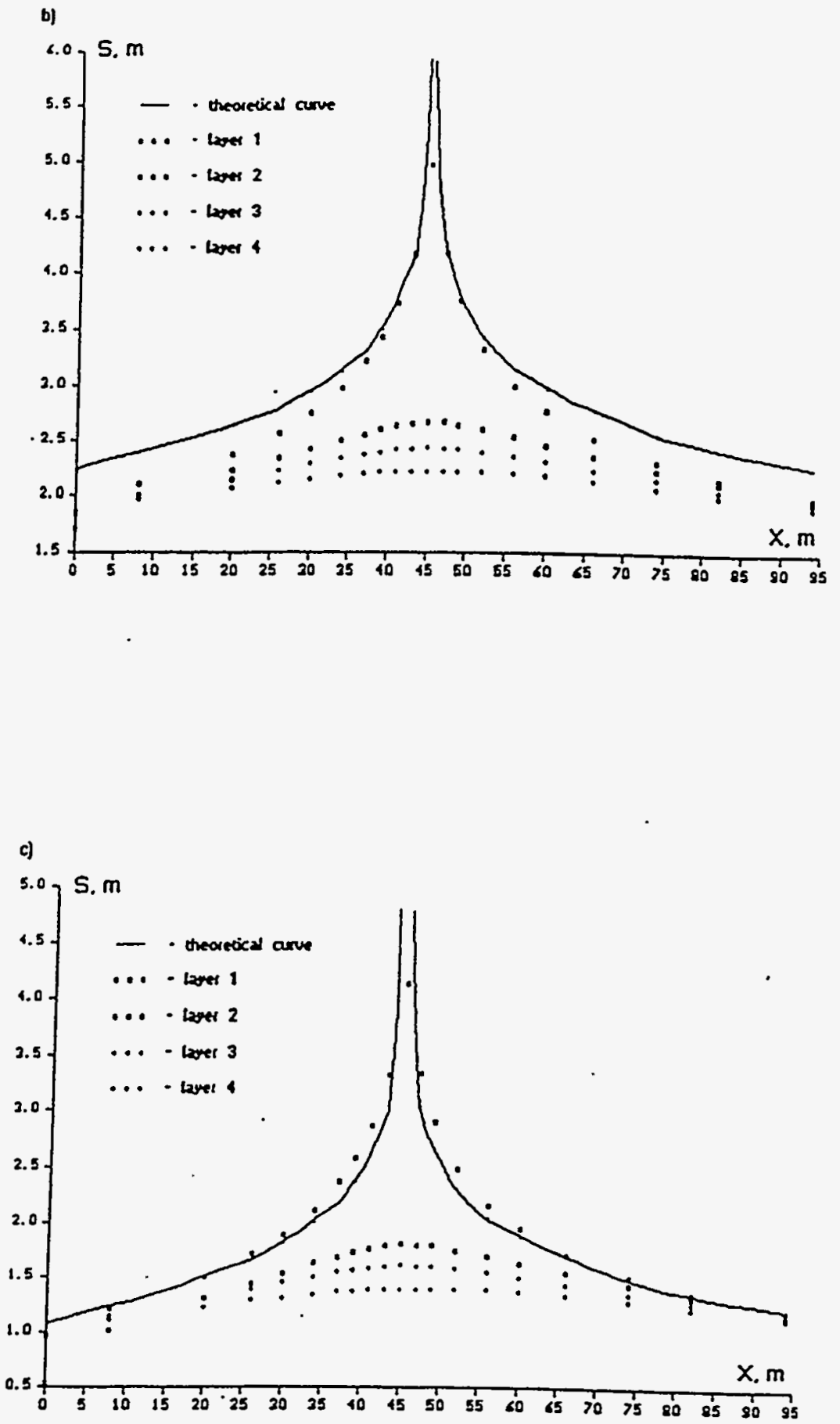

Fig.5.9 continued 
necessary, their heterogeneous analogs could be found in the monograph (Mironenko and Rumynin, 1986).

\subsection{Solutions for tracer tests in the divergent flow formed by a single injection well}

A study of an axi-symmetric advection and dispersion in a homogeneous medium has a wide reflection in literature (Gelhar and Collins, 1971; Tsang and Babu, 1979; Hsieh, 1986; Verigin et al., 1977; Shestakov, 1962; Sauty, 1978; Roshal, 1981; Alekseev et al., 1989; Moench, 1989, etc.). Most of publications deal with asymptotic approximations of an exact solution or equations inferred from some simplified ideas on dispersion near the piston flow front having the ongoing coordinate $r^{*}=\sqrt{Q t / \pi m n}$ (where $Q$ is the recharge rate). Approximated solutions differ mostly by the representation of the automodel variable $\xi\left(t_{r}, P e\right)$ (Appendix A) in the formula:

$$
\bar{C}=0.5 \operatorname{er} f c(\xi) \text {. }
$$

Comparison of calculations results for the well-known fundamental solution (Tang and $B a b u$, 1979; H sieh, 1986; Alekseev et al, 1989) with approximations (6.3) shows that they virtually are identical to each other for the values of $P e=r / \delta_{L}>20-30$, where $r$ is the distance to the observation point. Minimal differences, up to the complete identity, can be observed at the point $\bar{C}=0.5$.

\subsection{Solutions for impulse injection of tracer into observation well during pump- ing}

\subsubsection{A fully penetrating well in a cross-sectionally isotropic aquifer}

There are many analytical solutions for processing the data of impulse injection of tracer during pumping (Fig. 6.1, a) (Mironenko and Rumynin, 1986; Roshal, 1981; Lenda and Zuber, 1970, etc.). All these yield similar results in case the specific parameter Pe values are not too low. This fact makes it possible to choose the solution which reflects to the fullest extent the conditions of tracer enter into the aquifer (Appendix B):

$$
C=\frac{M}{\pi r^{2} m n}\left(\frac{3 P e}{16 \pi \tau}\right)^{1 / 2} \times \exp \left[-\frac{(1-\tau)^{2}}{16 \tau / 3 P e}\right] .
$$

where $M$ is mass of injected tracer, $\tau=Q t / \pi r^{2} m n$. According to. this solution, the relative time $\tau_{\max }$ of the "peak" of the tracer concentration $\left(C_{\max }\right)$ coming to the observation point (the pumping well) is:

$$
\tau_{\max }=\left(\sqrt{1+P e^{2}}-1\right) / P e
$$

\subsubsection{A partially penetrating well in a cross-sectionally anisotropic aquifer}

The test's flow model proceeds from the assumption of uniform discharge distribution along the well screen (Fig. 6.1, b). The solution of the characteristic equation (Appendix 3) allows to obtain an expression for finding the time of the tracer's travel from a given point $(r, z)$ within the aquifer to the pumping well:

$$
t_{0}=\frac{4 \pi l^{3} n}{Q}\left(\phi_{0}-1\right)\left[\frac{1}{3}\left(\phi_{0}^{2}+\phi_{0}+1\right)-\psi_{0}^{2}\right],
$$

where $l$ is the screen length; $\phi_{0}$ and $\psi_{0}$ are elliptic coordinates of the injection point linked to Cartesian coordinate, system $r$ and $z$ by the equations: 


$$
\begin{aligned}
& \phi_{0}=\left[\frac{1}{2}\left(1+\overline{r_{0}^{2}}+\overline{z_{0}^{2}}\right)+\left(\frac{1}{4}\left(1+\overline{r_{0}^{2}}+\overline{z_{0}^{2}}\right)^{2}-\overline{z_{0}^{2}}\right)^{1 / 2}\right]^{1 / 2}, \\
& \psi_{0}=\left[\frac{1}{2}\left(1+\overline{r_{0}^{2}}+\overline{z_{0}^{2}}\right)-\left(\frac{1}{4}\left(1+\overline{r_{0}^{2}}+\overline{z_{0}^{2}}\right)^{2}-\overline{z_{0}^{2}}\right)^{1 / 2}\right]^{1 / 2}
\end{aligned}
$$

In case of a cross-sectionally anisotropic aquifer, we have:

$$
t_{0}=\frac{4 \pi l^{3} n}{Q \chi^{2}}\left(\phi_{0}-1\right)\left[\frac{1}{3}\left(\phi_{0}^{2}+\phi_{0}+1\right)-\psi_{0}^{2}\right], \quad\left(\phi_{0}, \psi_{0}\right) \rightarrow(\chi r, z),
$$

where $\chi=\left(k_{z} / k_{r}\right)^{1 / 2}$ is the coefficient of anisotropy.

For impulse injection, the time $t_{0}$ is equal to the time $t_{\max }$ of the peak concentration which permits, using the formulas (6.6) and (6.7.), to estimate the coefficient $n$ or combined parameter $n / \chi^{2}$

Approximating a radial flow by a linear one, we get a solution for dispersivity in case of impulse tracer injection which is similar to (6.4):

$$
\begin{gathered}
C=\frac{M}{2 r A}\left(\frac{P e}{\pi \tau}\right)^{1 / 2} \times \exp \left[-\frac{(1-\tau)^{2} P e}{4 \tau}\right], \\
A=\frac{4 \pi l^{2} n\left(\phi_{0}-1\right)\left[\frac{1}{3}\left(\phi_{0}^{3}+\phi_{0}+1\right)-\psi_{0}^{2}\right]}{\phi_{0} \sqrt{\left(\phi_{0}^{2}-\psi_{0}^{2}\right) /\left(\phi_{0}^{2}-1\right)}-\psi_{0} E(\alpha, 1 / \psi)} \\
\tau=t / t_{0}^{\prime}, \quad t_{0}^{\prime}=4 \pi r^{3} n / 3 Q, \\
\alpha=\arcsin \left(\sqrt{\left(\phi_{0}^{2}-\psi_{0}^{2}\right) /\left(\phi_{0}^{2}-1\right)}\right),
\end{gathered}
$$

$E(\alpha, k)$ is an elliptic second-type integral. For approximated estimates, the formula for calculating $A$ can be represented as

$$
A \approx 2 \pi l^{2} n\left(\phi_{0}^{2}-1\right)^{1 / 2}\left[\left(\phi_{0}^{2}-1\right)^{1 / 2}+\phi_{0}^{2} \arcsin \left(1 / \phi_{0}\right)\right]
$$

\subsection{Solutions for doublet tests}

\subsubsection{An areal (subhorizontal) doublet}

The regularities of mass transport in the hydrodynamic field of two interacting, pumping and injecting, wells (Fig. 6.2, a) have been analyzed scrupulously enough (Grove and Beetem, 1971; Hunt, 1978; Mironenko and Rumynin, 1986, etc.). In addition to this, Appendix D exhibits a more complete solution of the anisotropic problem. The output curves of doublet experiments (Mironenko and Rumynin, 1986) are characterized by a faint influence of dispersivity comparing with tracer dispersion due to the strong deformation of the flow net. The breakthrough curves' low sensitivity to the dispersivity within the area of $\bar{C}>0.1$ allows for interpreting it by the approximate equation

$$
\bar{C}=\frac{2}{\pi} \arccos \left[\left(t_{0} / t\right)^{1 / \pi}\right], \quad t \geq t_{0},
$$

obtained in the framework of sharp interface assumption for tracer's movement in fractures; here. $t_{0}=\pi r^{2} m n / 3 Q$ is the time of tracer travel through the shortest pathline. 

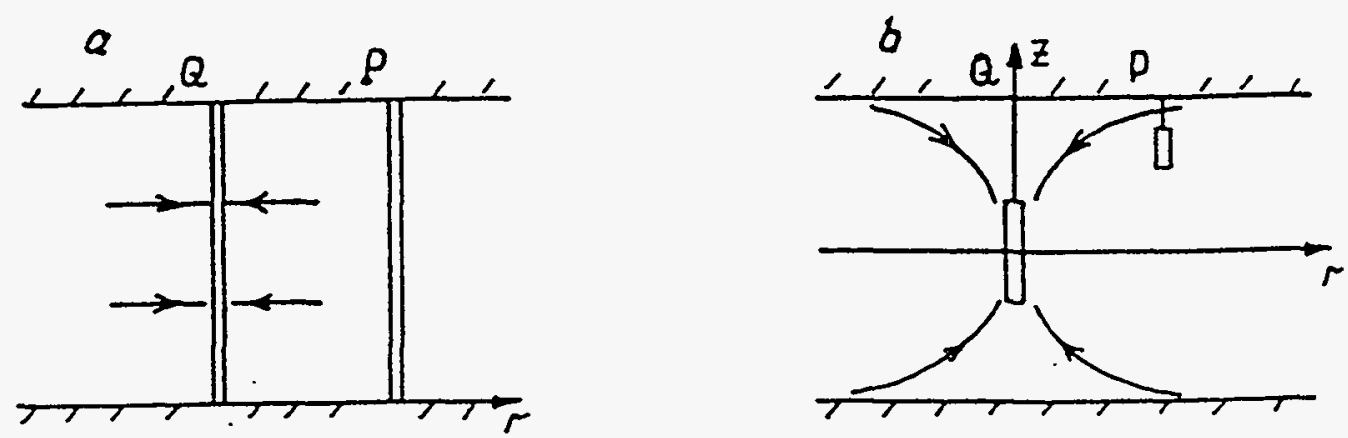

Fig.6.1 Flow lines toward a fully (a) and partially (b) penetrating well in confined aquifer during tracer injection into piezometer $Q$ - water - withdrawal well, $P$ - piezometer 
a)
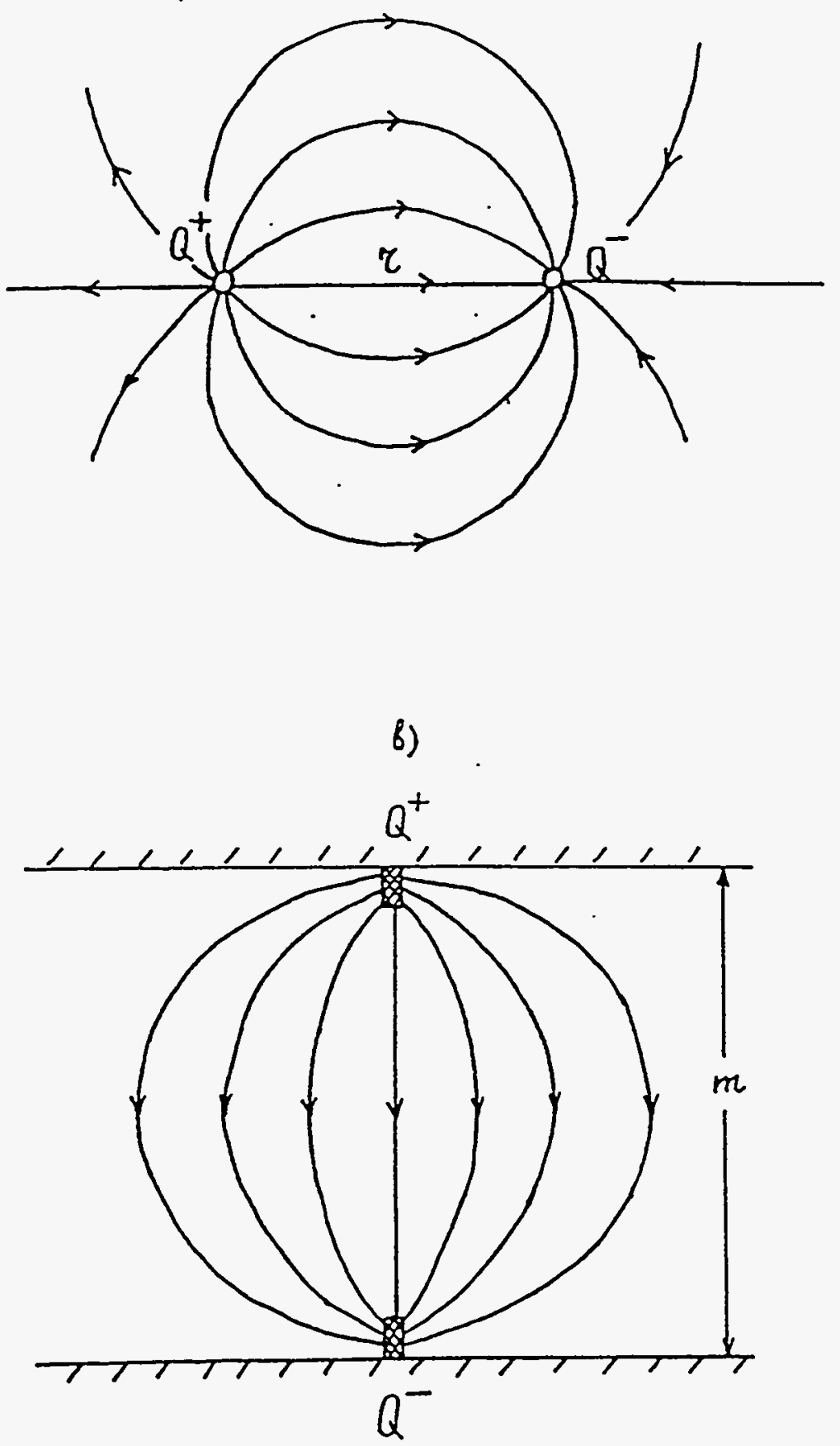

Fig.6.2 Flow structure for doublet tracer testing: a - Horizontal doublet b - Vertical doublet 


\subsubsection{A vertical doublet}

The hydrodynamic impact is created by the circulation system of two wells the screens of which are positioned one under the other (Fig. 6.2, b). The approximation (with the error of not more than $10 \%$, given $\bar{C}>0.1$ ) of the exact solution analyzed in Appendix $E$ is yielded by a simple analytical formula:

$$
\bar{C}=1-\left(t_{0} / t\right)^{3 / 2}, \quad t \geq t_{0},
$$

where $t_{0}=0.4 m^{3} n / Q \chi^{2}, \quad \chi=\left(k_{z} / k_{x}\right)^{1 / 2}$ is the coefficient of the cross-sectional flow anisotropy. So, from the results of the tracer test one can estimate the complex parameter $\chi^{2} / n$.

Using the method of superposition, a similar solution can be obtained for interpreting a doublet test in aquifers with initially nonuniform hydrochemical cross-section. In this case, the test could be carried out without special tracer and one can use data concerning the changes of the pumped out water composition due to the shifts in hydrochemical zonation.

A similar approach could be used for single pumping wells situated above the subhorizontal hydrochemical boundary. The appropriate solution is given in the monograph by Mironenko and Rumynin, 1986.

\subsection{Tests in the natural-gradient groundwater flow}

In the course of such tests it is possible to estimate the medium's dispersion parameters (the constants $\delta_{x}=\delta_{L}$ and $\delta_{y}=\delta_{T}$, and the fractured porosity $n$ ). Here, the Darsy's 1D flow velocity $(v)$ is assumed to be estimated independently. The equation describing the tracer "spot" spreading after its pulse injection is well-known:

$$
C=\left[\frac{M}{m v x t}\right] \frac{P e}{4 \pi \sqrt{\delta_{y} / \delta_{x}}} \exp \left\{\frac{P e}{2}\left[1-\frac{1}{2 \tau}\left(1+\frac{\delta_{x}}{\delta_{y}} \frac{y^{2}}{x^{2}}\right)-\frac{\tau}{2}\right]\right\}
$$

where

$$
\tau=v t / x n, P e=x / \delta_{x} .
$$

This solution was used as a basis for test data processing by type curve method (see Section 9 ).

\subsection{On possible discrepancies between actual and modelled schemes of migra- tion}

Natural-gradient flow, areal flow anisotropy, and its nonuniformity and heterogeneity have a serious impact on the accuracy of the tests results processing when using the above solutions.

\subsubsection{Distortion of the radial symmetry of areal flow for injection (pumping) tests}

One can obtain corresponding estimates by comparing the modelled $\left(t^{\prime}\right)$ and actual $(t)$ times of tracer's piston flow in various directions from injection well operating either in a natural-gradient flow with the background velocity $v_{e}(B e a r, 1972)$ or in an anisotropic aquifer with $v_{e}=0$ (see Mironenko and Rumynin, 1986). The relative deviation in resident time $e_{t}=\left(t_{0}^{\prime}-t_{0}\right) / t_{0}$ is linked to the relative error of estimating the fracture porosity by the equation

$$
e_{n}=-e_{t} /\left(1-e_{t}\right)
$$

To estimate the values $e_{t}$, one can use graphs in Fig. 6.3. and 6.4. The first one meets the test conditions in a natural-gradient flow having the velocity $v_{e}$ in $x$ direction $\left(\bar{v}_{e}=v_{e} r m / \theta, \theta\right.$ is the 
angle between the radius $r$ and the direction $x$ ). In constructing the other graph, the coordinate axes $x$ and $y$ were assumed to be oriented along the main anisotropy axes here $\left(\chi=k_{x} / k_{y}, k_{x}\right.$ being the minimal value of the hydraulic conductivity; $\phi$ is the angle formed by the radius $r$ with the $x$ direction).

\subsubsection{The approximate estimates of the influence of natural-gradient flow and ani- sotropy on doublet tests results}

The role of natural flow can be approximately estimated on the basis of a steady-state solution for the corresponding boundary problem (Gringarten and Sauty, 1975) comparing tracer's maximal concentration in the pumping well $C \infty$ with the concentration $\hat{C}_{\infty}$ in the absence of natural flow. The plots $\bar{C}_{\infty}=C_{\infty} / \hat{C}_{\infty}=f\left(\alpha, \bar{V}_{e}\right)$ where $\alpha$ is the angle between the natural flow direction and the straight line linking the test wells, are displayed in the mentioned article.

For a known (arbitrary) orientation of the doublet axis in relation to the main anisotropy axes, one can correct the test results (given $\bar{V}_{e}=0$ ), by the approximate expression (6.10) in which

$$
t_{0}=\pi r^{2} m n\left(\cos ^{2} \alpha+\chi^{2} \sin ^{2} \alpha\right) / 3 Q \chi,
$$

where $\alpha$ is the angle between the doublet axis and the minimal permeability direction (see Appendix D).

\subsubsection{Tests errors caused by the actual three-dimensionality of the flow}

The effect described below manifests inself during testing cross - sectionally nonuniform (layered) strata when the test - induced response is coupled with the influence of natural-gradient flow ( $R u$ mynin, 1991). In this case, tracer injection into a cross-sectionally nonuniform stratum can result in ambient water intrusion into the areas which are regarded as "watersheds" in an areally 2D migration problem. In other words, the actual three-dimensionality of the process leads to an advective blurring of the boundaries between the injected fluid and ambient ground water. Each of the cross-sectional flow zones (Fig. 6.5), can have its own neutral pathline, as the injection well slice may stay uniform (Fig.6.5,a).

Should the observation well fall into the above area of a steady-state mixing, the maximum (given $t \rightarrow \infty$ ) tracer concentration in it will always be lower than the concentration $\left(C_{0}\right)$ of the injected fluid by the value governed by the hydrodynamic features of the flow, the cluster-well spacing, and also by the degree of the stratum's heterogeneity, the latter factor conditions the upper limit of the output concentration function $(C)$ for transient mass transport. The analytical solution obtained for the particular case of a wedge-shaped (in profile) boundary between two zones with permeabilities $k_{1}$ and $k_{2}$ is given in Appendix F.

The example presented there shows that the actual rock nonuniformity in combination with intruding of the ambient water into the tracer-affected area leads to a change in the concentration front movement velocity and smoothing of the plots $\mathrm{C}-\mathrm{t}$ as compared with the ideal piston flow. Correspondingly, neglecting the above effect will result in considerable errors in migration parameter estimation. Moreover, the test process diagnosis proves essentially hindered. In particular, a failure to reach the relative concentration of $\bar{C}=C / C_{0}=1$ could be erroneously linked to the manifestation of the intrinsic heterogeneity (double porosity) of fractured rock.

\subsubsection{A draining effect of a large fracture tapped by the well}

When testing fractured strata, the main inflow to a discharge well (or outflow from a recharge well in case of the injection test) can very often be conditioned by a single fracture intersected by the well. Here, of interest would be to estimate the tracer travel time between the given well and the observation wells located in the low-fracturing zone beyond the main fractured limits. 


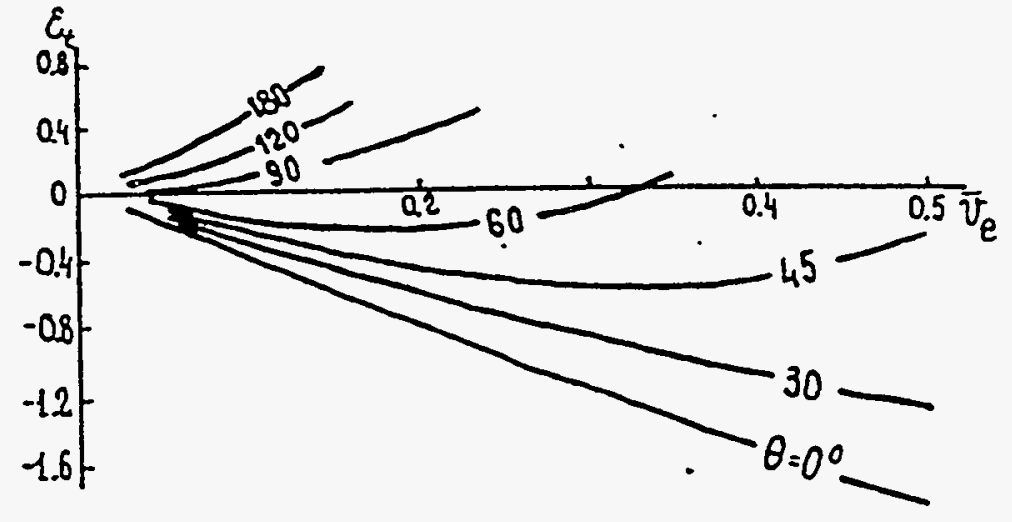

Fig.6.3 Plot of the function $\epsilon_{t}=f\left(\bar{v}_{e}\right)$

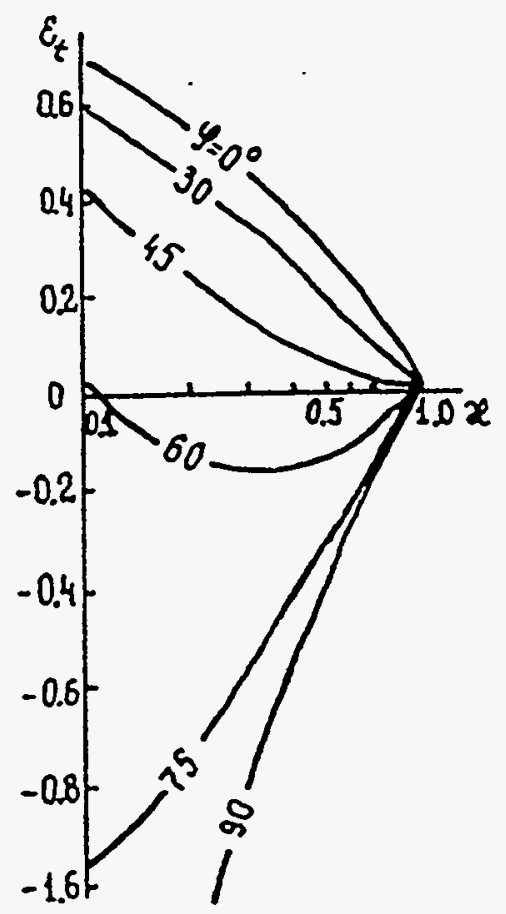

Fig.6.4 Plot of the function $\epsilon_{t}=f(x)$ 


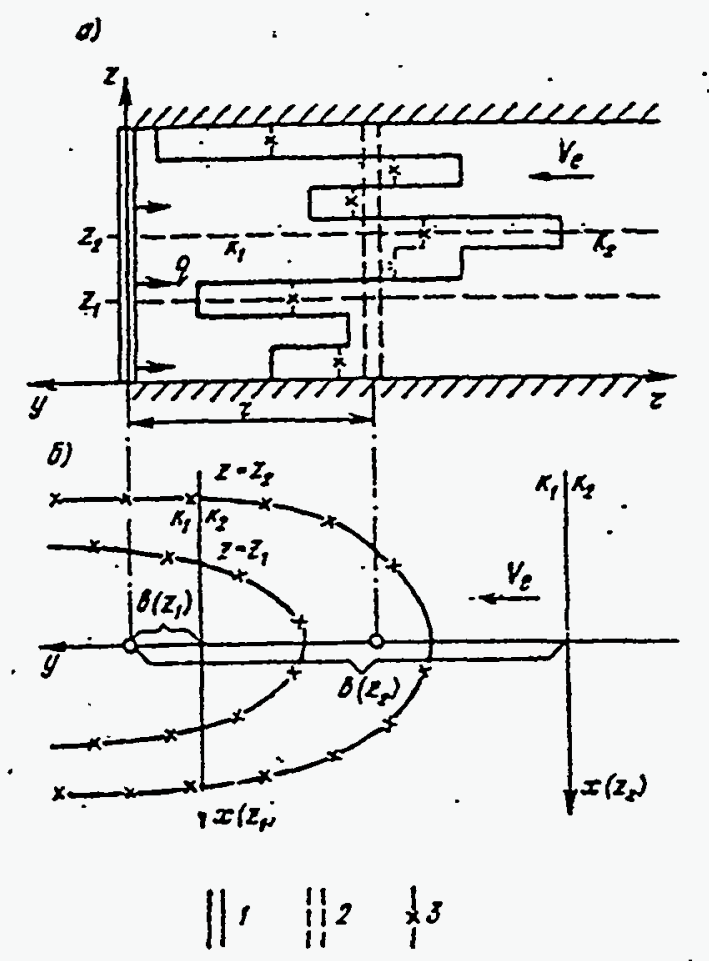

Fig.6.5 Features of boundary formation between the traced and natural gradient water in a nonuniform aquifer: a - Idealized prafile

b - Typical flow zones in individual layers 1 - injection well

2 - observation well

3 - water dividing line 
Let's assume the main fracture to be vertical and have a limited length (2l); the well's position coincides with the symmetry axis (Fig. 6.6.). Here, the fracture may be regarded as a linear sink (Gringarten and Witherspoon, 1972). The tracer travel time to the fracture (the tracer travel time through the very fracture can be a priori negligible) is estimated by the equation (see Appendix G):

$$
t_{0}=\frac{\pi l^{2} m n}{Q}\left[\phi\left(\phi^{2}-1\right)^{1 / 2}+\left(1+2 \psi^{2}\right) \ln \left|\phi+\left(\phi^{2}-1\right)^{1 / 2}\right|\right]
$$

where $\phi$ and $\psi$ are the coordinates of the injection point linked to the Cartesian coordinate system by the expressions:

$$
\begin{aligned}
& \phi=\left[\frac{1}{2}\left(1+\overline{x^{2}}+\overline{y^{2}}\right)+\left(\frac{1}{4}\left(1+\overline{x^{2}}+\overline{y^{2}}\right)^{2}-\overline{x^{2}}\right)^{1 / 2}\right]^{1 / 2} \\
& \psi=\left[\frac{1}{2}\left(1+\overline{x^{2}}+\overline{y^{2}}\right)-\left(\frac{1}{4}\left(1+\overline{x^{2}}+\overline{y^{2}}\right)^{2}-\overline{x^{2}}\right)^{1 / 2}\right]^{1 / 2}
\end{aligned}
$$

where $\bar{x}=x / l, \bar{y}=y / l$.

To analyze the process in an anisotropic stratum, the transition will be needed:

$$
t_{0} \rightarrow \chi t_{0}, \quad(\phi, \psi) \rightarrow(x, y / \chi)
$$

where $\chi=\left(k_{y} / k_{x}\right)^{1 / 2}$ is the coefficient of anisotropy.

\subsection{The hydrochemical lag of observation wells}

Tracer and ambient-water mixing in an observation well and, often, the lowered permeability of the adjacent area results in the tracer concentration in the stratum $C$ (directly outside the screened area of the well) being different from the concentration in the well $C_{w}$. The time period during which such a discrepancy can be noted is sometimes comparable to the duration of the entire test. In this case, one can speak of the hydrochemical lag of the observation wells used for tracer registration (Mironenko and Rumynin, 1980, 1986).

In a mathematical model of the test, this phenomenon should be taken into account by defining the equation of tracer balance in the well space filled with water. Thus, given $P e>10-20$ (when it is admissible to neglect the diffusion component of the mass transport through the piezometer walls), this equation could be written in the following $1 \mathrm{D}$ form:

$$
\alpha n r \frac{d C_{w}}{d t}=V_{r}\left(C-C_{w}\right)
$$

where $\alpha$ is the coefficient of hydrochemical lag:

$$
\alpha=\frac{\pi r_{w}}{2 \xi r n}
$$

and $\xi$ is the coefficient of flow deformation near the well $(0 \leq \xi \leq 2)$. Hence, knowing the solution for concentration in the stratum $C$, the solution for concentration in the well $C_{w}$ can be obtained in an integrated form:

$$
C_{w}=b \int_{0}^{t} c(\tau) e^{b(t-\tau)} d \tau
$$

where $b=Q / 2 \pi r^{2} \alpha \cdot m n$. 


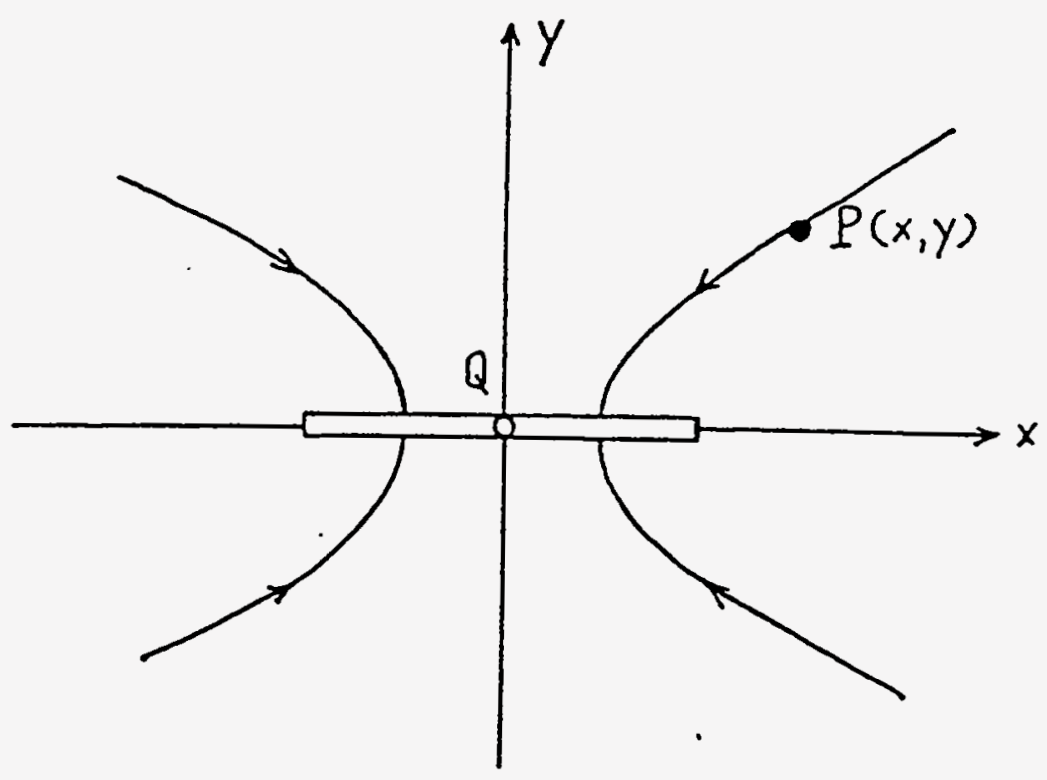

Fig.6.6 A single high-permeable fracture of finite length in a fissured rock mass: $Q$ - withdrawal well $\mathbf{P}$ - piezometer 
From the analysis of the solutions for homogeneous rock, it follows that an improper regard of this lag can lead to overestimating of mass - transport parameters. The errors in determining the active porosity $\varepsilon_{n}$ and the dispersivity constants $\varepsilon_{\delta}$ has the orders of

$$
\varepsilon_{n} \approx \alpha, \quad \varepsilon_{\delta} \approx 2 \alpha^{2} r / \delta_{L}
$$

\subsection{Models describing sorption processes}

The peculiarities of the setup and interpretation of the tests are conditioned by:

1. Hysteresis of the sorption process, e.g. desorption parameters obtained while injecting fresh water into the polluted stratum do not match the respective absorption parameters governing the polluted water front spreading, and

2. Kinetics due to which the time of reaching chemical equilibrium in the system could be comparable to the duration of tests.

If one would neglect a priori the kinetics factor, it might be allowable to utilize the previous basic models of nonreactive component transport in analyzing the physically and chemically equilibrium processes. The role of sorption could be accounted for pretty easily by the effective parameter $n_{e}=n+\Delta n_{i}\left(\Delta n_{i}=K_{2_{i}}=K_{a_{i}} S_{b}\right.$ is the additional storage capacity of the fracture system in relation to the sorbed $(i=1)$ /desorbed $(i=2)$ component (See Section 6.1). Since, judging by the literature, the constants of sorption $\left(\Delta n_{1}\right)$ and desorption $\left(\Delta n_{2}\right)$ might differ essentially (the condition $\Delta n_{1} \ll \Delta n_{2}$ being fairly typical of radionuclides), the tests should be set up in such a manner as to enable the comparison of the values $\left(\Delta n_{1}\right)$ and $\left(\Delta n_{2}\right)$.

\subsubsection{A "package" tracer injection}

Fresh water injection into a well during the limited period of time permits to track the interfaces of both the desorption front wave and the absorption rear wave. The respective solution of the radial migration problem can be obtained by superposition. So, for the base solution (6.3-A.5) (Roshal, 1981), one has

$$
\begin{array}{r}
\bar{C}=1-\frac{1}{2} \operatorname{erfc}\left[\sqrt{\frac{3 P e}{4 \bar{t}}}\left(\frac{1-\bar{t}}{2}\right)\right]+ \\
\frac{1}{2} \operatorname{erfc}\left[\sqrt{\frac{3 P e}{4 \Delta \bar{n}\left(\bar{t}-\bar{t}_{n}\right)}}\left(\frac{\Delta \bar{n}-\bar{t}+\bar{t}_{n}}{2}\right)\right], \quad t \geq t_{n}, \\
\bar{t}=\frac{t}{t_{01}}=\frac{Q t}{\pi r^{2} m\left(n+\Delta n_{2}\right)}, \quad \Delta \bar{n}=\frac{n+\Delta n_{1}}{n+\Delta n_{2}}, \quad \bar{t}_{n}=\frac{Q t_{n}}{\pi r^{2}\left(n+\Delta n_{2}\right) m}, \quad P e=\frac{r}{\delta_{L}}
\end{array}
$$

From the type curves given in Fig. 6.7. it follows that the parameter difference $\Delta n_{2}>\Delta n_{1}$ contributes to the intensive extinguishing of the aquifer response, since the sorption rear wave rapidly overtakes the desorption front wave. It can easily be shown that, given a piston-line flow, the interference of the waves occurs at the distance of

$$
r *=\sqrt{\frac{Q t_{n}}{\pi m\left(\Delta n_{2}-\Delta n_{1}\right)}}
$$

from the injection well. The ratio ( 6.21$)$ can be handy when planning such test. 


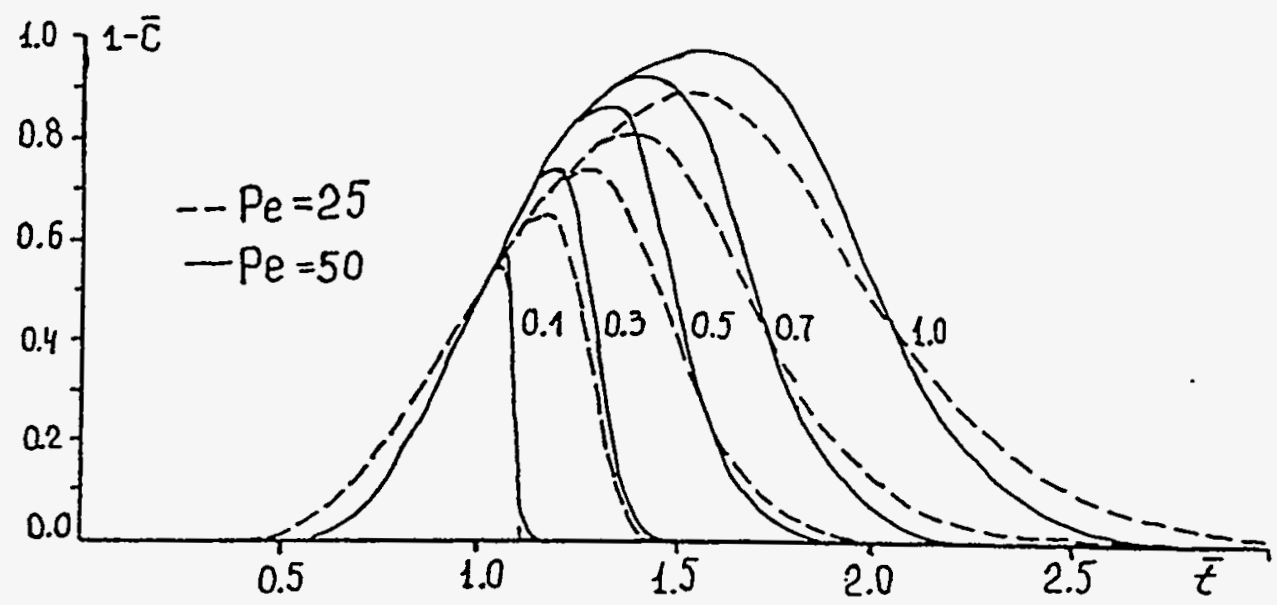

Fig.6.7 Break-curves of the "package" fresh water injection into the polluted aquifer; the parameter $\Theta \bar{n}$ is the code of the curves 


\subsubsection{A model of the single-well tracer injection/pumping into the aquifer}

The known solution of the migration problem (Gelhar and Collins, 1971, Alekseev et al., 1989) can be rewritten for the event of a nonsymmetric desorption/sorption process in the shape of

$$
\begin{gathered}
\bar{C}=\frac{1}{2} \operatorname{erf} c(\xi), \quad \xi=\frac{1-\phi t}{\left\{16 \rho / 3[2-\sqrt{|1-\phi t|}(1-\phi t]\}^{1 / 2}\right.} \\
\phi=\Delta \bar{n} / t^{*}, \quad \Delta \bar{n}=\frac{n+\Delta n_{2}}{n+\Delta n_{1}}, \quad \rho=\frac{\delta_{L}}{r_{0}}=\delta_{L} \sqrt{\frac{\pi m\left(n+\Delta n_{2}\right)}{Q t^{*}}} .
\end{gathered}
$$

( $t^{*}$ is the injection time). Evidently, the test's interpretation allows for estimating only some combined parameters.

\subsubsection{Taking account of the kinetics of the sorption process}

The role of the kinetics factor could be fairly important considering a relatively short duration of tests due to a high velocity of migration through fractures. An exact solution of the radial problem is complex enough, and this holds true even in case of the approximation of physico-chemical interactions by the simplest linear equation

$$
\frac{\partial N}{\partial t}=\alpha\left(C-N / K_{2}\right)
$$

(Here, $N$ is a volumetrical species concentration on the rock skeleton; $\alpha$, the kinetic constant). Therefore, it would be sensible to confine oneself to the following approximated solution in the integral form (Rumynin, 1983):

$$
\bar{C}=\int_{0}^{t} \frac{\partial \bar{C}^{1}(\Theta)}{\partial \Theta} H_{0}(t, \Theta) d \Theta
$$

where $\bar{C}^{\prime}(\Theta)$ is the solution of the radial problem for the nonreactive component (Appendix A); $H_{0}(t, \Theta)$ the influence function;

$$
\begin{array}{r}
H_{0}(t, \Theta)=1-e^{-\tau} \int_{0}^{\eta} e^{-y} I_{0}(2 \sqrt{\tau y}) d y, \\
\tau=\frac{\alpha}{K_{2}}(t-\Theta), \quad \eta=\frac{\alpha \Theta}{n} .
\end{array}
$$

Integrating by part (Lindstrom, 1976) yields

$$
\bar{C}=\bar{C}^{\prime}(t) e^{-\alpha t / n}-\int_{0}^{t} \bar{C}^{\prime}(\Theta) \frac{\partial H_{0}(t, \Theta)}{\partial \Theta} d \Theta
$$

or, in the dimensionless form, finally:

$$
\begin{array}{r}
\bar{C}=\bar{C}^{\prime}(t) e^{-\bar{\alpha} \bar{t}}+\int_{0}^{\bar{t}} \bar{C}^{\prime}(\Theta) e^{-\bar{\alpha}(\bar{t}-z) / K_{n}} e^{-\bar{\alpha} z} . \\
\left\{\bar{\alpha} I_{0}\left(2 \bar{\alpha} \sqrt{\frac{(\bar{t}-z) z}{K_{n}}}\right)+\bar{\alpha} \sqrt{\frac{z}{K_{n}(t-z)}} I_{1}\left(2 \bar{\alpha} \sqrt{\frac{(\bar{t}-z) z}{K_{n}}}\right)\right\} d z
\end{array}
$$


where

$$
\bar{\alpha}=\frac{\pi \alpha r^{2} m}{Q}, \quad K_{n}=\frac{K_{2}}{n}, \quad \bar{t}=\frac{t}{t_{0}}, \quad\left(t_{0}=\frac{\pi r^{2} m n}{Q}\right) .
$$

Example calculations under the formula (6.27) are given in Fig. 6.8. The selected values of the parameter $K_{n}=K_{2} / n=K_{a} S_{b} / n$ equal to 2 and 10 meet the conditions of migration of moderately sorbing pollutants through a fractured aqiufer. The value of the parameter $P e=r / \delta_{L}=50$ is fairly typical for the scale of tracer tests in aquifers. One could see that the character of output curves is governed by the dimensionless coefficient $\bar{\alpha}=\pi \alpha r^{2} m / Q$, with its low values $(\bar{\alpha}<0.1)$ virtually excluding the influence of sorption on tests results. For $\bar{\alpha}>5 \div 10$, the degree of the sortion lag is close to the lower limit which is confirmed by the constant dimensionless coordinate

$$
\bar{t}_{\bar{c}=0.5}=1+K_{n},
$$

which characterizes the location of the point $\bar{C}=0.5$ on the resulting plot. Hence, by the way, the effective porosity can be expressed as $n_{e}=n+K_{a} S_{b}$, e. g. using advection-dispersion transport models with some effective dispersive parameter $\delta_{e}$ is possible (Mironenko and Rumynin, 1986). The expression for the corresponding dimensionless Peclet number is

$$
P e_{e}=\frac{1}{1 / P e+(1 / \bar{\alpha})\left(\frac{K_{n}}{1+K_{n}}\right)^{2}}
$$

This can be confirmed by the points locations on the curves $(\bar{C}, \bar{t})$ (Fig. 6.8 a and b) which have been found under the basic solution for $P e_{e}=15.5$ and $P e_{e}=9.7(\vec{\alpha}=10)$.

Analysis of the curves and numerical solution results shows that even for fairly low values of the kinetics constant $\alpha$ ranging within $1 \div 10$ days $^{-1}$, the tests interpretation within the framework of the simplest equivalent model can be justified in most cases, with $n_{e}=n+K_{a} S_{b}$ and $P e_{e} \approx P e$.

Using superposition, it is easy to obtain a solution for a package injection of tracer (or fresh water) into a polluted aquifer.

\subsection{Description of a thermal impact on aquifer}

To interpret thermal tracer tests, there are two different models their applicability being is determined by the extent to which the matrix space is involved into the heat exchange. When the criterion $\tau=\gamma t<0.5$ is met ensuring the heating of only the near-surface area of the matrix (the so called assumption of the infinite blocks' capacity), Laverier solution will be valid which can be written as (Mironenko and Rumynin, 1986):

$$
\begin{array}{r}
\bar{T}=\operatorname{erfc}(\xi), \\
\xi=\frac{t_{0} \sqrt{\lambda_{T}}}{2 \pi \sqrt{t-t_{0}}}, \\
t_{0}=\pi r^{2} m n / Q,
\end{array}
$$

where $\overline{\mathcal{T}}_{2}$ is the relative temperature values; $\gamma=a_{b} S_{b}^{2}$ and $\lambda_{T}=\gamma\left(C_{b} / C_{w}\right)^{2}$ are the heat exchange parameters (see section 6.1.).

In case of $\tau>0.5$, the equation obtained for the assumption of the "lumped block capacity" is:

$$
\begin{array}{r}
\bar{T}=J(\eta, \tau), \\
\eta=\gamma t_{0}\left(C_{b} / C_{w}\right) / n, \\
\tau=\gamma\left(t-t_{0}\right),
\end{array}
$$



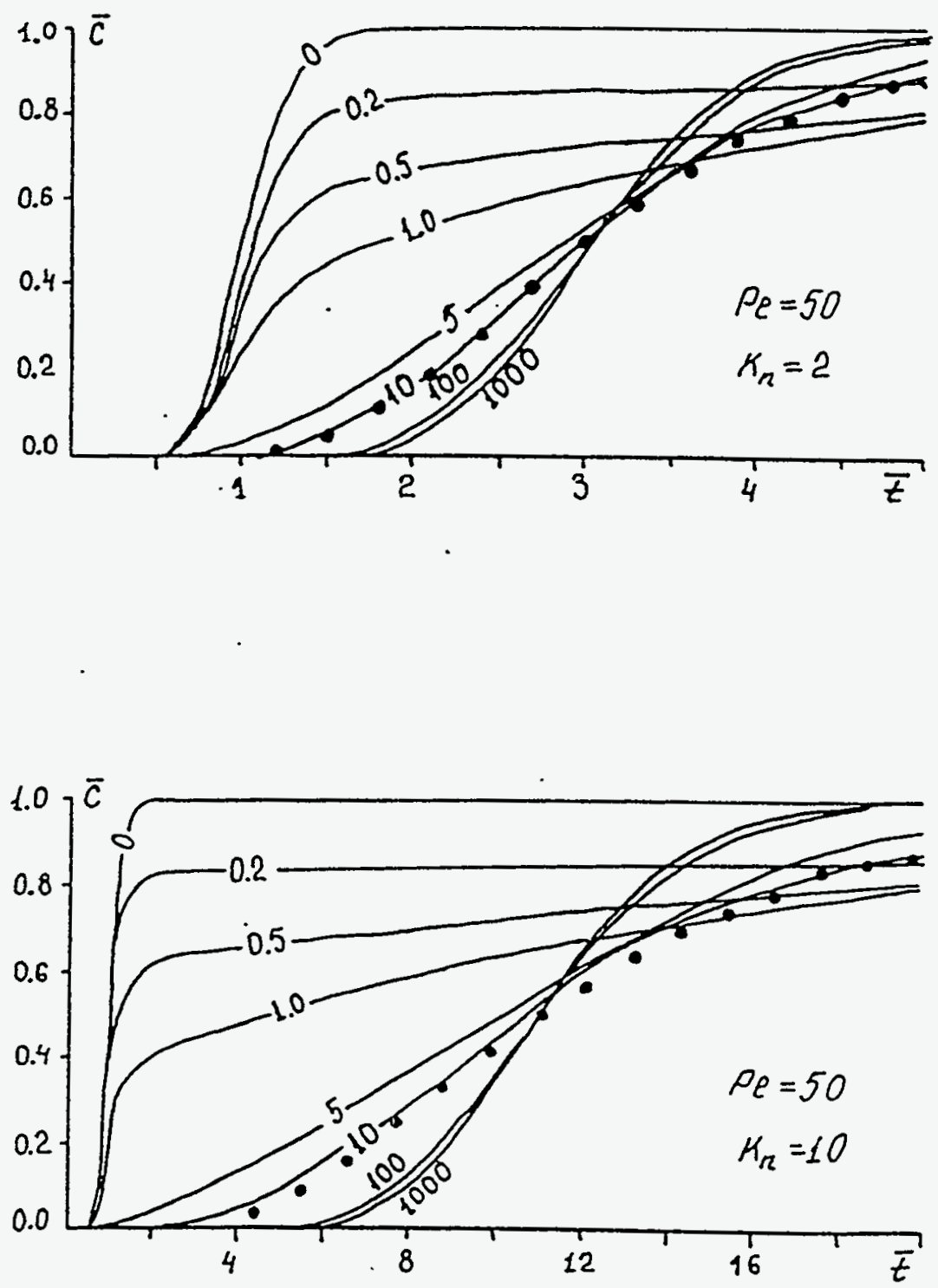

Fig.6.8 Concentration curves $\bar{c}(\bar{t})$ calculated to (6.27) for various values of the dimensionless parameters $\bar{\alpha}$ (the code of the curves), $P e$ and $K_{N}$. The points on the curves match the asimptotic solution of advection/dispersion model for effective parameters $P e^{\prime}=P e_{e}(6.29)$ and

$$
t^{\prime}=\bar{t}\left(1+H_{n}\right)
$$


where $J(\eta, \tau$ is the tabulated function the graphs of which can be found in the monograph by Mironenko and Rumynin (1986). In the work by Roshal (1981), the approximation of the solution (6.31) was reached by the formula:

$$
\begin{array}{r}
\bar{T}=0.5 \operatorname{er} f c(\xi), \\
\xi=-A \ln \left[\frac{1}{2}\left(\frac{\tau}{\eta}+1\right)\right]-B,
\end{array}
$$

where $A$ and $B$ depend on the dimensionless parameter $\eta$; the graph of the functions $A(\eta)$ and $B(\eta)$ are given in the work just mentioned.

When interpreting the results of thermal testing, one can find it handy to employ the solution for mean block temperature, if the latter is reflected by temperature measurements. The difference between the relative fracture-water temperature and the mean relative temperature of the porous matrix makes up:

$$
\triangle \bar{T}=e^{-\eta-\tau} I_{0}(2 \sqrt{\eta \tau})
$$

where $I_{0}(z)$ is a modified Bessel's first-type function of the zero order.

\subsection{Models for tests interpretation by type-curve matching}

Type-curve matching is a fairly traditional operation for interpreting field tests. Therefore, without elaborating on its correctness and reliability, we will only mention that we have utilized a special version of such matching. It was developed for the package of flow and migration programs. Below are some examples of using the type-curve procedure in processing pulse injection data (Section 6.3.1 and 6.5).

Type curves corresponding to the solution (6.4), for a migration scheme in a flow converging to the production well, are constructed in the bilogarithmic coordinates $\lg f \div \lg t$ where

$$
\begin{gathered}
f=\sqrt{\frac{3 \tau P e}{4 \pi}} \exp \left[-\frac{(1-\tau)^{2} 3 P e}{16 \tau}\right], \\
\tau=Q t / \pi r^{2} m n, \quad P e=r / \delta_{L} .
\end{gathered}
$$

Each type curve is characterized by its own value of the parameter $P e$. Pilot points are plotted on the graph $\lg F \div \lg t$ in the same scale as the type curves are $(F=Q t c / M)$. Type-curve matching is performed by movement of graphs along the X-axis only which allows, apart from other things, for controlling the tracer "loss" in the course of the test. A shift of the axes $\lg f$ and $\lg t$ (while type-curve matching) accords with the value $\lg t$ from which the value $n$ is to be found. From the value of the Peclet parameter corresponding to the selected curve, the value $\delta_{L}$ is to be found.

Fig. 6.9. illustrates matching on the computer screen of a theoretical curve and the experimental points obtained in the course of a specific tracer test in fractured rock.

Similar ideas serve as a basis for processing data of tracer injection in a natural-gradient flow (equation 6.11). The type curve is constructed in bilogarithmic coordinates $\lg f \div \lg t$ where

$$
f=\frac{P e}{4 \pi \sqrt{\delta_{y} / \delta_{x}}} \exp \left\{\frac{P e}{2}\left[1-\frac{1}{2 \tau}\left(1+\frac{\delta_{x}}{\delta_{y}} \frac{y^{2}}{x^{2}}\right)-\frac{\tau}{2}\right]\right\}
$$

Each curve is constructed for fixing $P e$ and $\alpha=\delta_{y} / \delta_{x} \equiv \delta_{T} / \delta_{L}$. Test points are plotted on the graph $\lg F \div \lg t$ in the same scale as the type curves are $\left(F=m v x t^{c} C / M\right)$. The processing procedure implies a series of type curves (for various $P e$ ) for each fixed ratio $\alpha$ in each observation well. Type-curve matching is performed in the interactive mode with automated parameter estimation. 
Figure 6.10 shows an example of type-curve matching where the experimental points were obtained in the course of one of the tracer tests.

\section{$7 \quad$ Numerical modelling for study of the tracer tests efficiency}

\subsection{Tracer transport modeling of the doublet well system}

One effective method for field scale determination of transport parameters is a tracer test during well injection. There are two common test schemes: radial flow test during injection in single well and horizontal doublet test with divergent-convergent flow pattern using two wells. The doublet test is considered to be more appropriate for heterogeneous aquifer as indicated by Mironenko and Rumynin [1986]. The goal of present study is to investigate the influences of spatial heterogeneity on breakthrough curves in the pumping well of a doublet system, and to calculate the effective transport parameters for such a system. Transport problems for such systems using advective and advective-dispersion approach studied by Grove and Beeten [1971] and Mironenko and Rumynin [1986], who obtained analytical solutions for advective-dispersive problem for the scale of heterogeneity much less then a doublet dimension (distance between injection and pumping wells). For strongly heterogeneous aquifer it is more common situation that the difference between the doublet dimension and the heterogeneity scale is not significant.

\subsubsection{Current study}

The advantages of the horizontal doublet test scheme for the entire thickness of aquifer had been discussed earlier by Mironenko and Rumynin [1986]. Given the same well yield, the flow lines of a doublet form a closed circuit between the wells, thus efficiently averaging the aquifer properties over the doublet's area of influence. It seems that this advantage may be only for the case that the doublet dimension much longer than the scale of heterogeneity. However for many fractured and porous aquifers the horizontal scale of heterogeneity of hydraulic permeability or transmissivity can be tens to hundred meter. From a practical point of view the doublet dimension usually does not exceed two hundreds meters because of the long time period requited by the test. The calculation assumes doublet dimension of $190 \mathrm{~m}$. and heterogeneity scale of $50 \mathrm{~m}$. This is an extreme case as a practical field test but still permits a analyses of the influence of the realistic field scale heterogeneity. The aims is to the effect of transmissivity heterogeneity on the results of tracer test. The influence of the porosity variation, natural flow gradient and vertical flow velocity are not considered in this paper..

Aquifer parameters used

The anisotropic exponential model of log transmissivity correlation was chosen for modeling of the random aquifer heterogeneity. The variance of $\log$ transmissivity was 1.1 . that exceeded the number for estimation of the aquifer macrodispersion property within the framework of stochastic hydrology theory. Modeling the random field of transmissivity with such a large value of variance could lead to abnormally high (on order of $n * 10^{4} \mathrm{~m}^{2} /$ day) and abnormally low (less than $10^{-3} \mathrm{~m}^{2} /$ day) transmissivity values. That is why a limited distribution was sought which would better describe the values near the small and large probability values but give values the lognormal distribution near median. The Johnson's $S$-V distribution was chosen which is normal for the transformed function $F_{T}$.

$$
F_{T}=\log \frac{T-T_{\min }}{T_{\text {nax }}-T}
$$

where $T$ is transmissivity; $T_{\min }$ and $T_{\text {max }}$ its minimum and maximum possible values. The horizontal correlation scales of $F_{T}$ were $L_{x}=30$ and $L_{y}=90$ meters. For the random field simulation 

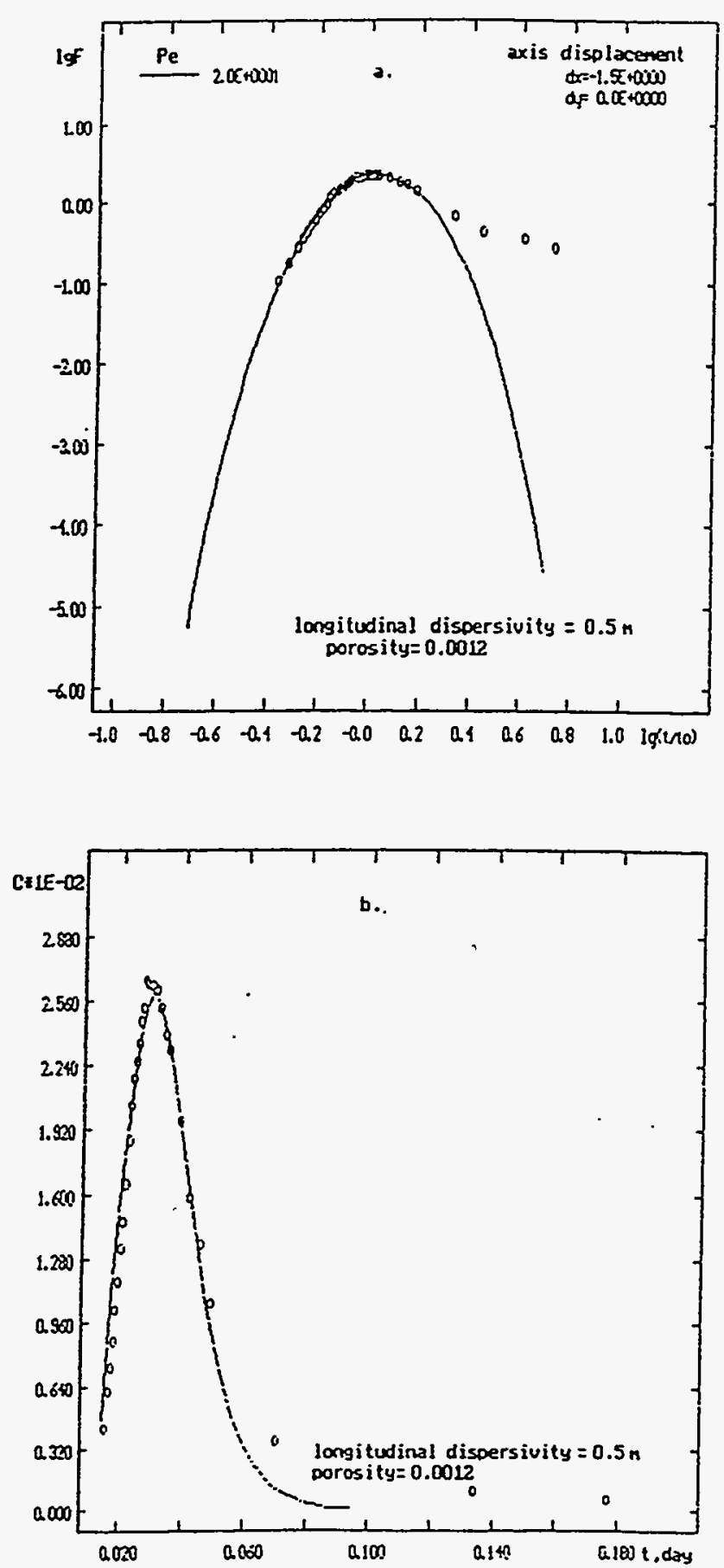

Fig. 6.9. An example of computer interpretation of tracer injection in convergent flow: a-plot of $\lg (F)$ versus $\lg \left(\frac{t}{t_{0}}\right)$, b-field data and theoretical curve 

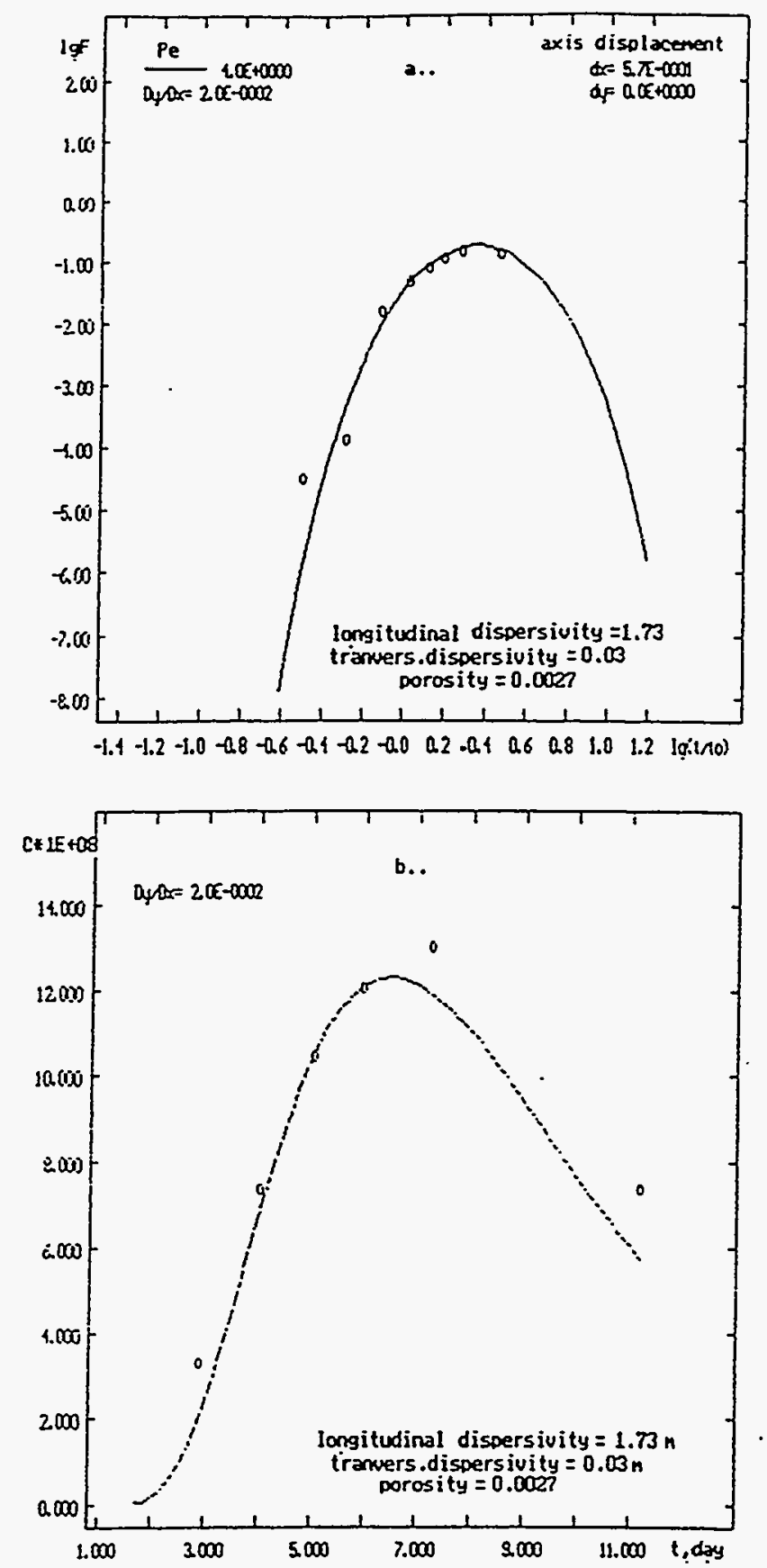

Fig. 6.10. An example of computer interpretation of tracer njection into piezometer located in natutal flow:

a - plot of $\lg (F)$ versus $\lg \left(\frac{t}{t_{0}}\right), \mathrm{b}$ - field data and theoretical curve 
"the source point method" (Appendix J) was used. The transformation used to obtain the random transmissivity field is in two steps:

a) obtain $F_{T}$ distribution for the $F_{T}$ function:

$$
F_{T}(x, y)=M_{F}+\sigma_{F} f(x, y)
$$

where $F_{T}(x, y)$ is the $F_{T}$ function at the point with coordinate $x, y ; M_{F}$ is the mean value of $F_{T} ; \sigma_{F}$ is the variance; and $f(x, y)$ is a unit random process with defined autocorrelation function $R(\bar{r})$;

b) transform $F_{T}(x, y)$ into $T(x, y)$ according to

$$
T=\frac{T_{\max } \exp \left(F_{T}\right)+T_{\min }}{1+\exp \left(F_{T}\right)}
$$

Parameters of the transmissivity distribution are: $M_{F}=-2.73, \sigma_{F}=2.0, T_{\min }=0.4 \mathrm{~m}^{2} /$ day, $T_{\max }=870 \mathrm{~m}^{2} /$ day. The average transmissivity value is $53 \mathrm{~m}^{2} /$ day. Aquifer porosity $\mathrm{n}$ assumed to be equal to 0.004 . Aquifer thickness $m$ was also constant and equal to 40 meters. Microdispersivity parameters were defined as $\lambda_{L}=0.05 \mathrm{~m} ., \lambda_{T}=0.01 \mathrm{~m}$. The coefficient of molecular diffusion was assumed to be equal to 0 . Sorption retardation and tracer decay were neglected.

Doublet test setup

The distance between well is $R=190 \mathrm{~m}$. The doublet rescharge-disharge flow rate $Q$ was chosen to be $300 \mathrm{~m}^{3} / \mathrm{day}$. Such a value, given the actual well radius and the interwell spacing of $190 \mathrm{~m}$., yields an average head difference value of $8-15 \mathrm{~m}$. which is quite realistic for the field tests. The tracer injection period was assumed as 100 days. According to the analytical solution for homogeneous aquifer after this period the concentration in the pumping well certainly exceed 0.5 the injection concentration. Simulation of the doublet system was conducted for 25 realization of random transmissivity field. For each realization of field, two tests were simulated:

a) the doublet axis lies along the direction of the larger transmissivity correlation scale;

b) the doublet axis lies normal to the direction of the larger correlation scale.

\subsubsection{Numerical modeling}

To simulate the doublet tests, the numerical code ASM by Kinzelbach and Rausch [1991] is used. This code allows simulation of $2 \mathrm{D}$ steady/unsteady state flow by the finite difference method and the contaminant transport, by the random walk particle tracing technique [Kinzelbach, 1988]. Displacement of a particle is decomposed into the advective component calculated by particles tracking technique and dispersive component calculated by random walk part at each point. A strongly divergent or convergent flow on a rectangular grid present a major problem in modeling. In such cases the particles tracking can lead to serious errors. To avoid these errors interpolation in nearest to source/sink nodes in original ASM code was improved by using logarifmic functional instead of the linear form. Another source of error in simulation of heterogeneous system could be connected with the bilinear velocity interpolation scheme. After this improvement, numerical modeling using ASM of advective doublet flow for the homogeneous system gave results, which when compared with approximate analytical solution of Mironenko and Rumynin [1986] showed a good agreement in terms of breakthrough curves. The size of model domain was $960 * 960 \mathrm{~m}$. covered by a grid of $60 * 60$. Two boundary blocks are defined at of the four sides with width $100 \mathrm{~m}$. All other internal 56 grid steps constant and equal to $10 \mathrm{~m}$. The doublet axis was parallel to one of the grid directions. Halfway between wells is at the center of the grid domain. The ratio of the grid step and minimum correlation length is 0.3 which is quite satisfactory. The external boundaries were defined as closed, and the wells flow rate is constant. Steady hydraulic head and flow velocity fields were oblained by solving the flow equation using the conjugate gradient method. The modeling time step for tracer injection during 100 days was 0.1 day (which is essentially lower then the Courant 
Table 7.1: *

\begin{tabular}{|c|c|c|}
\hline & $\begin{array}{c}\text { Doublet axis along the } \\
\text { direction of largest } \\
\text { correlation scale }\end{array}$ & $\begin{array}{c}\text { Doublet axis normal the } \\
\text { direction of largest } \\
\text { correlation scale }\end{array}$ \\
\hline Mean value $n / n_{\circ}$ & 0.70 & 1.04 \\
$n_{o}=0.004$ & 0.74 & 0.95 \\
\hline Standard deviation & 0.26 & 0.50 \\
& 0.23 & 0.17 \\
\hline
\end{tabular}

* The first value is based on the tracer arrival time method and the second is based on extracted volume curves fitting method.

grid criterion), the number of particles used is 2000 . The particles were initially distributed on a circle with a $10 \mathrm{~m}$. radius around the injection well. To monitor the tracer arrival, two observation points were chosen on the doublet axis, halfway between the wells and the other at $1 / 4$ the distance from the pumping well. Fields of head, velocity, concentration, breakthrough curves for pumping well and observation points were calculated and recorded in data base after each simulation.

\subsubsection{Results}

As an example of the simulation results Fig. 7.1. shows the fraction of extracted over injected tracer as a function of time for a number of realizations. Averaged breakthrough curves in pumping well are found in Fig 7.2. The modeling results were processed to estimate the effective porosity value. This is done based on the approximate solution for advective transport (Mironenko and Rumynin [1986]). The choice of this particular solution as basis was determined by the fact that the solutions (Grove and Beetem, [1971], Mironenko and Rumynin, [1986]) showed that then is little influence of the longitudinal microdispersion within a broad range of the Peclet number values. According to the above solution, the dimensionless concentration $\mathrm{C}$ in the pumping well is given by:

$$
C(\tau)=\pi^{-1} \text { inf } F(\psi), \quad \tau=\frac{t Q}{\pi R^{2} n m}, \quad F(\psi)=\frac{\sin \psi-\psi \cos \psi}{\sin ^{3} \psi}=\tau
$$

where inf is the function inverse to $F$.

Here, $C=0$ for time $t<t_{o}=1 / 3$ and $C>0$ for $t>t_{o}$ (Fig. 7.2) which enables one to use the onset time of tracer arrival $\left(t_{0}\right)$ as an interpretation parameter:

$$
n=\frac{3 t_{o} Q}{\pi R^{2} m}
$$

However, more reliable results could be found using the information on all breakthrough curves in terms of the extracted dimensionless volume of tracer $V$ :

$$
V=\left(\int_{\tau_{0}}^{\tau} C(\tau) d \tau\right) /\left(Q \tau_{0}\right) \doteq F_{\nu}\left(\tau / \tau_{0}\right)
$$

From the calculated extracted volume $V_{f}$ as a function of $t$ one can use the nonlinear curve fitting method find the best fit to the $V_{f}\left(t / t_{o}\right)$ and curves. After the porosity $n$ can be calculated trough the estimated $t_{0}$ value. Both procedures was used for processing the modeling results. The results are showed in Table 7.

One can found form Table 7 that the difference between results of arrival time methods and integral method is not significant but the second method demands longer testing time. The 
modeling confirmed the advantages of doublet tests. Even under such highly heterogeneous system the doublet tests results show an high stability of the calculated parameter for porosity.

\subsubsection{Discussion}

One can see from Fig. 7.3 a very asymmetrical shape of the tracer plume body. An analytical solution would give a symmetric picture according to flow lines. Taking into account the changing lengths of flow lines could improve the analytical solution in terms of macrodispersivity. The question is how can one correlate the change of flow paths with stochastic parameters of transmissivity field? A serious question is the influence of the vertical structure of the aquifer on breakthrough curve. In most porous and fractured aquifers the permeability and porosity change considerably with depth. To estimate the influence of vertical heterogeneity a layers transport calculation scheme could be used. Let us to consider an aquifer with the thickness $m$ and the total transmissivity $T$ to be composed of $N$ layers $(N \rightarrow \infty)$ with porosity ni and hydraulic conductivity $k_{i}$. According to this scheme, the Darsy velocity $\nu_{i}$ is equal to $Q_{i} / m_{i}$ in the $i-t h$ interlayer. This is determined as $Q * k_{i} / T$. The advective velocity for this layer is equal to $\nu_{i} / n_{i}$. Change in advective velocities for various layers as determined by $k_{i} / n_{i}$ changes with depth are the reason of pathline's in different layers have different arrival times to the pumping well. For this scheme let us introduce time dependent dimensionless concentration function $C(\tau)$ for a vertically homogeneous with depth aquifer. Then one can calculate the time dependent $C(\tau, \chi)$ function according to :

$$
C=(\tau, \chi)=\left(m^{-1}\right) \int_{0}^{m} C\left(\tau^{*} \chi(z)\right) d z, \quad \chi(z)=\frac{k(z)}{n(z)}
$$

\subsection{Analysis of the influence of rock macrofracturing on mass-transport field tests}

As it is well known, a microfractured medium can be schematized as quasi-homogeneous one with the effective coefficients of longitudinal and transverse dispersivity depending on the mean distance between fractures. This does not hold true with macrofractures, because the distance between them is comparable with the dimensions of the tested area. In this case, the representation of aquifer as a continuous medium becomes irrelevant.

To analyze the character of mass-transport in a macrofractured medium, it was simulated using the software of the Russian- Swedish firm Geosoft-Eastlink (Geolink) developed for IBM PC-486 and compatibles. Ground-water flow was modelled by the finite-difference method (the adaptive iteration procedure, or Chebyshev's chess algorithm), while mass-transport was modelled using the method of characteristics (MOC) based on the algorithm stated by Konikov and Bredehoeft. The algorithm was somewhat modified to improve, first of all, the velocity field calculations.

Doublet test in a confined rectangular aquifer was simulated on the model. The area was discretized by a regular square grid of $41 \times 41$ blocks and the $D X$ and $D Y$ steps equal 2 meters. At the point with coordinates 15,15 and 27,27 the pumping and the injection wells were symmetrically located. Wells yield was assumed $Q= \pm 1000 \mathrm{~s}^{3} /$ day (for the injection and the pumping well, respectively); aquifer thickness, $m=40 \mathrm{~m}$; porosity, $n=0.004$. For a comparative analysis, two options were simulated, that is, a heterogeneous isotropic aquifer with the transmissivity $T=$ $200 \mathrm{~m}^{2} /$ day (a) and a heterogeneous isotropic aquifer $\left(T=200 \mathrm{~m}^{2} /\right.$ day $)$ which, unlike the first option, was crossed by a system of faults (macrofractures) spreading along $X$ and $Y$ axes; the macrofractures are located in each 8 th block of the model grid, their effective transmissivity makes up $T_{x, y}=10000 \mathrm{~m}^{2} /$ day. The doublet axis is oriented at an angle of 45 degrees to the coordinate axes, and the wells are positioned symmetrically versus the macrofracture system but outside the fractures themselves (Fig. 7.4). 


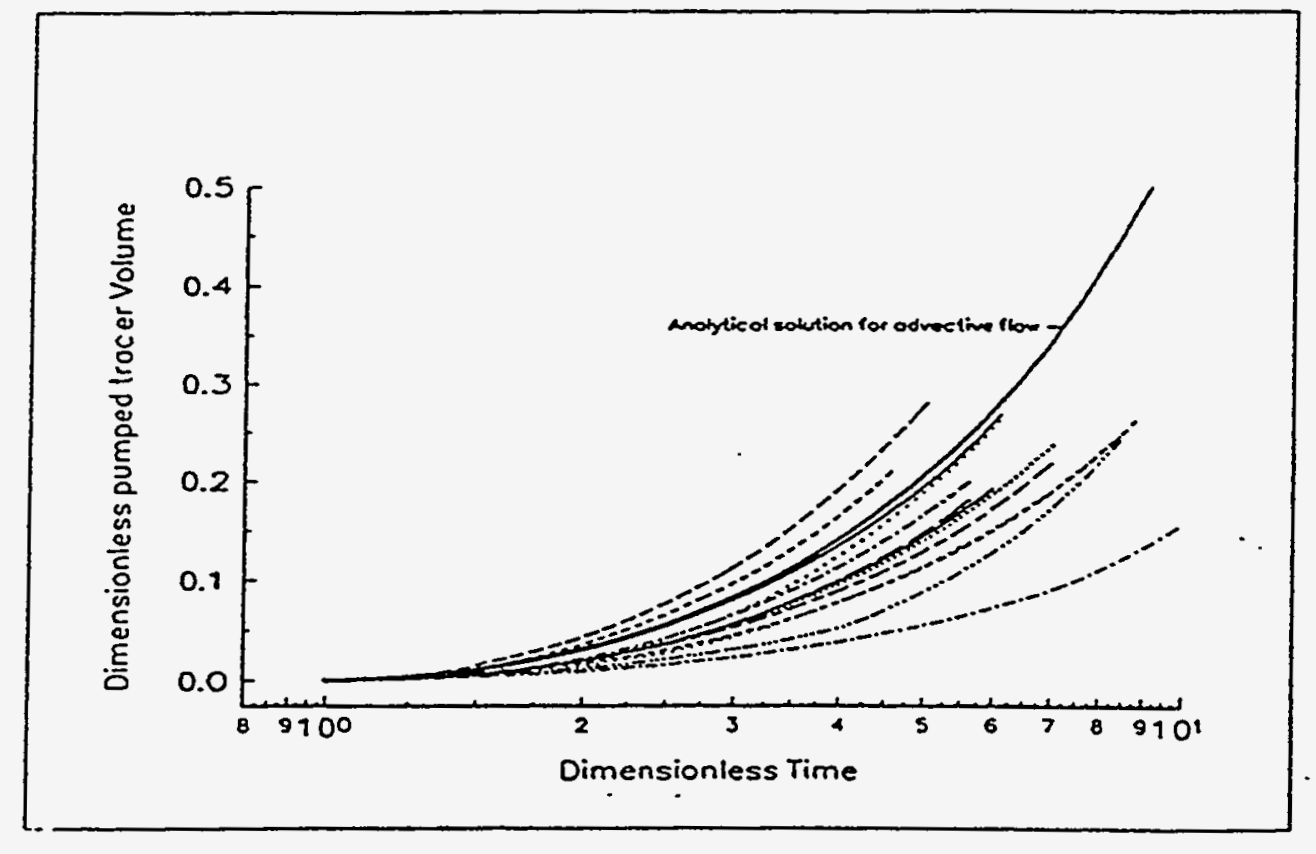

Fig. 7.1. An example of breakthrough curves

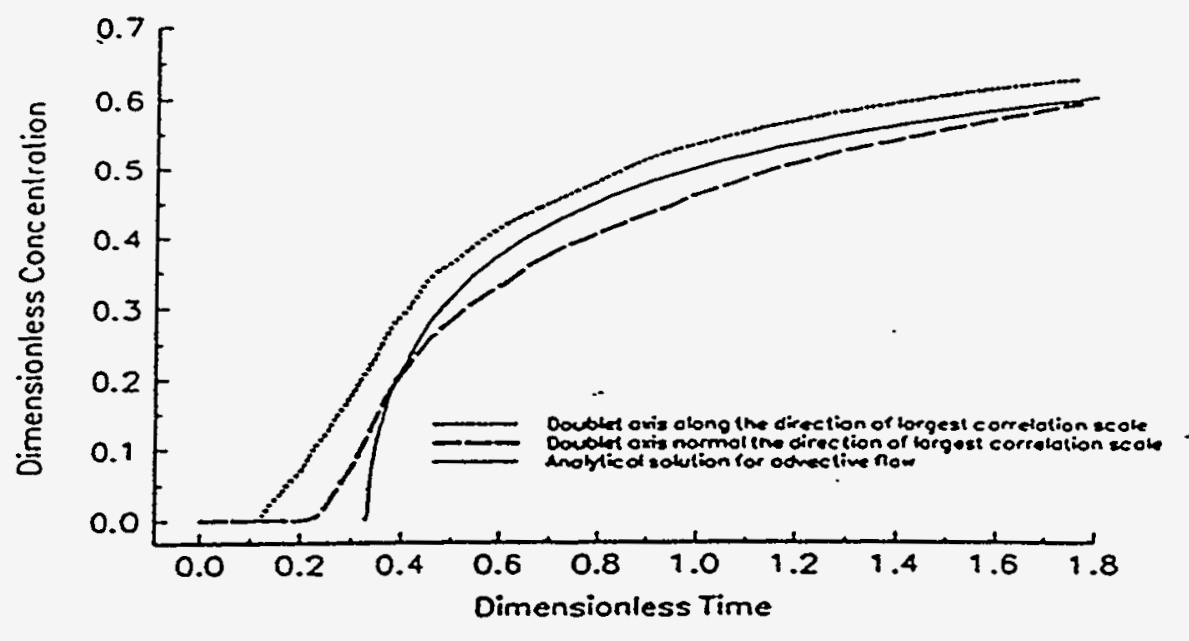

Fig. 7.2. Averaged breakthrough curves 


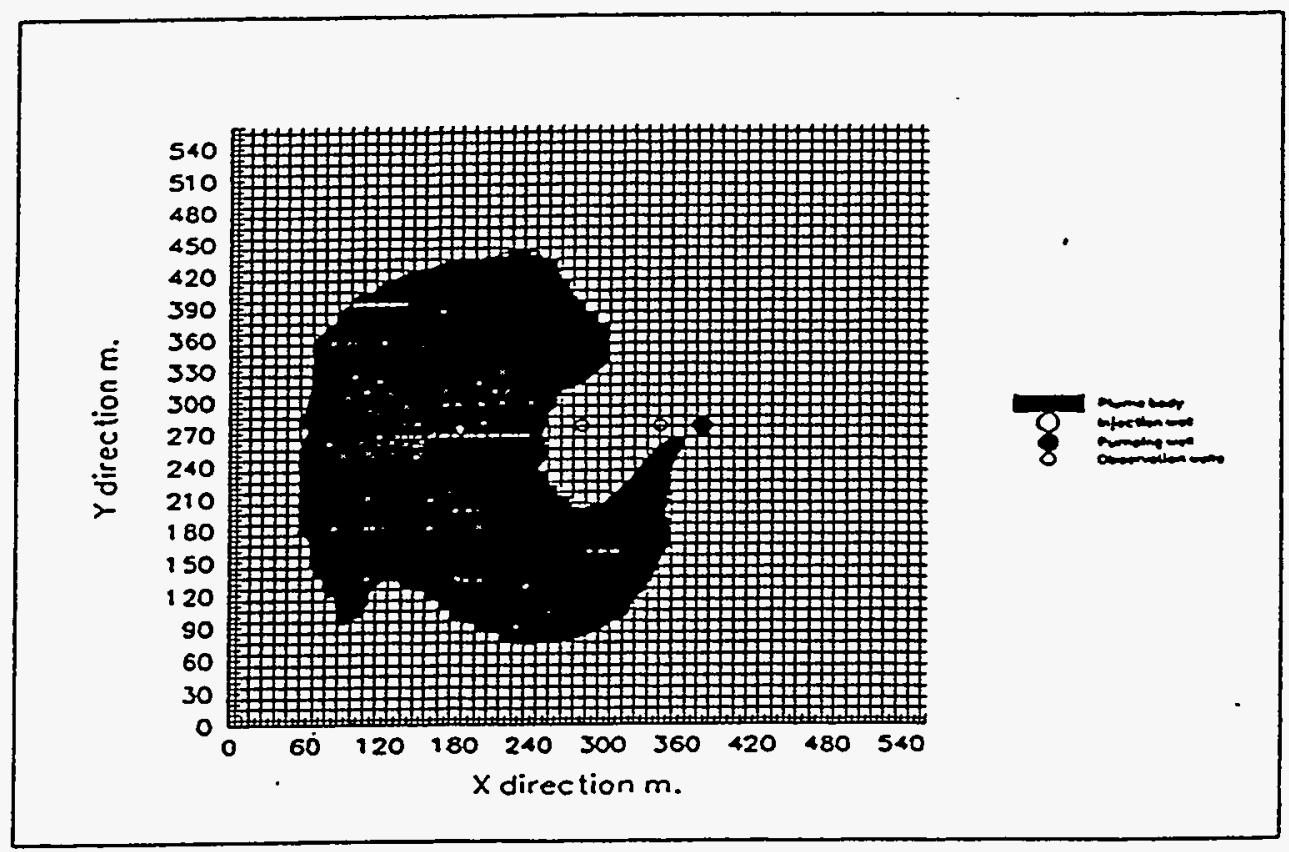

Fig. 7.3. An example of the plume boby in time of coming to pumping well 
Naturally, the last option does not imply the macrofracture width to match the spatial step size (2 meters). This only means that the fractured porosity in those zones is much higher than in the basic rock matrix (e. g., it could be a single $8 \mathrm{~mm}$-thick fracture without filling).

Since all the major difficulties of numerical solving mass-transport problem come out most clear for purely advective flow, both options do not consider molecular diffusion, and the longitudinal and transverse dispersivities were assumed equal to zero. Option's (a) simulation was used for assessing the proper number of particles for MOC-scheme in this particular case, - otherwise, the modelling results would be of an irregular character (Fig.7.5.a). So, 13 and 19 particles were proved to be good enough for the further calculations (Fig.7.6.a)

Simulation of option (b) shows the rock macrofracturing to result in quite different time-andspatial picture of tracer solution movement. As should have been expected, the solution first spreads to macrofractures, then along them, and, finally, fills very slowly the matrix (Fig.7.6.a). The breakthrough curve is characterized by the following features (Fig. 7.6.b). The arrival time of the solution's first portions is nearly two times less than in a homogeneous medium which is quite natural. The initial part of the breakthrough curve up to the relative tracer concentration $C=0.5$, similar to the previous case, has a higher concentration growth as compared to the theoretical one. In the last case, however, this effect cannot be accounted for by a small number of particles involved into the simulation. Actually, the tracer concentrations for this particular part of the breakthrough curve practically matches the analytical solution for the aquifer with porosity (or thickness) of the modelled one. As follows from the analysis, the tracer arrives to the discharging well only from the nearest two (directed to the injection well) macrofractures. For comparatively big time when the tracer starts to arrive to a discharging well from other macrogractures, this regularity is disturbed. Here, the influence of the model boundaries is also much more tangible than in option (a). Option (b) modelling data prove nonapplicability here of the dispersion medium model, which could be also fairly naturally inferred from the modelled conditions.

On the whole, modelling results show that the data of field testing of macrofractured rock can dramatically differ from solutions obtained for a homogeneous aquifer. Therefore, their sound interpretation requires collecting additional data on macrofractures' individual characteristics, which is known to be far from easy. Nevertheless, one should note a surprising stability of doublet tests results; even in the above extreme scenario, the calculated values of active porosity are proved to be real enough. It is easy to see (and demonstrate on the model) that a test involving one pumping well or one observation well will yield, under similar conditions, altogether unacceptable results.

\subsection{A study of tracer tests using $3 \mathrm{D}$ numerical models}

The objective of the modelling was to study the role of some inter-related factors which distort tracer test interpretation on the basis of simplified analytical solutions. Among them are: the actual 3-dimensionality of flow formed near a partially penetrating pumping well (1) and the nonuniformity and anisotropy of the flow cross-section in the presence of a river within the upper zone of the first layer near the testing site (2). At the same time, possible scales of tracer tests were evaluated for the cluster well considered in Section 4.2 (Fig. 4.1).

The modelling was conducted using two basic numerical codes, MODFLOW and MODPATH. The latter enabled one to calculate the particle movement trajectories and the characteristic residence time (disregarding dispersion).

The cross-section considered in the previous task (Table 5.5) was used as a basic one. Areally, the modelled area measured 4060 by $2515 \mathrm{~m}$ was represented by 860 blocks ( $43 \times 20$ ). A discharging well with the yield of $500 \mathrm{~m}^{3} /$ day was located in the central block, in the second, most permeable, layer $(j=23, i=1, k=2$ ) (Fig. 7.7). Model block sizes made up tens of centimeters near the central well expanding in geometriacal progression in the direction of model boundaries up to tens and first hundreds of meters. Boundary conditions are characterized by Fig. 7.7. 


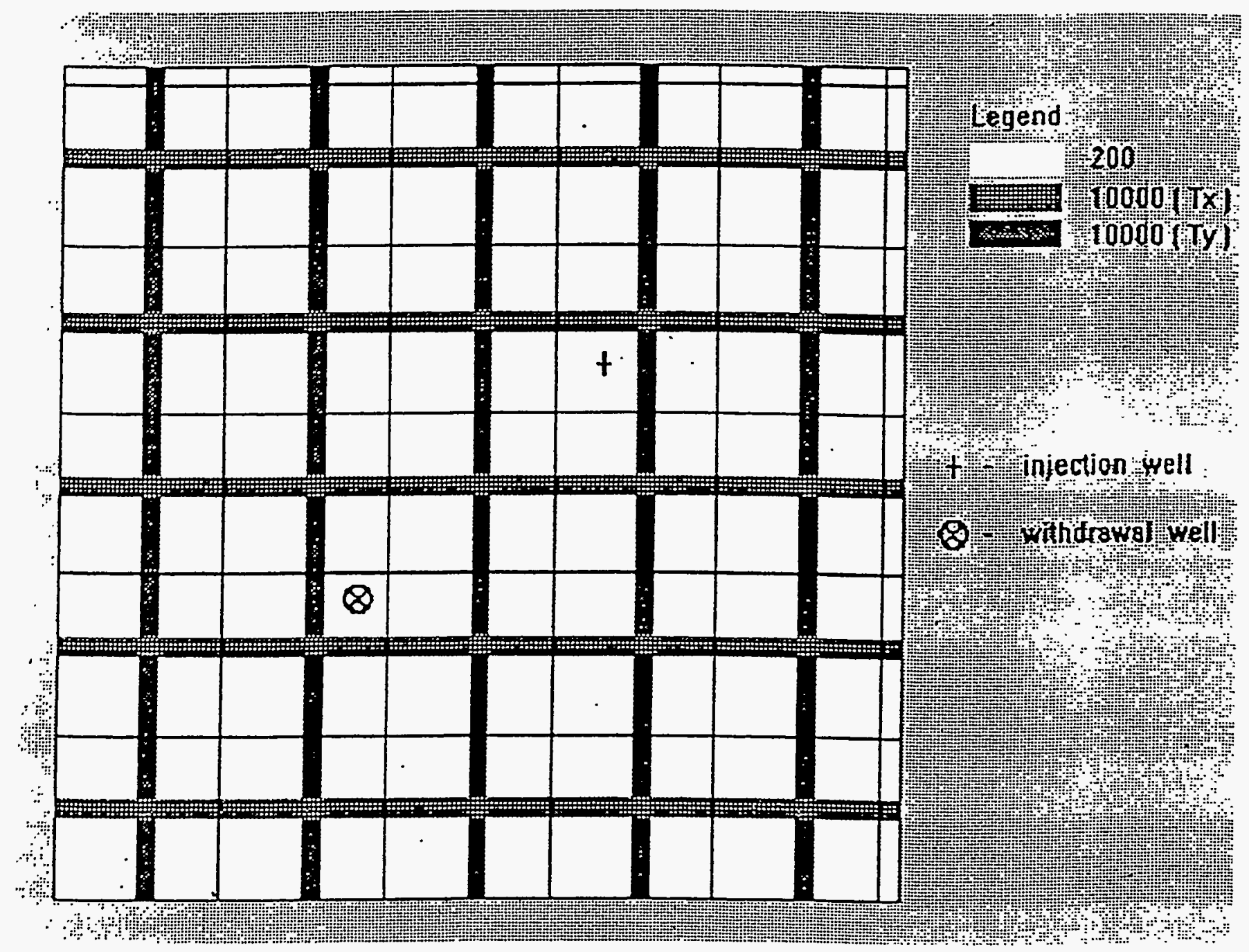

Fig. 7.4. Transmissivity field for heterogeneous media 


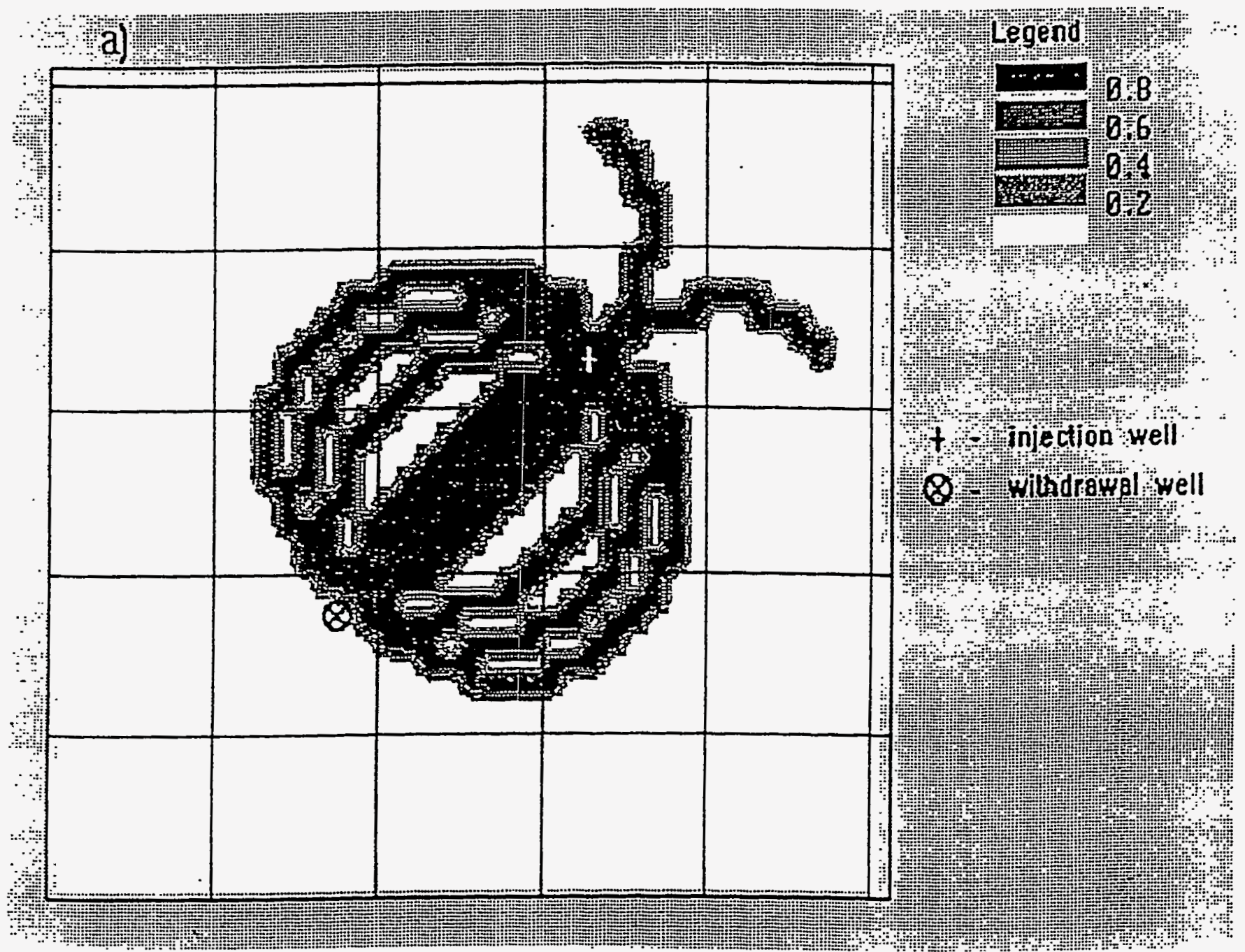

Fig. 7.5. Model concentration distribution for $\tau=1$

a) for homogeneous media; b) for heterogeneous media). 


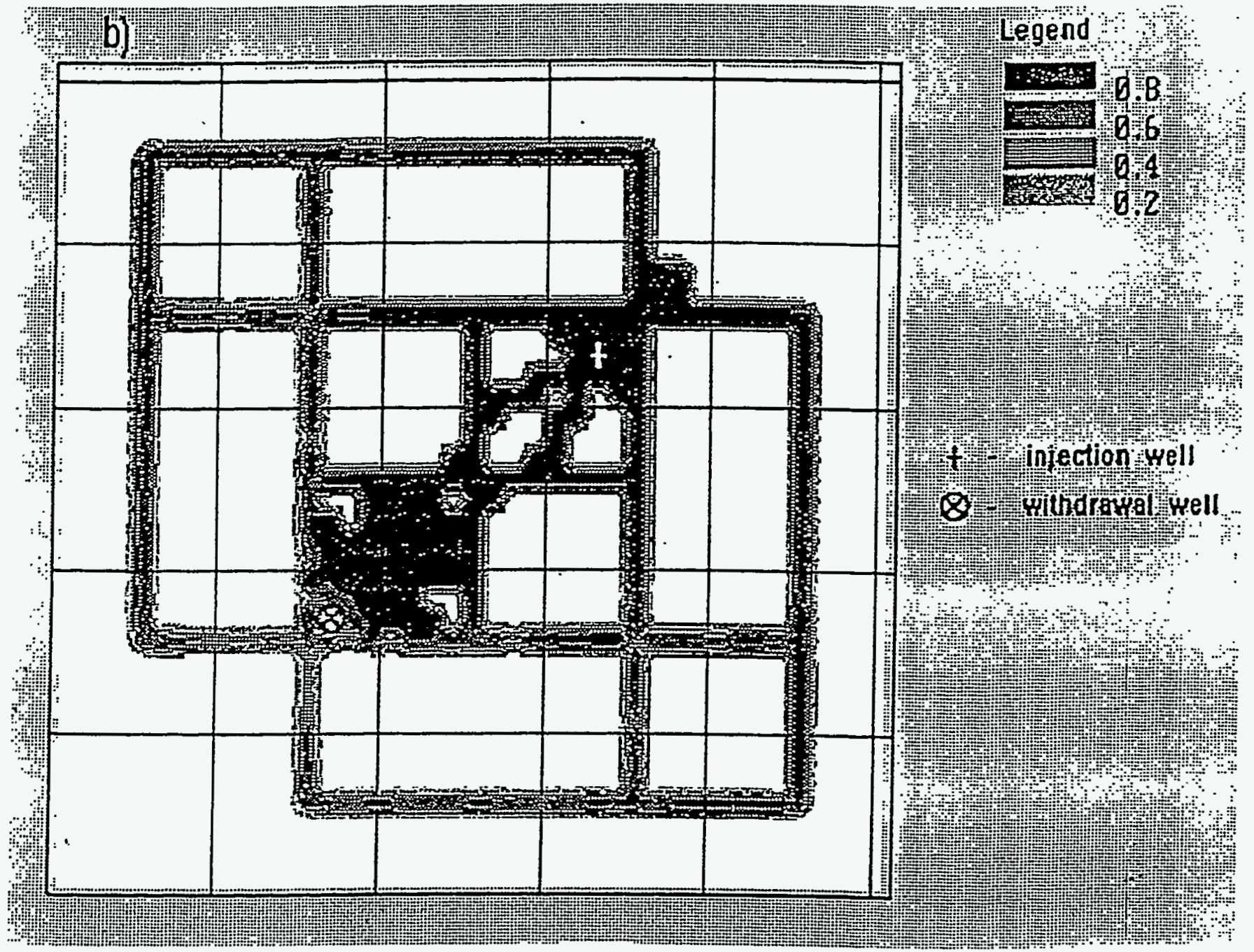

Fig. 7.5. (continued) 

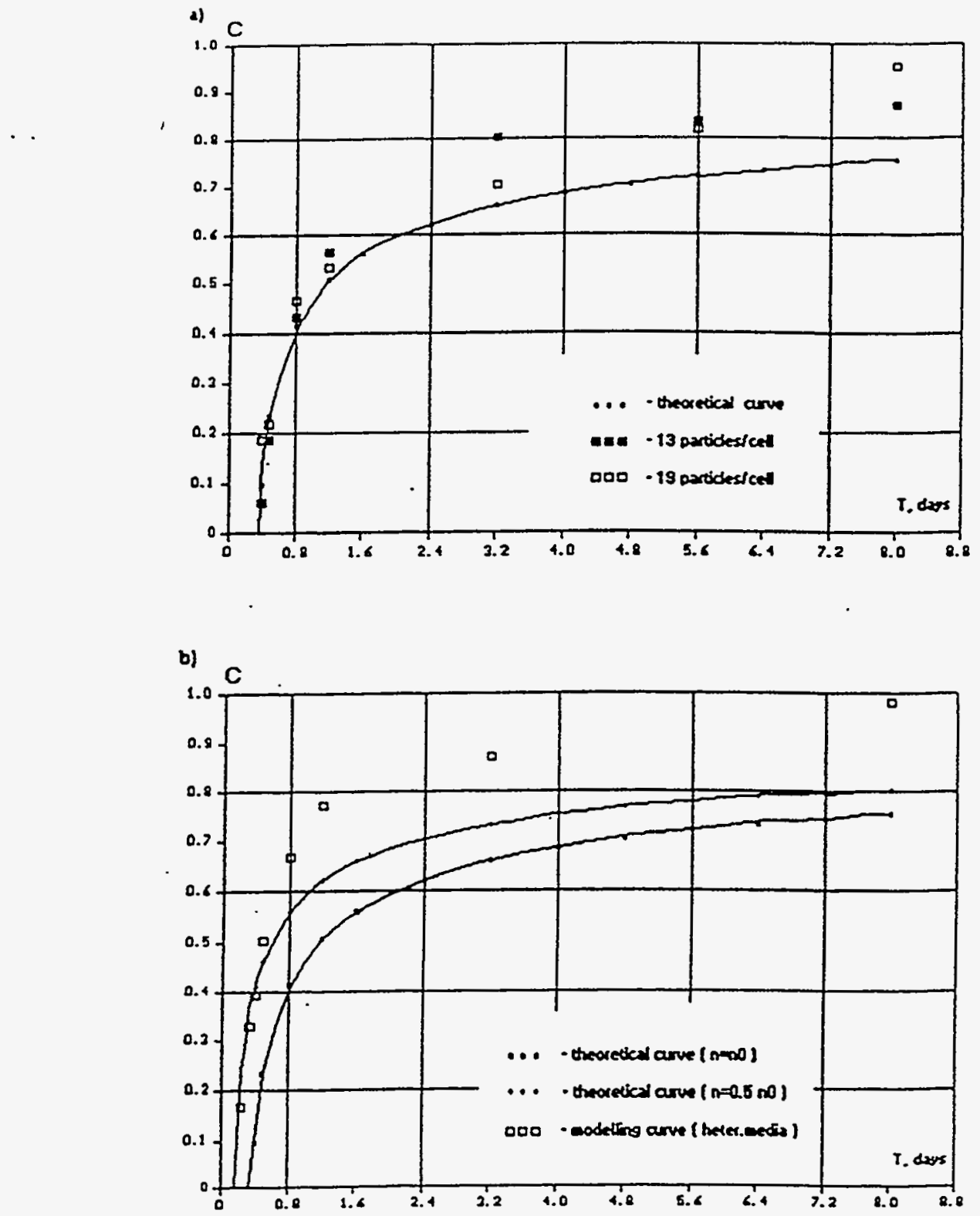

Fig. 7.6. Comparison of the modelled and theoretical breakthrough curves for homogeneous and heterogeneous media:

a) a) for homogeneous media;

b) for heterogeneous media. 


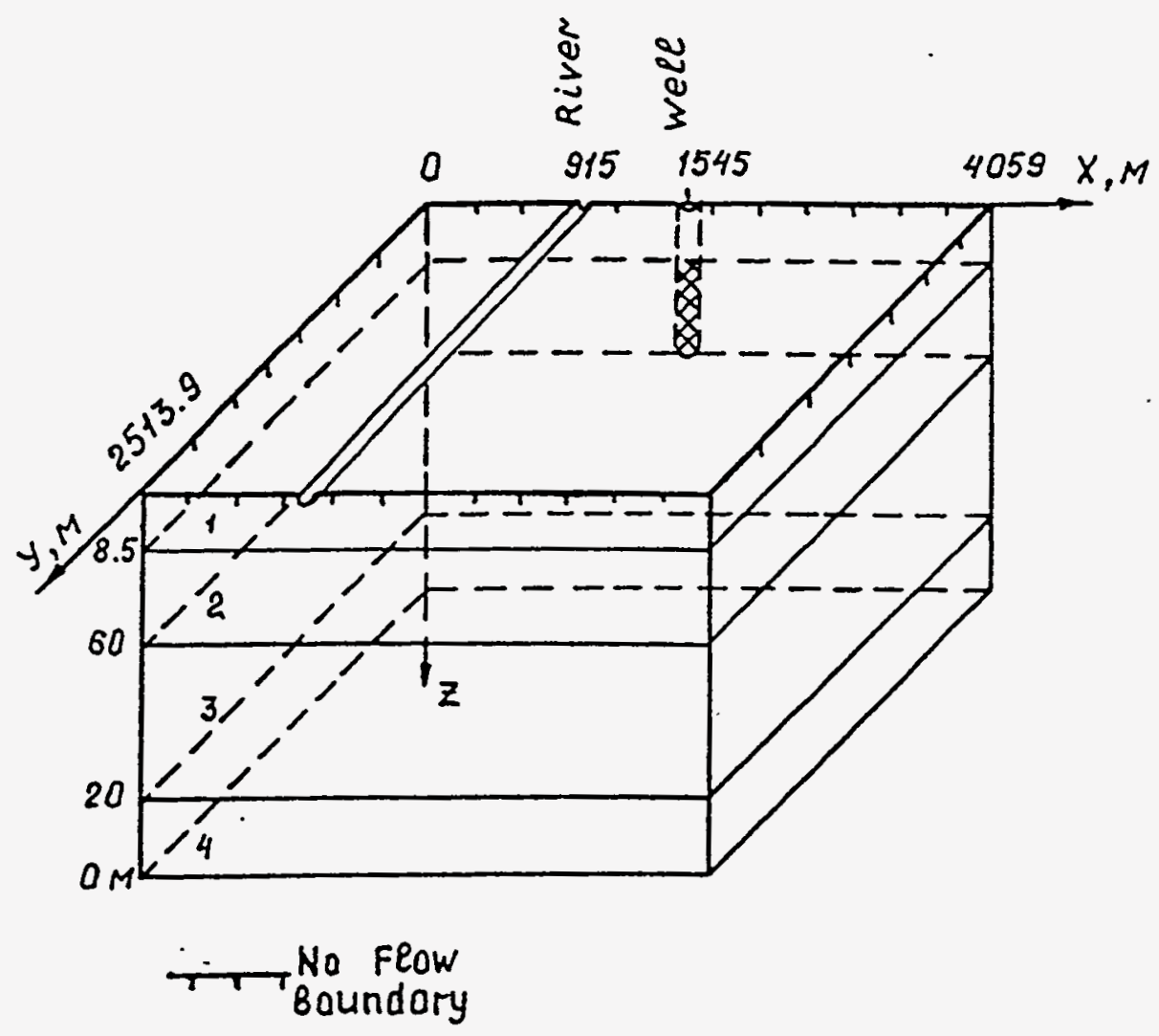

Fig. 7.7. Flow diagram of the numerical model 
Table 7.2:

\begin{tabular}{|c|c|c|c|c|c|c|c|c|c|c|c|c|}
\hline & \multirow{2}{*}{\multicolumn{4}{|c|}{$\begin{array}{c}\text { Analytical } \\
\text { calculation/formula (7.8) }\end{array}$}} & \multicolumn{8}{|c|}{ Simulation } \\
\hline & & & & & \multicolumn{4}{|c|}{$k_{z} \ll k_{x}$} & \multicolumn{4}{|c|}{$k_{z}=k_{x}$} \\
\hline$\overline{r_{o}, m}$ & 0.0 & 16.5 & 37.5 & 120.0 & 0.0 & 16.5 & 37.5 & 120.0 & 0.0 & 16.5 & 37.5 & 120.0 \\
\hline$t_{01}$ & & & & & 0.32 & 1.04 & 2.41 & 27.84 & 0.038 & 0.24 & 0.92 & 33.3 \\
\hline$t_{02}\left(t_{0}^{\prime}\right)$ & 0.0 & 0.042 & 0.22 & 2.26 & 0.0 & 0.043 & 0.265 & 6.69 & 0.0 & 0.045 & 0.34 & 17.3 \\
\hline$t_{03}$ & & & & & 1.03 & 6.50 & 14.5 & 146.6 & 0.22 & 2.06 & 6.54 & 223.6 \\
\hline$t_{04}$ & & & & & 98.9 & 139.2 & 231.4 & 1890.0 & 14.29 & 22.8 & 49.2 & 1066.3 \\
\hline
\end{tabular}

The river was $5 \mathrm{~m}$ wide, the riverbed level being $95 \mathrm{~m}$. Initial heads throughout the entire field were $H=100 \mathrm{~m}$. The upper (No. 1) layer was simulated as an unconfined one, the rest of the layers being assumed confined ones. The duration of the pumping test was 30 days.

The drowdown surface in the layer 2 at the end of pumping is illustrated by Fig. 7.8.

For all layers the potential surfaces of groundwater practically coinside. From this one can gather that at the site "Transit"the influence of the river does not change essentially the flow field structure, at least, within the first hundreds of meters from the pumping well. This is accounted for by a comparatively poor permeability of the upper layer which, in this particular case, suppresses the influence of a riverbed resistance variability on the final result.

After solving the flow problem, the travel of particles was studied considering various points of their injection into the layer (Table 7.2). The residence time $\left(t_{o_{k}}\right)$ was regarded as the main parameter ( $k$ is the number of the layer in the central point of which particle injection was imitated). Simultaneously, the tracer migration time was calculated according to the balance formula:

$$
t_{o}^{\prime}=\frac{\pi r^{2} m_{2} n}{Q}
$$

where $m_{2}$ is the thickness of the main layer (from which water is pumped-out). The results of all calculations for the basic scenario are presented in Table 7.2. Within the zone under consideration $(r \approx 120 \mathrm{~m})$, a quasi-steady flow was expected to be reached during pumping. Therefore, an increase in the duration of pumping would not change the further results.

First of all, calculations using a simplified balance scheme (7.8) yield, given $r<50 \mathrm{~m}$, the particles residence time in the main layer $\left(t_{o}^{\prime}\right)$ being fairly close to the actual (modelled) value $t_{02}$. This is due to the fact that the points of tracer injection into the layer are located within a zone where the layers interconnection has little influence on the horizontal velocity governed by the ratio $V_{r}=Q / 2 \pi m_{2} n r$. As $r$ increases to the values $r>m_{\Sigma}=100 \mathrm{~m}$, the time $t_{02}$ (compared to $t_{0}^{\prime}$ ) is markedly growing.

A change of the injection point to one of the low-permeability layers extends the residence time values dramatically. This confirms the high sensitivity of tracer injections to the vertical permeability of the aquifer. To illustrate this, the results of other experiments are represented in Table 7.2 when the layers were regarded as isotropic ones $\left(k_{z_{k}}=k_{x_{k}}\right)$.

As one can see, an increase in $k_{z}$ values, for the same $k_{x}$, leads to a more retarded transport through the main (No. 2) layer. Unlike this, the residence times $t_{01}, t_{03}, t_{04}$, for injection points located in the low-permeable layers near the pumping well $(z \leq 37.5 \mathrm{~m})$, are decreasing, which seems to be natural enough. Yet, quite opposite result gives an evaluation of the times $t_{01}$ and $t_{03}$ for the point $r=120 \mathrm{~m}$. An increase of $k_{z}$ leads here to the growth of the characteristic time of transport. The point $t_{04}$ (the same distance $r$ ) does not display such an inversion. The mentioned 


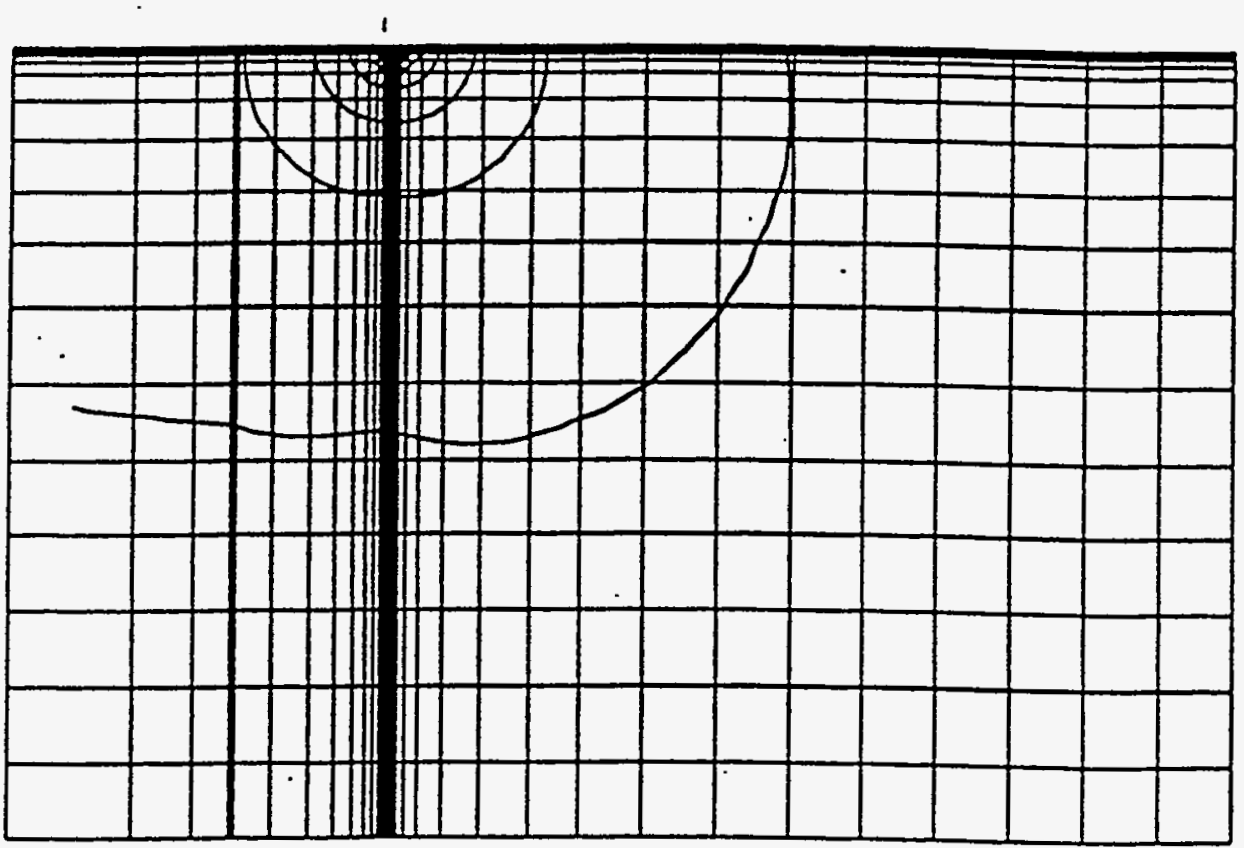

MIN $=.05$. MAX $=7.4$ DELIA $=.25$ Scale $1: 40000$

Fig. 7.8. Contours of the head drawdown in the 2nd layer 
anomaly can be accounted for by the features of the particles trajectories: they rapidly go into the high-permeable layer where, at a considerable distance from the pumping well, migration velocity is decreasing due to intensive vertical inflow from the neighboring layers.

So, a lack of a detailed information on permeability (flow velocity) distribution over the crosssection may result in an incorrect interpretaion of tracer tests with a partially penetrating well tapping a layered anisotropic aquifer; and it is the more so, the farther the injection point from the pumping well.

Finally, the modelling has shown that the time of brines upconing from the bottom (No. 4) layer is going to be measured by tens of days, at least.

Practically all these conclusions would not undergo any qualitative changes if a pumping well is moved closer to the river and the flow structure aquires a more pronounced 3D steady-state character. In this case, the portion of inflow from the lower layers is decreasing while the time of brines upconing and the degree of its dilution is growing respectively.

On the whole, the additional modelling permits to make some improvements in the design of tracer tests for convergent flow. In particular, considering the practical duration of such tests, it would be hardly expedient to inject a tracer through observation wells screening low-permeable layers 30-40 $\mathrm{m}$ and more away from a pumping well.

\section{Simulation of tests conducted at experimental grouting sites}

Such tests are conducted in two stages. At the first stage, fracture parameters are estimated in the aquifer in its initial state which allows to select the optimal injection conditions and the grouting mixture type. At the second stage, control of the grouting quality is conducted. A theoretical validation of the entire testing is the subject of another study. So, only the simplest models are considered here.

\subsection{Models for individual fracture aperture estimation}

Most data of fractured zone parameters can be obtained by a combined testing which includes tracking of the hydraulic and tracer response in an individual fracture (isolated by well packers). The formulas utilized for test interpretation are fairly simple in appearence (Novakowski et al., 1985; Smith et al., 1987):

- for hydraulic testing

$$
b_{h}=\left[\frac{Q}{\triangle H} \frac{6 \mu}{\pi \rho g} \ln \left(\frac{r_{0}}{r_{w}}\right)\right]^{1 / 3},
$$

- for tracer testing

$$
b_{t}=\left[\frac{6 \mu}{\rho g} \frac{\ln \left(r_{0} / r_{w}\right)}{t_{0} \Delta H}\left(r_{0}^{2}-r_{w}^{2}\right)\right]^{1 / 2},
$$

where $b_{h}$ and $b_{t}$ are "hydraulic" and "tracer" apertures; $\mu$ and $\rho$ are water viscosity and density, respectively; $g$ is the gravitational acceleration constant; $Q$ is the discharge rate; $\Delta H$ is the difference in the hydraulic head at the radial distances $r_{0}$ and $r_{w} ; t_{0}$ is the travel time from an input point to the withdrawal well.

In practice, hydraulic and tracer methods usually yield noticeably varied values of $b_{h}$ and $b_{t}$ (with $\left.b_{h} \ll b_{t}\right)$. This can be accounted for by the actual geometry of the void space. So, the hydraulic fracture resistance (which controls well discharge/ recharge rate in estimating $b_{h}$ ) depends upon the minimal distances between the fracture walls. On the other hand, the resident time of the tracer (used in estimating $b_{t}$ ) depends on the total fracture's storage capacity, i.e. is governed by 
its overall geometric dimensions. Appendix 8 shows the corresponding derivation using the simplest fracture model pattern.

The absolute values of $b_{h}$ and $b_{t}$ as well as their ratio $b_{h} / b_{t}$ could be used in planning of individual fractures grouting.

Unfortunately, under in-situ conditions, there are a number of factors (2D flow in the tested fracture, the presence of unconsidered fractures intersections with the main fracture) which could make estimating of b quite nonreliable ( $S$ mith et al., 1987). These drawbacks necessitate an independent assessment of grouting efficiency.

\subsection{Sensitivity analysis for tests evaluating the grouting quality}

Using the theory of complex variable functions, the authors have developed analytical models for flow and migration tests near impermeable cutoffs (Konosavski et al., 1992)-Appendix I. In particular, these models proved helpful in estimating the sensitivity of the tests to the presence of the local alteration of rosk properties.

One of the principal questions in using the suggested interpretation method is the assessment of drawdown value sensitivity in relation to the boundary length, which can be done on the basis of the solution (I.6). In Fig.8.1, one can see graphs of the drawdown value error $(\delta \bar{S})$ depending on observation well positioning (on the ray perpendicular to the boundary) given various (but constant for each graph) error in value $L$. As seen from Fig. 8.1, the maximal sensitivity to value $L$ is characteristic of drawdown in wells positioned on the opposite side of the boundary (in relation to the test well). For observation points near the central well, maximal sensitivity is characteristic of an area adjacent to the boundary $(x>0)$. Observation wells positioned on the axis of the boundary $(x=0)$ are characterized by minimal drawdown sensitivity to the boundary length $\left(\delta \bar{S} \sim n \cdot 10^{-6}\right.$ given the same parameters as in the above case. The analysis conducted affords a basis for the optimal (from the viewpoint of sensitivity to $L$ ) choice of observation well spacing scheme in the test cluster. So, when estimating the boundary length, observation wells should be placed on both sides off the boundary, near its center.

To interprete pulse tracer injections into the observation wells at the quasi-stationary stage of the flow when pumping near the short impermeable boundary, one can use the same conformable transform (I.1) as in case with field flow tests. Flow pathlines in the plane of the transform $(w)$ (see Fig I.1) has the shape $\left(q_{c w}\right)$

$$
\frac{\frac{q}{p+b_{1}}+\frac{q}{p+b}+\frac{q^{3}}{p\left(p+b_{1}\right)(p+b)}-\frac{q}{p}}{1+\frac{q^{2}}{p\left(p+b_{1}\right)}-\frac{q^{2}}{\left(p+b_{1}\right)(p+b)}+\frac{q^{2}}{p(p+b)}}=\text { const, }
$$

where $p, q$ are coordinates in plane $w ; b \equiv p_{c w} b_{1}$ is coordinate $\mathrm{p}$ of the reflected source off the circular boundary. Then the time of pulse (of the maximal tracer concentration in the pumped water) can be estimated by the formula

$$
t_{z}=\frac{4 \pi m n}{Q} \int_{p_{c w}}^{p_{0}} \frac{g_{p p} d p}{\partial \phi / \partial p}
$$

where $t_{z}$ is the actual time of traveling in plane $z, n$, fracturing; $m$, layer thickness; $Q$, pumping yield; $\phi$, the flow potential (see formula I.3); $p_{0}$, coordinate $p$ (in plane $w$ ) of the injecion point; $g_{p p}$ , the Lame coefficient (the main component of the curvature tensor in plane $w$ )

$$
g_{p p}=g_{q q}=\frac{L^{2}}{16}\left\{\left[1+\frac{p^{2}-q^{2}}{\left(p^{2}+q^{2}\right)}\right]^{2}+\frac{4 p^{2} q^{2}}{\left(p^{2}+q^{2}\right)^{4}}\right\}
$$


In Fig. $8.2 \mathrm{~b}$ one can see graphs showing how, in a pulse injection, the time of maximal tracer concentration reaching the pumping well depends on the position of the injection point (Fig. 8.2 a).

Injection points in the "shady area" are characteristic of the maximal sensitivity to the boundary (and, correspondingly, to its length) $\bar{t}$ differs by hundreds of percents in comparison $\bar{t} \equiv 1$ with . For injection points lying on the same side off the boundary as the central well, $\bar{t}$ is a bit less than one. Injection points with $\alpha \approx 0$ (see Fig. $8.2, a$ ) have the maximal sensitivity to the boundary influence.

A wide range of investigations has been performed on $2 D$ numerical model ASM (Kinzelbach, 1990). This confirmed the main conclusions resulting from previous analysis. In particular, it was found that the most sensitive scheme is associated with a divergent flow test when the injection and pumping wells are located on the different sides of the tested cut-off.

\section{Conclusions}

1. The present work suggests modeling methods for planning and interpretation of field hydrogeological tests at key sites in the area affected by radioactive pollution. These methods are essentially based on the analytical solutions obtained, in particular, by the authors. Using such soluions, with a limited involvement (as necessary) of numerical procedures, allows to:

a) identify major dimensionless complexes for an efficient description of the field tests conditions by a minimal number of variables;

b) adjust expedient test parameters, such as the necessary number of wells, their spacing, test intervals, pumping/injection rates, characteristic duration of the test,etc.

c) design the efficient schemes of tests interpretation.

2. The additional numerical modelling has permitted to assess the conditions for conducting field tests at the sites "River" and "Transit"in case of presence of radioactive brines in the lower zone of the aquifer. In particular:

a) pumping tests using partially penetrating wells screened through the main layer (layer N 2) can fairly well estimate the aquifer's integrated flow parameters during 2-3 weeks's time which precludes the possibility of arriving to the well of radioactive brines in inadmissible concentrations;

b) at the same time, more prolonged (several months) pumping tests of such kind resulting in brines upconing to the wells can be used for estimating the vertical permeability of rocks underlying the main permeable zone;

c) for estimating the lower zone's parameters, including its effective thickness (the position of the low-permeable bedrock), its direct testing will be needed which should be predominantly conducted under the injection testing regime with an obligatory areal tracking 6 . for the heads and tracer arrival times over a number of observation wells screening the same testing interval;

d) injection tests in of the aquifer's lower zone filled by dense radioactive brines could be efficient only after excluding the density advection by injecting the solution of the same density.

\footnotetext{
${ }^{6}$ In particular, the modelling has shown that it is the only kind of tracking which alows a more-or-less reliable estimation of the transmissivity of the tested interval in the lower zone of the aquifer
} 


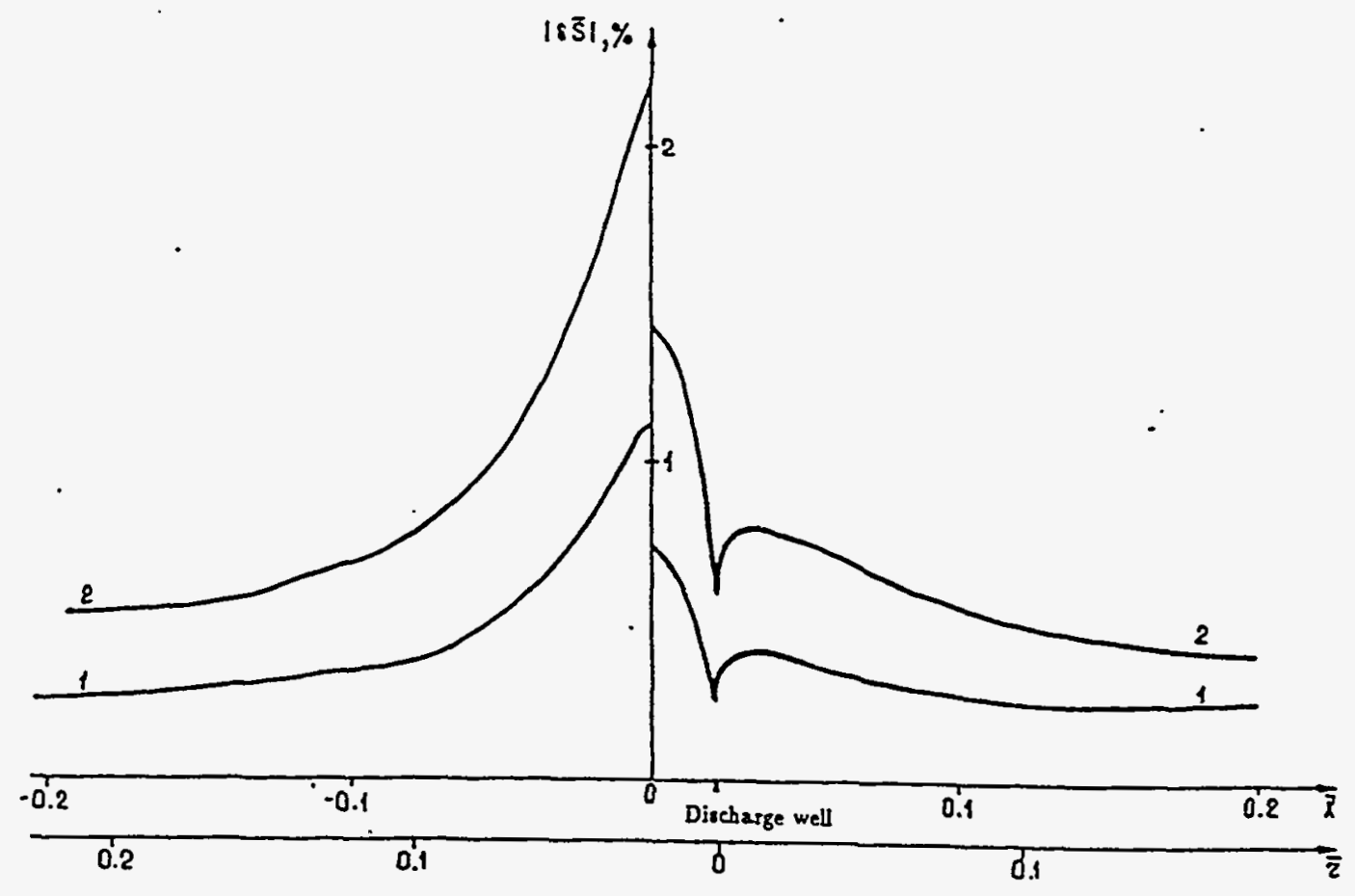

Fig. 8.1. Dependence of the drawdown error value on the position of the observation point (on the line $y=0$ ) given the fixed error in the boundary length $(1--\delta L=10 \%, 2--\delta L=20 \%)$, $\tilde{x}=x / R, \bar{r}=r / R, R^{2}=2.25 a t, \bar{m}=m / R=0.02, \tilde{x}_{u c}=0.02, \tilde{y}_{u c}=0$ 

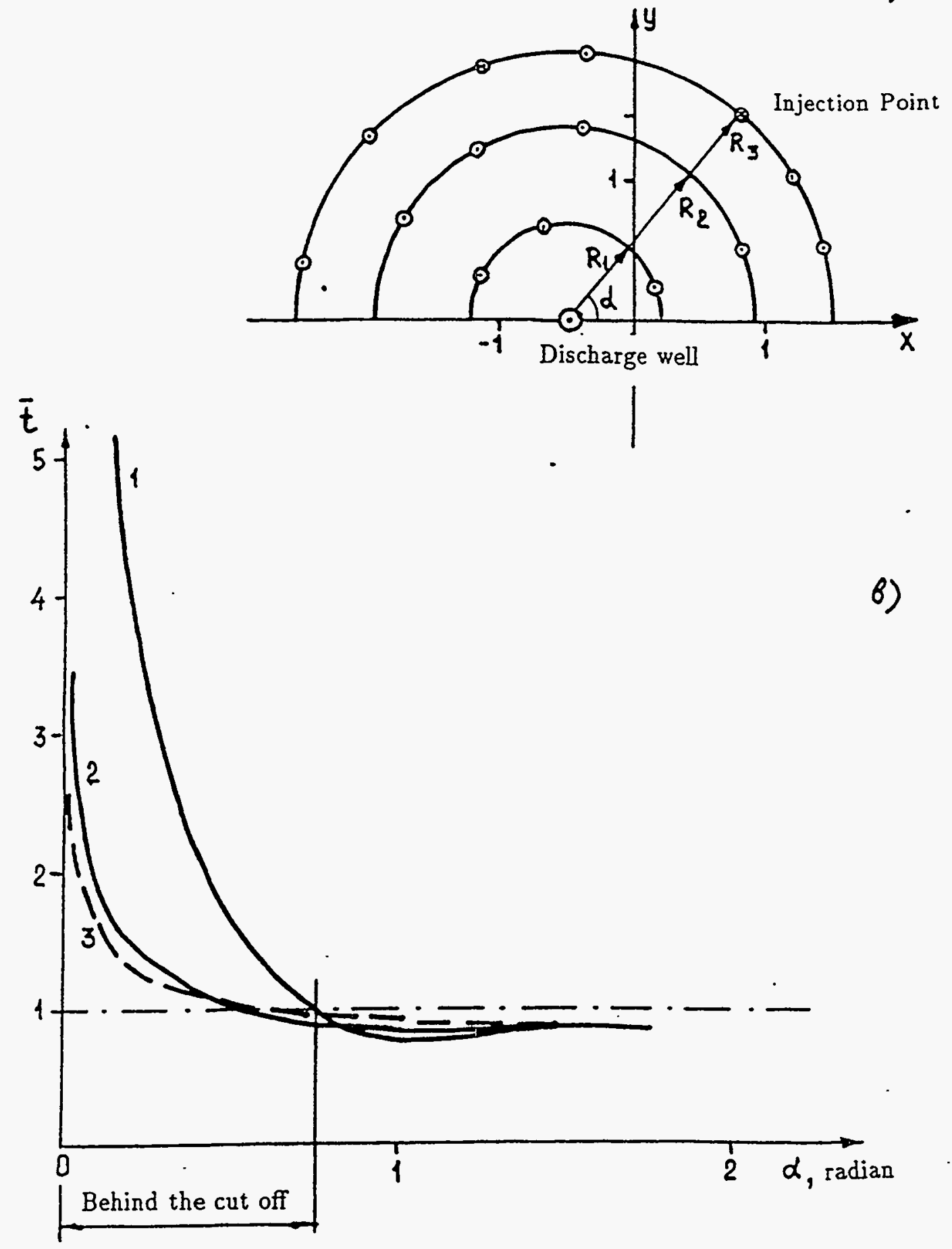

Fig. 8.2. Position of the central and observation (injection) wells vis-a-vis the boundary (a) and graphs of dependence of the dimesionless time of the peak tracer concentration entering the pumping well on the injection point position (b). The solid curve number matches the corresponding circle in Fig. $a$, the dot-and-dash strait line matches a uniform layer without a boundary

$$
\bar{x}_{c w}=0.5, \bar{y}_{c w}=0, \bar{t}=t /\left(\pi r^{2} m n / Q\right)
$$


3. The numerical modelling has revealed the fairly limited efficiency of tracer injection into observation wells when dealing with a partially penetrating pumping well. Under the conditions of the studied layered aquifer such injections make sense predominantly for estimating the effective porosity of the main permeable layer only. In this case, the distance between the observation well and the central well should not exceed the thickness of the tested zone. Tracer injections into the adjacent intervals of relatively low-permeable layers can be used only for a qualitative judgement on their vertical permeability.

4. The numerical modelling has once again confirmed the advantages of doublet tests compared to other kinds of tracer tests. Even under the conditions of a very high flow heterogeneity and nonuniformity, doublet tests results show an exclusively high stability of the obtained parameters of the fractured porosity. This is explained, first of all, by a large-scale averaging of the medium's properties by doublet testing which occurs due to all pathlines' convergence (and the respective data "convolution") to the pumping well of the doublet. It is also important that, contrary to the other testing schemes, doublet test evaluates one and the same aquifer's area for both flow and mass-transport parameters. Because of all these and some other well known advantages, doublet testing is recommended as the principal technique of field tests at the studied site.

5. The study allows to deliniate the range of advisable test schemes and the circle of hydrogeological parameters which could be estimated by them at various types of sites within the region. Here, of principal importance would be the key site "Transit" referred to an area where water-protection facilities (a drainage system or protective barrier) are most likely to be installed. Of secondary importance would be the key sites near the Lake and the River.

The principal design of tests looks as follows:

a) the integrated flow parameters of the aquifer (its transmissivity and gravitational storage) at the sites "Transit" and "River" are estimated by pumping tests while the subhorizontal permeability profile is studied by injection from the most permeable zone (layer 2) tests and flowmeter measurements within isolated intervals of the wells;

b) the vertical permeability of the upper and lower layers are estimated by the same pumping tests (a) supplemented by data on chemical composition changes in the water pumped out of the lower layer ${ }^{7}$. The vertical permeability of the main water-bearing layer is estimated according the the "vertical doublet" scheme;

c) to roughly estimate the aquifer's low-permeable bottom boundary, data obtained from flowmeter measurements and partially penetrating injection wells within the lower layer are used;

'd) among field mass-transport tests, the best prospects have those conducted under the "horizontal doublet" scheme with variable spacing between the injection and the pumping wells within the packerd by which intervals, in particular; these tests, the fractured porosity values ${ }^{8}$ and the approximate values of dispersivity could be estimated;

e) in parallel with the above-mentioned doublet tests, or as an alternative to them, tracer (and some nonconservative species) injection into the central wells of the testing clusters is recommended;

f) to enhance the amount of supplementary data on the fractured porosity and dispersivity as well as the areal flow anisotropy of the aquifer, tracer injections into observation wells during pumping are used;

\footnotetext{
'Until the activity of the pumped out water would be less than the permissible level.

${ }^{8}$ Including the likely influence of species sorption onto fracture surfaces and the "instant" diffusion into the secondary clianged thin adjacent zones of the rock matrix.
} 
6. As additional migration tests for the special purposes, the following could be recommended:

- tracer injection into a natural-gradient flow to determine subhorizontal transversal dispersivity,

- single well tests with nonconservative tracers under the scheme "injection of tracer

- its conservation in the aquifer and its instantaneous pumping" (the so -called

"huff-puff" tests to estimate sorption/desorption "properties,

- injecting fresh water into the polluted zone of the aquifer which could possilbly

help to evaluate roughly the profle transversal dispersivity,

- thermal tracer injection to estimate the specific surface of fractured rock.

7. To estimate fracture apertures at the pilot grouting site, labelled fluid injections into vals by isolated packers ( the "single fractures" intervals in particular) are suggested.To evaluate the quality of grouting, tracer tests are to be performed using observation and pumping wells located at different sides of the barrier. The most efficient version of this experiment presumes an upstream observation well for tracer input and downstream pumping well for its sampling.

8. In most cases, the interpretation of the suggested tests can be also based on the abovementioned analytical solutions using corresponding type curves and the procedures of their matching. For some types of tests, especially flow tests, an efficient interpretation could be achieved in the space of Laplace-transformed functions: If necessary, the interpretation can be complemented by numerical methods, including those used, in this study.

9. From the above it is clear that a special emphasis in the present work is being laid on using analytical methods for planning and interpretation of field tests. Such an approach seems most efficient and reliable. Given the proper setup of tests a priori oriented to reproducing the elementary, as possible, situations, this ensures a reliable diagnosis and identification of the appropriate model. Nevertheless, we have conducted also the analysis and testing of efficient numerical methods which have essentially widened and supplemented the scope of the tests conditions studied by analytical methods. Here, we have confined ourselves, with some exceptions (pumping near the river), to $2 \mathrm{D}$, predominantly axisymmetric, models without exhausting, however, all possible situations of such kind.

10. In parallel with the present work, we are analyzing the potential of more comprehensive, 3D numerical models which are most likely to require further serious investigations as applied to the studied area. In particular, it is clear that the field tests conducted at the key sites, even if in their best realization, will not yield all necessary data for designing and implementation of water-protection measures. Therefore, such data will have to be found by the test-and-operational approach on the basis of observations during the water-protection facility construction. It is no doubt that in so doing we are to resort to analyzing the appropriate field situations on $3 \mathrm{D}$ numerical models the development of which for the given site presents a great challenge. In this connection, it would be undoubtedly expedient to combine the efforts of the leading Russian and American specialists for managing this challenge. We are hopeful that the present work will give a first impetus to such cooperation. It will be stimulated also by the fact that, in more general terms, the problems of ground-water remedeation at the radioactively contaminated sites in both our countries could contribute to transforming these sites into unique field laboratories for conducting cooperative research by the Russian and American scientists. 


\section{Acknowledgments}

This work was prepared under the auspices of Russian-American Center for Contaminant Transport

Studies at the Lawrence Berkeley Laboratory. We appreciate the funding from the Department of Energy's

Office of Environmental Management, Office of Technology Development (DOE/EM-OTD) and the Office of Energy Research, Office of Basic Energy Sciences (DOE/ER-BES) through Contract Number DC-

AC03-76SF00098. The authors are also grateful to Chin-Fu Tsang, John A. Apps and Joe Wang for their review, and to William Lay for his assistance for the publication of this report. 


\section{A The approximated solutions of the $1 \mathrm{~d}$ radial microdispersion problem}

A fairly complete synopsis of the known approximated solutions can be found in literature (Mironenko and Rumynin, 1986; Alekseev et al., 1989). The major solutions could be represented by the formula (6.3) with the folowing generalized version of the parameter $\xi$ :

$$
\xi=\frac{1-t_{r}}{2 \sqrt{\sigma}} \text {. }
$$

So, in accordance with $P$. Raimondi et al. solution (1959),

$$
t_{r}=Q t / \pi r^{2} m n, \quad \sigma=4 / 3 P e, \quad\left(P e=r / \delta_{L}\right) ;
$$

for V.M. Shestakov's solution (1962),

$$
t_{r}=Q t / \pi r^{2} m n, \quad \sigma=4 t_{r}^{3 / 2} / 3 P e
$$

for V.S. Alekseev et al. solution (1989),

$$
t_{r}=\left(Q t / \pi r^{2} m n\right)^{1 / 2}, \quad \sigma=4 t_{r}^{1 / 2} / 3 P e ;
$$

and, finally, for the most precise A.A. Roshal's approximation

$$
t_{r}=Q t / \pi r^{2} m n, \quad \sigma=4 t_{r} / 3 P e .
$$

\section{B The pulse tracer injection into 1d flow within homogeneous stratum}

In the basis of the derivation lies the transition to a radial coordinate system within the known . solution for concentration changes in a $1 D$ linear flow affected by an infinitely thin (of thickness $d x$ ) layer of an instantaneously injected (as described by the pulse Dirac function $\delta(t)$ ) tracer.

In a $1 \mathrm{D}$ linear flow the solution for pulse tracer input can be written as follows:

$$
\bar{C}=\frac{\partial \overline{C_{n}}}{\partial x} d x
$$

where $\overline{C_{n}}$ is the solution for a step-like initial concentration distribution $\left(C=C_{0}\right.$ for $x \leq 0$, and $C=0$ for $x>0$ )

$$
\bar{C}_{n}=0.5 \operatorname{er} f(\xi), \quad \xi=(x-v t / n) /(2 \sqrt{D t / n}) .
$$

The transition to radial coordinates is performed through the dimensionless variable $(\tau, P e)$ using the following averaging procedures:

$$
\tau=t / t_{0}, \quad t_{0}=\int_{O\left(r_{e}\right)}^{r} n d r / v(r), \quad P e=t_{0}^{2} / \delta \int_{0\left(r_{c}\right)}^{r} n^{2} d r / v^{2}(r),
$$

where $\delta$ is longitudinal dispersivity.

Finally, one has:

$$
C=\frac{M}{2 \pi r^{2} m n} \sqrt{\frac{3 P e}{4 \pi \tau}} \times \exp \left[\frac{(1-\tau)^{2} 3 P e}{16 \tau}\right] .
$$

In the known solution by Lenda and Zuber (1970), an instantaneous change of the 1st-type boundary condition at the inlet point $(C(0, t)=$ const) takes place and thereby the tracer mass balance disturbance is predetermined. Unlike this, the formula ( B.4) implies that the total mass of the injected tracer within the stratum is the same for all moments of time. 


\section{Tracer movement in the area of a partially penetrating well}

Generally, the time $\left(t_{0}\right)$ of tracer travel along an arbitrary flow line $(L)$ can be obtained from the formula

$$
t_{0}=\int_{L} \frac{d l}{\frac{k}{n} \frac{d s}{d l}}
$$

where $S$ is the drawdown function, $k$ and $n$ are hydraulic conductivity and porosity (fracturing).

To estimate gradient $d S / d l$, let's consider the problem in the coordinate system the axes of which are the flow lines $(\psi)$ and the equal head lines $(\phi)$ : in the vicinity of the pumping well's screen and far enough from the stratum's top and bottom, this will be the coordinate system of an elongated ellipsoid (Korn and Korn, 1968). Then, for the drawdown function, one has:

$$
S=\frac{Q}{4 \pi k l} * \tanh ^{-1}(\phi), \quad(1<\phi<\infty)
$$

from which

$$
t_{0}=\int_{1}^{\phi_{0}} \frac{\sqrt{g_{\phi \phi}} d \phi}{\left(k / n \sqrt{g_{\phi \phi}}\right)(d s / d \phi)}
$$

where $g_{\phi \phi}$ is the main component of the metric tensor of the elliptical coordinate system $(\phi, \psi)$, $g_{\phi \phi}=l^{2}\left(\phi^{2}-\psi^{2}\right) /\left(\phi^{2}-1\right), l$ is the screen length. Substituting $d S / d \phi$ from the equation ( C.2) into the formula ( C.3) yields, after integrating, the formula (6.6).

\section{Horizontal doublet test in an anisotropic homogeneous stra- tum (a piston-like flow)}

Similar to solving flow problems, a preliminary scaling of Cartesian coordinates through replacing $x, y$ by $x / \sqrt{k_{x}}, y / \sqrt{k_{y}}$ permits to substitute an anisotropic medium by an isotropic one. Moving on to bicylindrical coordinates the axes of which are equal head lines $(\phi)$ and flow lines $(\psi)$, one can obtain the known solution for the travel time along the arbitrary flow line $\psi$ :

$$
\bar{t}=\frac{\sin \psi-\psi \cos \psi}{\sin ^{3} \psi},
$$

where $\bar{t}=\tilde{Q} t /\left(4 \pi m \tilde{a}^{2} n\right), \quad \tilde{Q}=Q / \sqrt{k_{x} k_{y}}$,

$\tilde{a}=a \sqrt{\cos ^{2} \alpha+\chi^{2} \sin ^{2} \alpha} / \sqrt{k_{x}}$,

$a$ is the half-distance between the doublet wells in $(x, y)$ coordinates, $\alpha$ is the angle between the doublet axis direction and the minimal permeability axis $x, \quad \chi=\sqrt{k_{x} / k_{y}}$.

For the $C$ function in an areally anisotropic stratum, the following expression would be appropriate according to the law of mixing:

$$
\bar{C}=\frac{Q *}{Q_{\pi}}=\left.\frac{1}{Q_{\pi}} \int_{0}^{\psi^{*}} r m k_{x} \frac{d s}{d x}\right|_{x=\sqrt{r^{2}-x^{2} y^{2}}} \frac{d \psi}{\cos \psi^{*}} .
$$

where $r=\sqrt{\chi^{2} y^{2}+x^{2}}, \quad Q_{\pi}=Q / 2$.

Integrating ( D.2) yields:

$$
\bar{C}=\frac{1}{\pi}\left[\arctan (\chi \tan \alpha)-\arctan \left(\chi \tan \left(\alpha-\psi^{*}\right)\right)\right] .
$$

By transition from $(x, y)$ coordinates to $(\phi, \psi)$ coordinate, one can obtain the following relationship between $\phi$ in the formula (D.1) and $\psi^{*}$ in (D.3) 


$$
\psi=\arctan \left(\chi * \tan \psi^{*}\right)
$$

Finally, one has

$$
\begin{array}{r}
\bar{t}=\frac{t}{4 \pi m a^{2} n\left(\cos ^{2} \alpha+\chi^{2} \sin ^{2} \alpha\right) / Q \chi}= \\
\frac{\sin (\pi \bar{C})-\pi \bar{C} \cos (\pi \bar{C})}{\sin ^{3}(\pi \bar{C})}
\end{array}
$$

- see Fig.D.1 For the shortest flow line (along the doublet axis):

$$
t_{0}=\frac{4}{3} \pi m a^{2} n\left(\cos ^{2} \alpha+\chi^{2} \sin ^{2} \alpha\right) / Q \chi
$$

One can easily prove that a good approximation of the solution ( D.5), with the error of less than $0.6 \%$, is

$$
\bar{C}=\frac{2}{\pi} \arccos \left[\left(t_{0} / t\right)^{1 / \pi}\right]
$$

\section{E Vertical doublet test in a stratum of finite thickness}

Let us consider only the advective component of mass-transport assuming that the screens of the pumping and injecting wells adjoin the profile boundaries of the stratum. The zero point coincides with the pumping well, the $z$ axis is directed along the doublet axis. The well screens are approximated by a point source and sink.

The migration along an arbitrary flow line is governed by the following:

$$
t=\left(n / k_{z}\right) \int_{z_{0}}^{0} \frac{d z}{d s(r, z) / d z} .
$$

The equations for the flow-lines along which the integrating is performed could be written as

$$
\begin{array}{r}
\frac{\bar{z}}{\sqrt{\bar{x}^{2}+\bar{z}^{2}}}+\sum_{i=1}^{\infty}\{R(2 i+z)-R(2 i-z)+ \\
R(2 i-1-\bar{z})-R(2 i-1+\bar{z})\}=\frac{1}{\sqrt{1+\chi^{2} \tan ^{2} \psi^{*}}}
\end{array}
$$

where

$\bar{z}=z / m, \quad \bar{x}=\chi x / m, \quad R(2 i+z)=(2 i+z) / \sqrt{\bar{x}^{2}+(2 i+\bar{z})^{2}}$.

For tracer concentration in the pumping well, according to the law of mixing, one has

$$
\bar{C}=\frac{Q_{\psi^{*}}}{Q_{\pi}}=1-\frac{1}{\sqrt{1+\chi^{2} \tan ^{2} \psi^{*}}} .
$$

From the fixed $C$-value in the formula ( E.3), the central angle $\alpha$ can be estimated which matches the boundary flow line deliniating the segment of labelled water coming into the well. The time of stabilization of $C$-values in the pumped water can be derived from the equation (E.1) where integrating is performed by the flow line with the central angle $\alpha . C(t)$ function for the problem under consideration could be presented in a graphic form (Fig. E.1). 


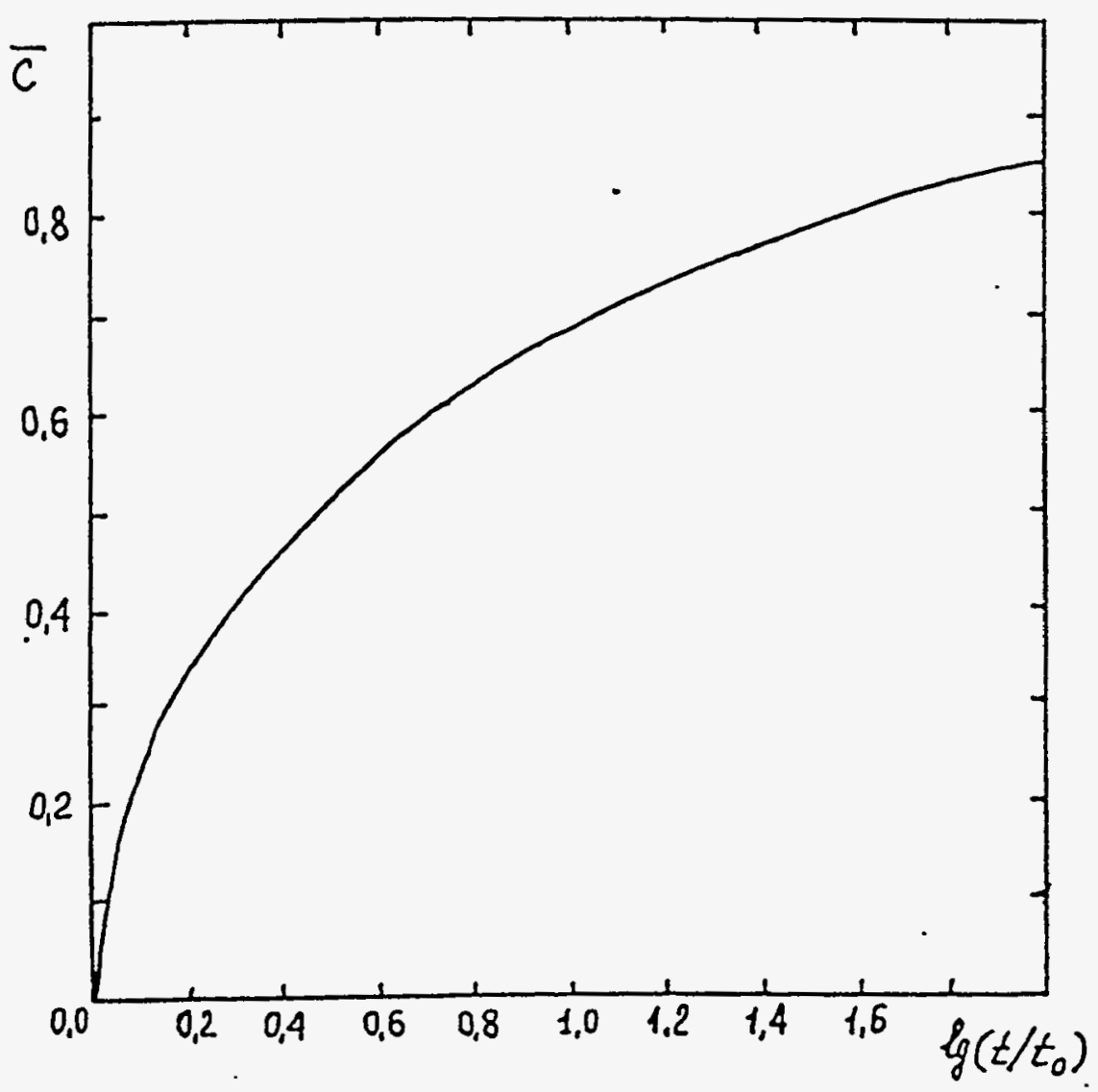

Fig.D.1 The type curve (exact solution) of the tracer test according to the horizontal doublet scheme in an areally anisotropic aquifer; $t_{0}=\pi m r^{2} n\left(\cos ^{2} \alpha+\sin ^{2} \alpha \cdot x^{2}\right) /(3 Q \chi)$ 


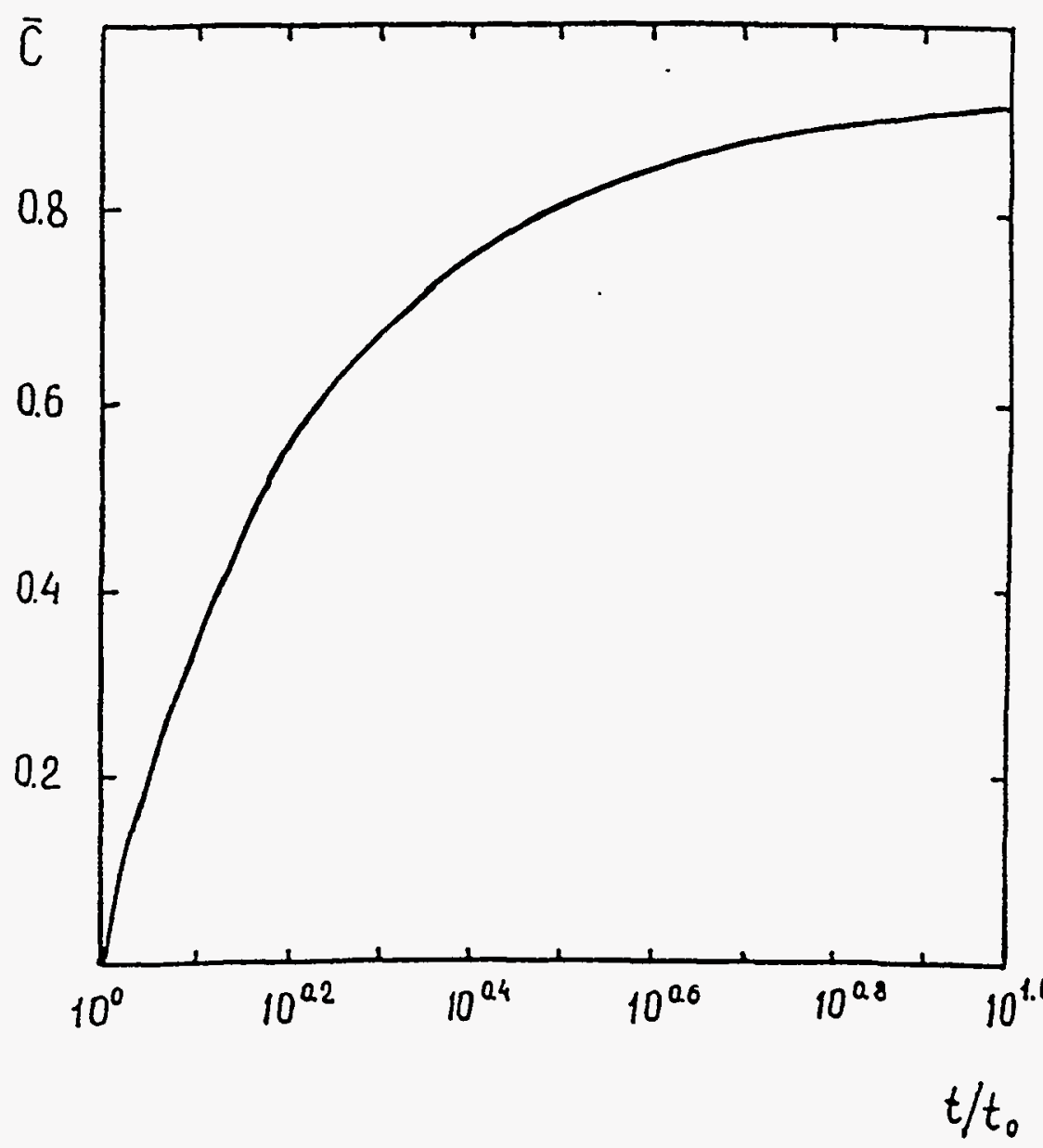

Fig.E.1 The type curve (exact solution) of the tracer test according to the vertical doublet scheme in an areally anisotropic aquifer of the limited thickness;

$$
t_{0}=0.4 m^{3} n / Q x^{2}
$$




\section{F About the combined impact of natural-gradient flow and aquifer nonuniformity on tracer tests results}

Let's consider the problem of tracer injection into the nonuniform aquifer with natural-gradient flow where a boundary exists between two zones characterized by permeabilities $k_{1}$ and $k_{2} \quad\left(k_{1}>k_{2}\right)$ (see Fig. F.1). Assume for simplification that observation wells are located along the central axis $y$ the direction of which coincides with that of the velocity vector $v_{e}$. From the flow problem solution for a nonuniform layer, one has the following formula for estimating the location of the critical ("watershed") point $y_{k p}\left(r_{k p}\right)$ :

$$
\begin{array}{r}
y_{k p}(z)=b-c \\
r_{k p}(z)=c .
\end{array}
$$

- if the neutral flow line spreads into the less permeable zone, e. $g$. when the following condition is met:

$$
\begin{array}{r}
c=q\left(1-\chi_{12}\right) / 2 \pi v_{e}>b \\
y_{k p}=\frac{C^{\prime}}{2}\left[\sqrt{\left(1+\chi_{12}\right)^{2}+4 b^{\prime}\left(b^{\prime}+\chi_{12}^{-1}\right)}-\left(1+\chi_{12}\right)\right]
\end{array}
$$

or

$$
r_{k p}(z)=b-y_{k p}(z)
$$

if the neutral flow line falls into a higher permeable zone, e. $g$. when $c<b$; here, $\chi_{12}=$ $\left(k_{1}-k_{2}\right) /\left(k_{1}+k_{2}\right), c^{\prime}=q / 2 \pi v_{e}$,

$b=\alpha(z), b^{\prime}=b / c^{\prime}, \alpha=\arctan \left(m / b_{k}\right)$, see Fig F.1; $q$ is the specific (per unit of the layers thickness) injection rate.

Knowing the location of the characterisic point $r_{k p}(z)$ and the distance to the observation well, one can estimate the proportion of water mixing in the well as well as the time $t_{0}(z)$ of registering the tracer coming into the well through various layers (with the parameters $\chi_{12}, b(z)$ - see Fig.F.1, a). In the latter case, the folowing cinematic equation can be used:

$$
t_{0}(z)=\int_{0}^{r} \frac{n d r}{v_{y}(r, z)}
$$

where

$$
v_{y}=\frac{q}{2 \pi}\left[\frac{1}{r}-\frac{\chi_{12}}{2 b-r}\right]-v_{e}
$$

for a zone where $k=k_{1}$, and

$$
v_{y}=\frac{q\left(1-\chi_{12}\right)}{2 \pi r}-v_{e}
$$

for a zone where $k=k_{2}$.

The relative concentration $\bar{C}$ in the observation well is estimated according to the formula of mixing $\bar{C}=\left[m-z\left(t_{0}\right)\right] / m$ (in the domain $z_{k p^{2}}<z<m$ ). Similarly, equations can be constructed for estimating the behavior of the concentration function at any point of the stratum. 


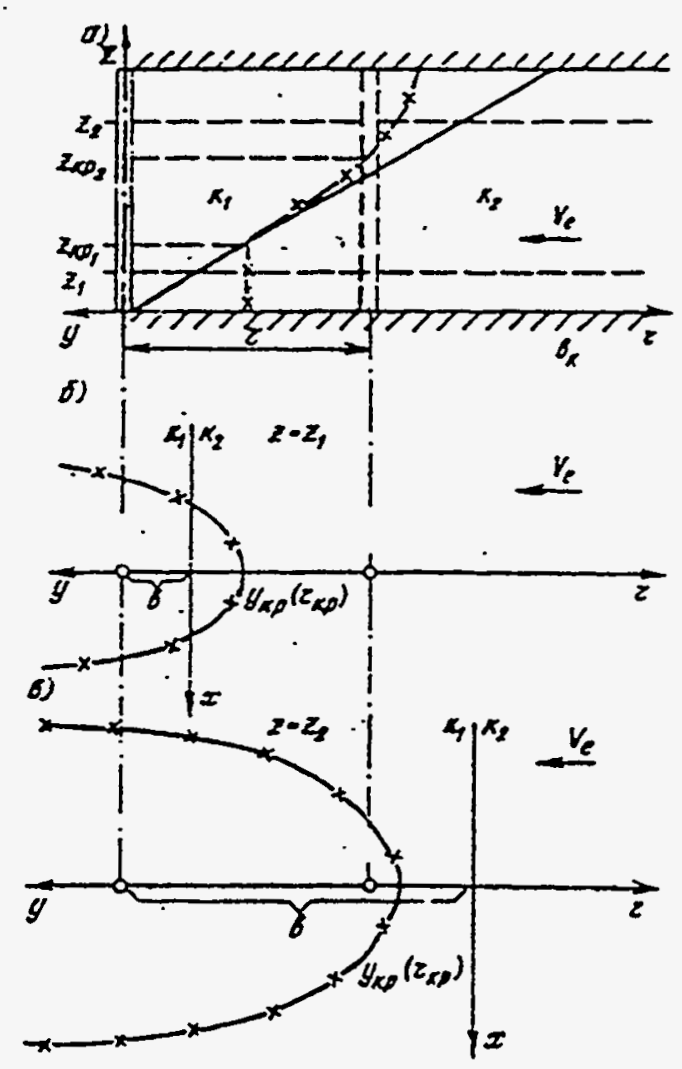

Fig.F.1 A schematic view of the stratified layer (a) and its modelled elements for two characteristic sections:

$z=z_{1}$ (b) with $c>b$, and $z=z_{2}$ (c) with $c<b$

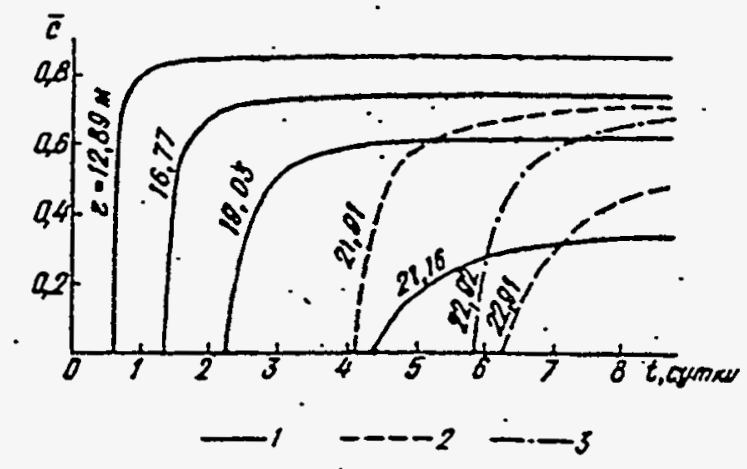

Fig.F.2 Model curves according to observation wells located upstream from the injection well; 1,2 , and 3 for $\chi$ being equal respectively to $0.5,0.1$, and 0.05 


\section{G Mass-transport within the fracture of finite length with an infinitely high permeability}

The time of tracer migration $t_{0}$ to the fracture (Fig.6.6) can be estimated using the equation (C.3) where in the elliptical coordinates one has

$$
\frac{d s}{d \phi}=\frac{Q}{2 \pi T \sqrt{\phi^{2}-1}}, \quad g_{\phi \psi}=l^{2}\left(\phi^{2}-\psi^{2}\right) /\left(\phi^{2}-1\right),
$$

$l$ being the half-length of the fracture and $T$, transmissivity of the stratum. After integrating, one obtains the equation (6.14).

\section{H Flow and mass transport in a single fracture with a variable aperture}

Physical and mathematical modelling of flow through fractures with a real surface morphology shows (Schauf T.W., Evans D.D., 1986; Tsang and Tsang, 1989, etc.) the dependence of flux $(q)$ on the fracture aperture (b) to be fairly complex, that is, as the number of contacts between fracture walls increases, the flow in the fracture is getting more and more governed by regularities of flow in channels (the function $q(b)$ tends to acquire the form of $q \sim b^{4}$ ).

The actual morphology of fracture surfaces results in uncertainties of field tests interpretation conducted "within a single fracture" when estimating the aperture according to flow and migration tests. So, replacing a fräcture with a step-wise changing aperture by that with $b=$ const on the basis of the flow resistnace method yields

$$
b_{e f f}=\left(\frac{L}{\sum_{i=1}^{N} l_{i} / b_{i}^{3}}\right)^{1 / 3}
$$

where $L$ is fracture length; $l_{i}$ the length of the fracture segment with the aperture $b_{i}$.

A similar replacement assuming an equivalent tracer travel time yields

$$
b_{e f f}=\frac{1}{L} \sum_{i=1}^{N} l_{i} b_{i}
$$

Comparison of the above equations explains for the discrepancies in field tests interpretation. For more complex models of $b(l)$, the difference could be much more significant.

\section{The peculiarities of describing flow near "short" boundaries}

For a quasi-steady flow, a solution for a well in an areally infinite stratum can be presented as a sum of two functions. One of those functions depends only on space coordinates (the flow potential), and the other one depends only on time (which is equivalent to assuming successive steady states). This makes it possible to employ the method of conformity transforms for estimating the flow potential which is sufficient for areal drawdowns distribution evaluation. In this particular case (Fig.l.1), we used the transforming of the exterior domain with the impermeable boundary of the length $L$ (the plane $z$ ) on the exterior domain of an isolated circle (the plane $w$ ). Such a transform can be realized by the function (Lavrentjev and Shabot, 1973).

$$
z=\frac{m}{2}(w-1 / w),
$$

where $m=L / 2$. 
The coordinates $(x, y)$ of the plane $z$ and the $(p, q)$ of the plane $w$ are linked to each other through the equations

$$
\begin{array}{r}
x=\frac{m}{2}\left(p-\frac{p}{p^{2}+q^{2}}\right), \\
y=\frac{m}{2}\left(q+\frac{q}{p^{2}+q^{2}}\right), \\
p^{2}+q^{2} \geq 1 .
\end{array}
$$

In the plane images $(w)$, the flow field created by a point source (a well) is described by the flow potential in a uniform, isotropic stratum which is equal to

$$
\phi=\ln \left(1 / r_{1}\right)+\ln \left(1 / r_{2}\right)-\ln \left(1 / r_{3}\right)+\text { const },
$$

where $\phi=2 \pi T S_{w} / Q ; T$, the layer transmissivity; $S_{w}$, the drawdown fuction differring from the actual drawdown in the aquifer $\left(S_{z}\right)$ by a certain constant; $r_{1}=\sqrt{\left(p_{c w}-p\right)^{2}+\left(q_{c w}-q\right)^{2}}, \quad r_{2}=$ $\sqrt{\left(p_{2}-p\right)+\left(q_{2}-q\right)^{2}}$ $r_{3}=\sqrt{p^{2}+q^{2}}, \quad p_{2}=p_{c w} /\left(p_{c w}^{2}+q_{c w}^{2}\right), \quad q_{2}=q_{c w} /\left(p_{c w}^{2}+q_{c w}^{2}\right)$

$p_{c w}$ and $q_{c w}$ are the coordinates of the central well (source) in the plane w. This relationship can be presented in the form of

$$
\phi=\ln \frac{R_{w}}{r_{1} r_{2} / r_{3}}
$$

where $R_{w}$ is a circular contour of equal head points (here, $R_{w}$ is the function of time). A solution in the form of (A9.4) is valid when the condition $R_{w} \gg \sqrt{P_{c w}^{2}+q_{c w}^{2}}$ is met, which can always be reached by the appropriate selection of the value $R_{w}$.

The equation (I.3) can be directly used for the calcualtion of areal distribution of drawdowns in the observation wells. In the coordinates $S_{z} \div \ln \left(r_{1} r_{2} / r_{3}\right)$ the slope of the straight line $(=Q / 2 \pi T)$ allows for estimating the transmissivity $(T)$.

The transformation (I.1) for $p, q \rightarrow \infty$ yields the following link between the coordinates: $p=$ $2 x / m, \quad q=2 y / m$. Hence, far enough from the well, a circle is transformed into another circle, and it would be rightful to assume

$$
R_{w}=\frac{4}{m^{2}} * R_{z}
$$

At the same time, having assumed $R_{z}=\sqrt{2.25 a t}$ ( $a$ is the diffusivity of the stratum and $t$ being time coordinate), the solution (I.3) could be represented as

$$
\bar{S}=\ln \frac{9 a t / m^{2}}{r_{1}^{2} r_{2}^{2} / r_{3}^{3}},
$$

where $\bar{S}=4 \pi T S_{z} / Q$.

So, using some properties of the transformation (1.3), one could obtain the complete expression for the drawdown function of quasi-steady flow in a stratum with a short impermeable boundary. 


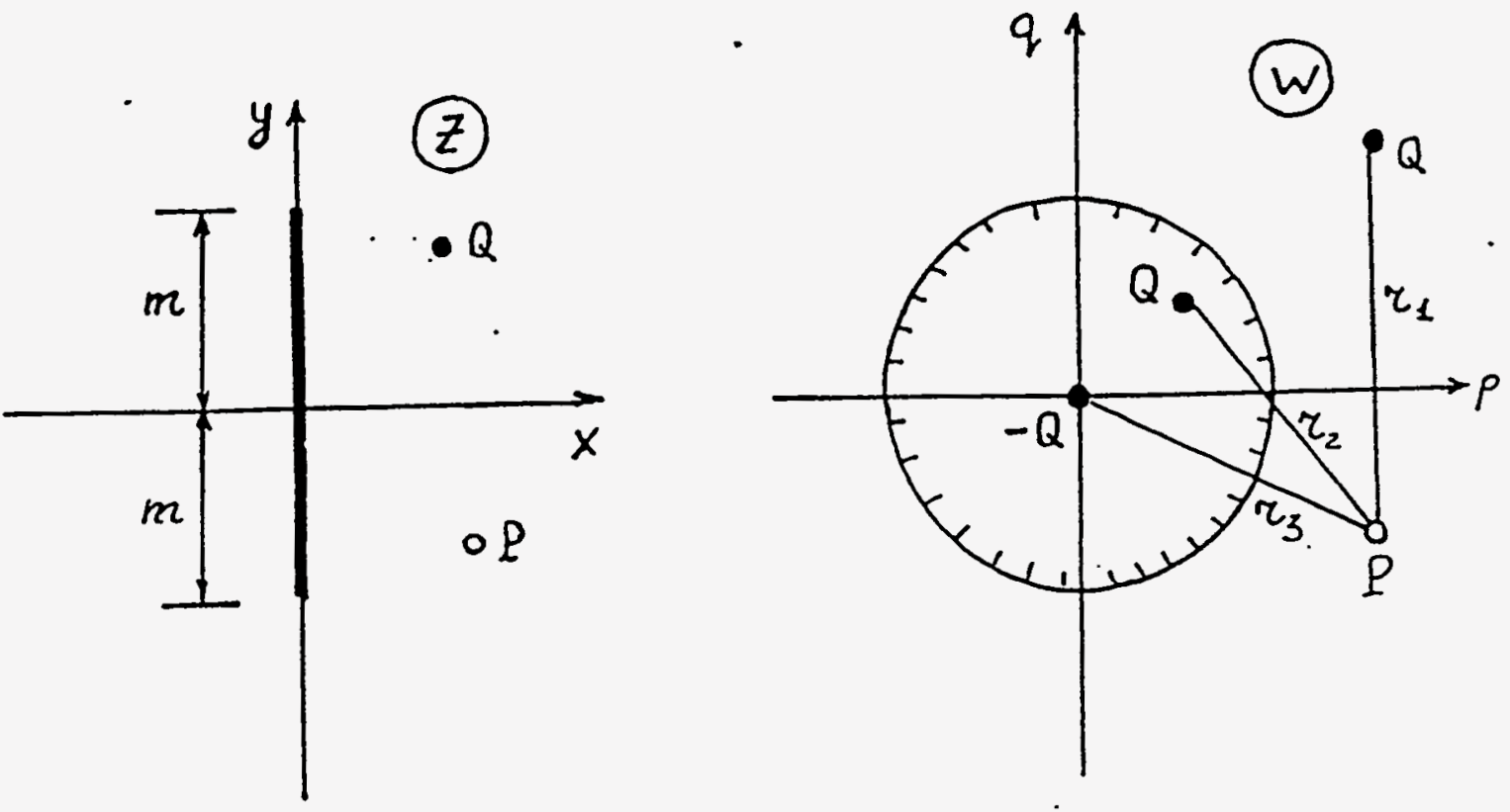

Fig.I.1 Transforming of a short boundary's outer area (plane z) onto that of a circle (plane w).

$P=$ observation well; $\mathrm{Q}=$ discharge. 


\section{J Random fields generation by the source point method}

The main idea of Source Point Method (SPM) is to calculate a random set of function values $f\left(x_{i}, y_{i}\right)$ in given points by the values at the sources, whouse coordinates are being randomly distributed as:

$$
f\left(x_{i}, y_{i}\right)=\sum_{j=1}^{N} \alpha_{i j} q_{j}
$$

where $q_{j}$ are a normally distributed values and $\alpha_{i j}$ are the weighting functions determined from

$$
\alpha_{i j}=\left[\left(x_{j}-x_{i}\right)^{2}+\left(y_{j}-y_{i}\right)^{2}\right]^{-1} / \sum_{j=1}^{N}\left[\left(x_{j}-x_{i}\right)^{2}+\left(y_{i}-y_{j}\right)^{2}\right]^{-1}
$$

where $N$ is the number of sources involved in the calculation of the function at a given point with $x_{i}$ and $y_{i}$ coordinate sand $x_{j}$ and $y_{j}$ are the random coordinates of $j$ - source. Evidently,

$$
\sum_{j=1}^{N} \alpha_{i, j}=1, \quad \sum_{j=1}^{N} \alpha_{i, j}^{2} \neq 1
$$

The performance of this method is exceptionally good because it only needs two generations of the uniformly distributed numbers for the coordinates of the sources, one generation of normal distributed numbers for source values and a small number of calculations for each point of field according to (J.1). It was shown that by using some empirical relations between the correlation length and the number of involved sources one can generate a field with the form of correlation function close to that of the exponential function. Let us simulate a normal distributed stationary field $f\left(x_{i}, y_{j}\right.$ with a mean $M$ and standard derivation $\sigma$, having the anisotropic correlation function $R(\vec{r})$ in the domain $\{X, Y\}$ :

$$
R(\vec{r})=\exp \left(-\sqrt{\left(x / L_{x}\right)^{2}+\left(y / \lambda L_{x}\right)^{2}}\right) ; \quad \lambda=L_{y} / L_{x} \geq
$$

where $X, Y$ are dimension of a domain $, L_{x}, L_{y}$, are correlation scales along $x$ and $y$ axes, respectively. Now us transform and include the modeled domain into a unity square so that the point coordinates $\left(x_{i}^{\prime}, y_{i}^{\prime}\right)$ in the latter are connected with the actual area coordinates $\left(x_{i}, y_{i}\right)$ by the ratios:

$$
y_{i}^{\prime}=\left(y_{i} / \lambda+L_{x}\right) / D_{\max }, \quad x_{i}^{\prime}=\left(x_{i}+L_{x}\right) / D_{\max }
$$

where $D_{\max }=\max \{X, Y\}+2 L_{x}$. Having the simulated isotropic field $f^{\circ}\left(x_{i}^{\prime} y_{i}^{\prime}\right)$ on the unity square with a zero mean and unit variance one can obtain the actual anisotropic field by using the inverse coordinates transformation and field scaling on non zero mean and actual variance:

$$
f\left(x_{i}, y_{i}\right)=M+\sigma \cdot f^{0}\left(x_{i}, y_{i}\right)
$$

\section{Procedure for Field calculation}

For generation of a field $f^{\circ}\left(x_{i}^{\prime}, y_{i}^{\prime}\right)$ using (J.1) and (J.2) it is necessary to estimate the total number $N_{s}$ of sources on a unit square, the parameters of the $q$ source value distribution and the number of source $N$ for calculations at each point of field. According to equations (1) and (2) the distribution of field values will be of the same type as the distribution of sources values i.e. a normal distribution. The mean of the field values distribution will be equal to the mean of distribution of sources values. There is no way apriory to estimate the variance of distribution of sources values that would give unit variance of the field. Thus we use a distribution of sources' values with zero mean and unit variance. In this case the distribution of values for the generated field $f^{o}\left(x_{i}^{\prime}, y_{i}^{\prime}\right)$ has non unit (less than one) variance and it has a mean closely to zero. This distribution is then 
transformed to zero mean and unit variance $N(0,1)$ distribution by using the estimated values of mean and variance obtained during this generation of field. The $N(0,1)$ distribution could easily transformed onto another normal distribution with expected values of variance and mean. For an estimation of $N_{s}$ and $N$ values we will use the following procedure. It is clear that the correlation length of generated field is comparable with the search radius of nearest sources. It means that for the search radius $R_{\text {search }}$ it is possible to assume an empirical equation:

$$
R_{\text {search }} \approx \beta \cdot L_{x} / D_{\max }, \quad 1 \leq \beta \leq 2
$$

Judging from the structure equation of $\alpha_{i j}$ these coefficients are rapidly increasing function, and hence, the total numbers $N$ of members of the series in (J.1) have to be kept below 10-20. From the above, it is possible to assume an empirical equation for $N_{s}$ :

$$
N_{s}=N \cdot \frac{D_{\max }^{2}}{L_{x}^{2} \pi \beta^{2}} ; \quad 1 \leq \beta \leq 2, \quad 10 \leq N \leq 20
$$

After generating a series of fields for various $N$ and $\beta$ values it is found that the best $N$ value is 16 and $\beta$ is 1.25 .

In summary, the procedure for field generation consists of the following steps:

- transform the field domain into the unit square;

- calculate the number of sources according to (J.8);

- generate a uniform random coordinates of sources on the unit square;

- generate a normal distributed sources values with $N(0,1)$ distribution;

- calculate field values on unit square according to (J.1) and (J.2) using $N$ nearest sources;

- transform field values to $N(0,1)$ distribution; . .

- inverse the coordinates transformation;

- find the field values using the expected values of mean and variance according to (J.6);

- transform the field as needed by exponentiation, etc.

\section{ACKNOWLEDGMENTS}

This work was prepared under the auspices of Russian-American Center for Contaminant Transport Studies at the Lawrence Berkeley Laboratory. We appreciate the funding from the Department of Energy's Office of Environmental Management, Office of Technology Development (DOE/EM-OTD) and the Office of Energy Research, Office of Basic Energy Sciences (DOE/ER-BES) through Contract Number DC-AC03-76SF0098. 


\section{References}

[1] Abelin H. I., Nerethieks I., Turnbrant S., Moreno L. Final report of the migration in a single fracture: Experimental results and evaluation // Stripa Proj. Sven. Karnbransleforsovjning Tech. Rep. 85-03, Nucl. Fuel Safety Proj. Stockholm, 1985.

[2] Алексеев В.С, Комнунар Г.М., Шержуков Б.С. Массоперенос в водонасыщенных горных породах. "Итоги науки и техники. Гидрогеология и инженерная геология".Москва, 1989, $144 \mathrm{c}$.

Alekseev V. S. , Kommunar G. M. , Sherzhukov V. S. Mass transport in water-bearing rock. "Advancements of Science and Technology. Hydrogeology and Engineering Geology". Moscow, $1989,144 \mathrm{p}$.

[3] Aziz K. , Seltari A. Petroleum reservoir simulation. Applied Science Publishers Ltd., 1979, 407 p.

[4] Bear J. Dynamics of fluids in porous media.Amer. Els. N.Y., 1972, 764 p.

[5] Bourke P. J. et al. Fracture hydrology relevant to radionuclide transport // AERE Rep., 11414, Atomic Energy Res. Estab. Harwell, United Kingdom, 1985.

[6] Черныищов C.Н. Фильтрация по сетям трещин. - Москва, Недра, 1970.

Chernyshov $S . N$. Ground-water flow through fracture nets. Moscow, "Nedra", 1970.

[7] Коллинз $K$. Течение жидкостей через пористые материалы. - Москва, Мир, 1964.

Collins $R$. Flow through porous media.Moscow, Mir, 1964.

[8] Гензель Г.Н., Карачевчев Н.Ф., Коносавский ПТ.К., Кравчук С.В., Мироненхо В.А., Румынин В.Г. Решение задач охраны подземных вод на численных моделях. - Москва, Недра, . $1992,240 \mathrm{c}$.

Genzel G. N. , Karachevtsev N. F. , Konosavsky P. K. , Kravchuk S. V. , Mironenko V. A. , Rumynin V.G. Solving ground-water protection problems on numerical models. Moscow, "Nedra", 1992, 240 p.

[9] Gringarten A. C. , Sauty J. P. A theoretical study of heat extraction from aquifers with uniform regional flow.J. Geoph. Res.. 1975, v. 80, N 35, p. 4956-4962.

[10] Gringarten A.C. and Witherspoon $P$. A. A method of analysing pump test data from fractured aquifers.Poc. Symp. Percolation through Fissured Rock (Stuttgart, 1971), 1972, p. T3-B-1 to T3-B-8.

[11] Gringarten A.C. Flow-test evaluation of fractured reservoirs.Reset Trends in Hydrogeology, sp.pp. 189, 1982, p. 237-263.

[12] Grove D. E. , Beetem W. A. Porosity and dispersion constant calculations for a fractured carbonate aquifer using the two well tracer method.Water Res. , 1971, v. 7, N 1, p. 128-134.

[13] Guvanasen V., Guvanasen V.M. An approximate semianalytical solution for tracer injection tests in a confined aquifer with a radially converging flow field and finite volume of tracer and chase fluid.Water Res. , 1987, v. 23, N 8, p. 1607-1619.

[14] Hockney R. W. and Eastwood J. W. Computer simulation using particles. McGraw-Hill Inc., 1981. 
[15] Hsieh P. A. , Neuman S. P. , Stiles G. K., Simpson E. S. Field determination of threedimensional hydraulic conductivity tensor of anisotropic media. 2. Methodology and Application to Fractured Rocks Water Res., 1985, v. 21, N 11, p. 1667-167.

[16] Hunt B. B. Dispersive sources in uniform fround-water flow. J. Hydraulics Div., 1978, N 1, p. 75-85.

[17] Kamineni D. C. Vandergraaf T. T. ,Ticknor $K . V$. Characteristics of radionuclide sorption on fracture-filling minerals in the Eye - Dashwa Lakes Pluton, Atikokan, Ontario.Canadian Mineralogist, 1983, vol. 21, pp. 625-636.

[18] Karasaki K. , Lon J. C. S. , Witherspoon P. A. A new analytical model for fracture-dominated reservoir // SPE Form. Eval., 1968, v. 3, N 1, p. 242-250.

[19] Kinzelbach W. and Rausch R., 1989, ASM-Aquifer Simulation Model. Ground water Flow and Transport Model. Kassel, FRG.

[20] Kipp K.L., 1987, HST-3D, A Computer Code for Simulation of Heat and Solute Transport in 3D Ground-Water Flow Systems, US GS, Water Resources Inv. Report, 86-4095, Denver.

[21] Konikow L.F, Bredehoeft J.D., Computer Model of Two-Dimensional Solute Transport and Dispersion in Ground Water, US Geological Survey, Washington.

[22] Коносавский П.К., Румянцев В.А., Новожилова Н.Д. Опытно-фильтрацнонные опробывания вблизи коротких гидродинамических границ (интерпретация и анализ чувствительности). Изв. ВУЗов, геология и разведка, 1990, $N$ 6, с. 64-69.

Konosavsky $P$. K. , Rumyantsev V. A. , Novozhilova N. D. Field tests near short hydrodynamic boundaries (interpretation and analysis of sensitivity). Izv. VUZov, "Geology and Exploration", 1990, N 6, p. 64-69.

[23] Korn G. A. and Korn T. M. Mathematical handbook for scientists and engineers. McGrawHill Book Company, 1968.

[24] Lavrentyev $M$. A. Shabat B. V. The methods of the complex-variable function theory. Moscow, Nauka, 1973, 736 p.

[25] Leap D. I. , Kaplan P. G. A single-well tracing method for estimating regional advective velocity in a confined aquifer: Theory and preliminary laboratory verification. Water Res. Res. 1988 , v. 24, N 7, p. 1111-1117.

[26] Lenda A. , Zuber A. Tracer dispersion in groundwater experiments.Isotope Hydrology. 1970, JAEA, Vienna (1970), 619.

[27] Ломакин E.A., Мироненко В.А., Шестаков В.М. Численное моделирование геофильтрации. Недра, 1988.

Lomakin E. A., Mironenko V. A., Shestakov V. M. The numerical modeling of ground-water flow. "Nedra", 1988.

[28] Лукнер Л., Шестаков В.М. Моделирование миграции подземных вод. Москва, Недра, . 1986, 208 c.

Luckner l. , Shestakov V. M. Modeling of ground-water migration. Moscow, "Nedra", 1986, $208 \mathrm{p}$.

[29] Maloszewski P. , Zuber A. Mathematical modelling of tracer behavior in short-term experiments in fissured rocks. Water Res. Res., 1990, v. 26, N 7, p. 1517-1528. 
[30] McDonald M.G. and Harbough A.W., 1988 MODFLOW, A Modular D3 Finite-Difference Ground-Water Flow Model US GS. Tec. Water-Resources Inv. Bk 6, Chap Al. Washington DC.

[31] Мироненко B.A., Румынин В.Г. Опытно-миграционные работы в водоносных пластах. Москва, Недра, 1986, 240 c.

Mironenko V. A. , Rumynin V. G. Migration tests in water-bearing strata. Moscow, "Nedra", $1986,240$.

[32] Мироненко В.А., Румьтия В.Г., Уиаев В.К. Загрязнение подземных вод в гонодобывающих районах. - Ленинград, Недра, 1980, 320 с.

Mironenko V. A. , Rumynin V. G. , Uchaev V.K. Ground-water pollution in mining areas. Leningrad, "Nedra", 1980, 320 p.

[33] Мироненко B.A., Шестаков B.M. Теория и методы интерпретации опытно-фильтрационных работ. - Москва, Недра, 1978.

Mironenko $V . A$. , Shestakov $V . M$. The theory and methods of field tests intepretation.Moscow, Nedra, 1978.

[34] Moench A.F. Convergent radial dispersions: a Laplace transform solution for aquifer tracer testing, Water Res. Res., 1989, v. 25, N 3, p. 439-447.

[35] Mucha I. Program description of computer code "Well". Bratislava, 1991.

[36] Невечеря И.К., Шестаков В.М. Интерпретация и постановка опытных откачек из реки с применением ЭВМ. "Водные ресурсы", N 6, 1990.

Nevecherya $I$. K. , Shestakov V.M. The computer-aided interpretation and setup of pumping tests near a river. "Water Resources, N6, 1990.

[37] Nordqvist A. W. , Tsang Y. W. , Tsang C. F. Dverstorp, Anderson J. A Variable aperture fracture network model for flow and transport in fractured rocks. Water Resources Research, 1992, vol. 28, N 6, pp. 1703-1713.

[38] Novakowski K. S. Flavelle P. A. , Raven K. G. , Cooper E. L. Determination of groundwater flow pathways in fractured plutonic rock using a radioactive tracer.Int. J. Appl. Rad. Isot., vol. 36, N 5, 1985, pp. 399-404.

[39] Подздяков С.П., Степаницев С.Л. Определение водоотдачи объемнобалансовым методом при откачке из безнапорного пласта. Вестник МГУ, сер. Геология, 1992, N 1, с. 71-82.

Pozdnyakov S. P. , Stepanishchev S. L. Water yield estimation by the volume-and-budget method in pumping from an unconfined aquifer. Vyestnik MGU, series "Geology", 1992, N1, p.71-82.

[40] Pollock D.W., 1989 MODPATH. Documentation of Computer Programs to Computer and Display Pathlines Using Results from the US GS Modular 3D Finite-Difference Ground Water Flow Model. US GS, Open File Report, 89-381, Denver.

[41] Raimondi P. , Gardner G. H. G. , Petrick C. B. Effect of pore structure and molecular diffusion on the mixing of miscible liquids flowing in porous media.Amer. Inst. Chem. Eng. Society of Petroleum Eng. Confer., 1959, Preprint 43.

[42] Raven K. G. , Novakowski K. S. Lapcevic P. A. Interpretation of field tracer tests of a single fracture using a transient solute storage model // Wat. Res. Res., 198S, v. 24, N 12, p. 20192032. 
[43] Рогатин Н.Н., Сенаторов Н.П. Противофильтрационные завесы на карьерах. - Москва, Недра, 1979, 127 с.

Rogatin N. N. , Senatorov N. P. Anti-flow walls at quarries.Moscow, Nedra, 1979, 127 p.

[44] Rogatin N. N., Senatorov N. P. Anti-flow walls at quarries.Moscow, Nedra, 1979, 127 p.

[45] Роми E.C. Фильтрационные свойства трещиноватых горных пород. Москва, Недра, 1966, $283 \mathrm{c}$.

Romm E. S. Flow properties of fractured rock. Moscow, "Nedra", 1966, 283 p.

[46] Рошаль А.А. Полевые методы определения миграционных параметров. Обзор ИВЭМС, сер. "Гидрогеология и инженерная геология", 1981, 61 с.

Roshal A. A. Field techniques for migration parameter estimation. VIEMS review, series "Hydrogeology and Engineering Geology", 1981, 61 p.

[47] Румьнин В.Г. О погрешностях индикаторных опробований водоносных пластов, обусловленных реальной трехмерностью фильтрационных потоков. "Формирование ресурсов и состава подземных вод" Записки Ленинградского горного института, 1991, т. 129, с. 91-94.

Rumynin V.G. Tracer test errors due to the actual 3-dimensionality of flow. "Ground-water resource and composition formation". Notes of the Leningrad Mining Institute 1991, vol. 129, p. 91-94.

[48] Самсонов Б.Г., Самсонова Л.М. Миграция вещества и решение гидрогеологических задач. - Москва, "Недра", 1987.

Samsonov B. G. , Samsonova L. M. Species migration and hydrogeological problem solving. M., "Nedra", 1987.

[49] Самсонова Л.М. и др. Обоснование плановой геофильтрационной модели Междуречья. Отчет. Москва, Фонды Спецгидрогеологи, 1992.

Samsonova $L$. M. et al. Validation of the areal flow model of the Watershed site.A report. M.,Stocks of Gidrospetsgeologiya, 1992.

[50] Saul'jev V.K. Intergration of equations of parabolic type by the method of nets. Pergamon Press, London, 1964.

[51] Tsang Y.W., Tsang C.F. Flow channeling in a single fracture as a two-dimensional strongly heterogeneous permeable medium. Water Resources Research, 1989, v.25, N 9, pp.2976-2080.

[52] Sauty J. P. Identification des parametres du transport hidrodispersif danse les aquiferes par interpretation de tracages en ecoulement cylindrique convergent on divergent.J. of Hydrology, 1978 , v. $49, \mathrm{~N} 1 / 2$, pp. 69-103.

[53] Tsang Y.W., Tsang C.F. Flow channeling in a single fracture as a two-dimensional strongly heterogeneous permeable medium. Water Resources Research, 1989, v.25, N 9, pp.2976-2080.

·54] Щипанский A.A. К вопросу оценки раскрытия фильтрующей трещины. Инженерная геология, 1991, N 5, с. 94-99.

Shchipanski $A$. $A$. To the question of estimating the aperture of a water-bearing fracture // Engineering Geology, 1991, N 5, p. 94-99.

[55] Шестаков B.M. Методика интерпретации опытно-фильтрационных наблюдений. Изд-во МГУ, 1982.

Shestakov V. M. Methods of interpreting field observations. MGU, 1982. 
[56] Шестахов B.М. К теории фильтрации растворов в грунтах. - В кн.: Вопросы формирования химического состава подземных вод. Москва, 1963, с. 192-213.

Shestakov V.M. To the theory of solute migration in ground water. In book: The questions of the formation of ground-water chemical composition. Moscow, 1963, p. 192-213.

[57] Smith L. , Mase Ch. W. , Schwartz F.W. Estimation of fracture aperture using hydraulic and tracer tests.28th US Symposium on Rock Mechanics, 1987, Tucson, p. 453-463.

[58] Tsang Y.W., Tsang C. F. Flow channeling in a single fracture as a two-dimensional strongly heterogeneous permeable medium. Water Resources Reseach, 1989, v. 25, N 9, pp. 2076-2080.

[59] Tsang C. F. , Tsang Y. W. , Hale F. V. Tracer transport in fractures: Analysis of field data based on a variable aperture channel model. Water Resources Research, 1991, vol. 27, N 12, p. 3095-3106.

[60] Vandergraaf T. T. , Abry D. R. M. Radionuclide sorption on drill core material from the the Canadian Shield.Nuclear Technology, 1982, vol. 57, pp. 399-412.

[61] Веригин H.H., Васильев С.В., Саркисян В.С.; IIержуков В.С. Гидрогеологические и Физико-химические свойства горных пород.Москва, Недра, 1977, 271 с.

Verigin N. N. , Vasilyev S. V. , Sarkisyan V.S., Sherzhukov V. S. Hydrodynamic and physico-chemical rock properties. Moscow, "Nedra", 1977, $271 \mathrm{p}$.

[62] Веселова В.Л., Шестаков В.М., Язвин А.Л. Интерпретация опытных откачек в долине p. Каферниген. "Гидрогеологические исследования в межгорньх впадинах Южного Таджикистана". Изд-во МГУ, 1991.

Veselova V.L., Shestakov V. M. , Yazvin A. L. Pumping test interpretation in the river Kafernigen valley. "Hydrogeological Studies in the Intermountain Depressions of South Tajikistan". MGU, 1991.

[63] Way S. C. and Mekec C. R. In situ determination of three dimensional aquifer permeability // Ground Water, 1982, N 20, N 5, p. 594-603. 